

\section{Heat Loss Testing of Schott's 2008 PTR70 Parabolic Trough Receiver}

\author{
F. Burkholder and C. Kutscher
}

Prepared under Task No. CP09.1001
Technical Report NREL/TP-550-45633

May 2009

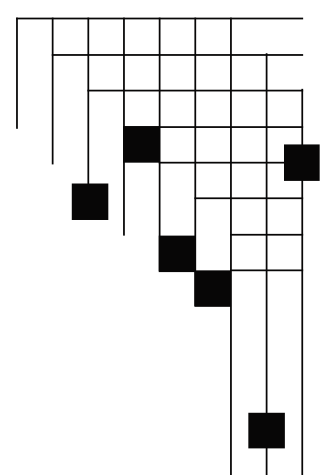




\section{NOTICE}

This report was prepared as an account of work sponsored by an agency of the United States government. Neither the United States government nor any agency thereof, nor any of their employees, makes any warranty, express or implied, or assumes any legal liability or responsibility for the accuracy, completeness, or usefulness of any information, apparatus, product, or process disclosed, or represents that its use would not infringe privately owned rights. Reference herein to any specific commercial product, process, or service by trade name, trademark, manufacturer, or otherwise does not necessarily constitute or imply its endorsement, recommendation, or favoring by the United States government or any agency thereof. The views and opinions of authors expressed herein do not necessarily state or reflect those of the United States government or any agency thereof.

Available electronically at http://www.osti.gov/bridge

Available for a processing fee to U.S. Department of Energy and its contractors, in paper, from:

U.S. Department of Energy

Office of Scientific and Technical Information

P.O. Box 62

Oak Ridge, TN 37831-0062

phone: 865.576 .8401

fax: 865.576 .5728

email: mailto:reports@adonis.osti.gov

Available for sale to the public, in paper, from:

U.S. Department of Commerce

National Technical Information Service

5285 Port Royal Road

Springfield, VA 22161

phone: 800.553.6847

fax: 703.605.6900

email: orders@ntis.fedworld.gov

online ordering: http://www.ntis.gov/ordering.htm 


\section{Table of Contents}

Executive Summary 1

Introduction 2

Test Description $\quad 4$

$\begin{array}{ll}\text { Results } & 8\end{array}$

Estimating Field Performance $\quad 11$

Calculating absorber emittance $\quad 12$

Modeling the HCE in a parabolic trough collector $\quad 18$

Determining the heat loss correlation coefficients 19

SAM/Excelergy heat loss coefficients 22

Solar field heat loss $\quad 23$

Demonstrating improved plant performance 27

$\begin{array}{ll}\text { Conclusion } & 30\end{array}$

$\begin{array}{ll}\text { Acknowledgements } & 30\end{array}$

References 31

Appendix I - Detailed data from one test near $400{ }^{\circ} \mathrm{C}$

Appendix II - Uncertainty analysis 39

Appendix III - 1D HCE heat loss model and sensitivity study 42

Appendix IV - Bellows shading calculation $\quad 52$ 


\section{Executive Summary}

Two Schott 2008 model year PTR70 receivers were tested on the National Renewable Energy Laboratory's parabolic trough receiver heat loss test stand from $100^{\circ} \mathrm{C}-500^{\circ} \mathrm{C}$ in $50^{\circ} \mathrm{C}$ increments. Heat loss in the laboratory, normalized per meter receiver length, is summarized by the following correlation:

$$
\text { Heat } \operatorname{loss}_{2008 P T R 70}=0.141 \cdot T_{a b s}+(6.48 E-9) \cdot T_{a b s}^{4}
$$

The absorber temperature in the above correlation is in ${ }^{\circ} \mathrm{C}$, and the calculated heat loss is in watts per meter $(\mathrm{W} / \mathrm{m})$ receiver length. There is $\pm 10 \mathrm{~W} / \mathrm{m}$ uncertainty associated with the results.

The emittance of the receiver absorber was calculated from the laboratory heat loss test results. The following correlation fits the calculated emittance to the absorber temperature.

$$
\varepsilon_{2008 P T R 70}=0.062+(2.00 E-7) \cdot T_{a b s}^{2}
$$

The emittance is a non-dimensional quantity and the absorber temperature in the correlation is in ${ }^{\circ} \mathrm{C}$. Emittance uncertainty depends on the testing temperature and is described further in the report. At an absorber temperature of $400^{\circ} \mathrm{C}$ the emittance uncertainty is \pm 0.005 .

A multi-step process was used to estimate solar field heat losses from the laboratory results. A parabolic trough collector/receiver model calculated solar field heat loss using the emittance curve correlation presented above and reasonable collector and solar field assumptions. Solar Advisor Model (SAM) and Excelergy heat loss correlation coefficients were generated from the heat loss outputs of the model. These coefficients are presented in Table 8 of this report.

The 2008 Schott PTR70 heat loss correlation coefficients were used in an annual SAM simulation for a $100 \mathrm{MW}_{\mathrm{e}}$ parabolic trough power plant with 6 hours of thermal energy storage. SAM shows that the heat loss associated with the Schott 2008 PTR70 will decrease the levelized cost of energy (LCOE) from the power plant by about $0.5 \phi / \mathrm{kWh}$ and increase annual electricity production by $5 \%$ relative to previous published PTR70 heat loss results. This analysis assumes that the 2008 PTR70 is priced similar to the previous model and that they share similar optical characteristics.

This report presents the thermal performance of the 2008 PTR70 parabolic trough receiver. We did not perform receiver optical, durability, nor structural tests. These factors also affect the solar plant performance of parabolic trough receivers and will be the subject of future testing. 


\section{Introduction}

A parabolic trough power plant generates electricity using concentrated sunlight as the heat source for its power cycle. Rows of single-axis-tracking, linear parabolic mirrors comprise a solar field that concentrates beam radiation onto tubular receivers (also known as heat-collection elements [HCEs]) located along the focal line of each parabolic trough. Heat-transfer fluid (HTF) pumped through the receivers is heated by convection from the sun-heated receiver walls. After being heated by the solar field, the HTF travels to a power block where it generates steam in a series of heat exchangers. The energy in the steam is converted to electricity in a Rankine steam-turbine power cycle. After heating the steam, the HTF returns to the solar field.

Figure 1 shows the solar field in an operating parabolic trough power plant. This photograph was taken at one of the nine Solar Electric Generating Systems (SEGS) built in California's Mojave Desert by Luz International Limited [1]. It illustrates receivers (HCEs) and parabolic mirrors mounted on supporting structures, collectively referred to as collectors. It also shows how collectors are linked in series to form "loops" in the solar field. The HTF travels from the power block to the solar field in large diameter "cold" header pipes. Then it flows through a "loop" of parabolic trough collectors where the HTF is heated by concentrated sunlight, as shown in Figure 1. Then the heated HTF flows into a "hot" header pipe which returns the heated HTF to the power block. Many loops comprise a solar field.

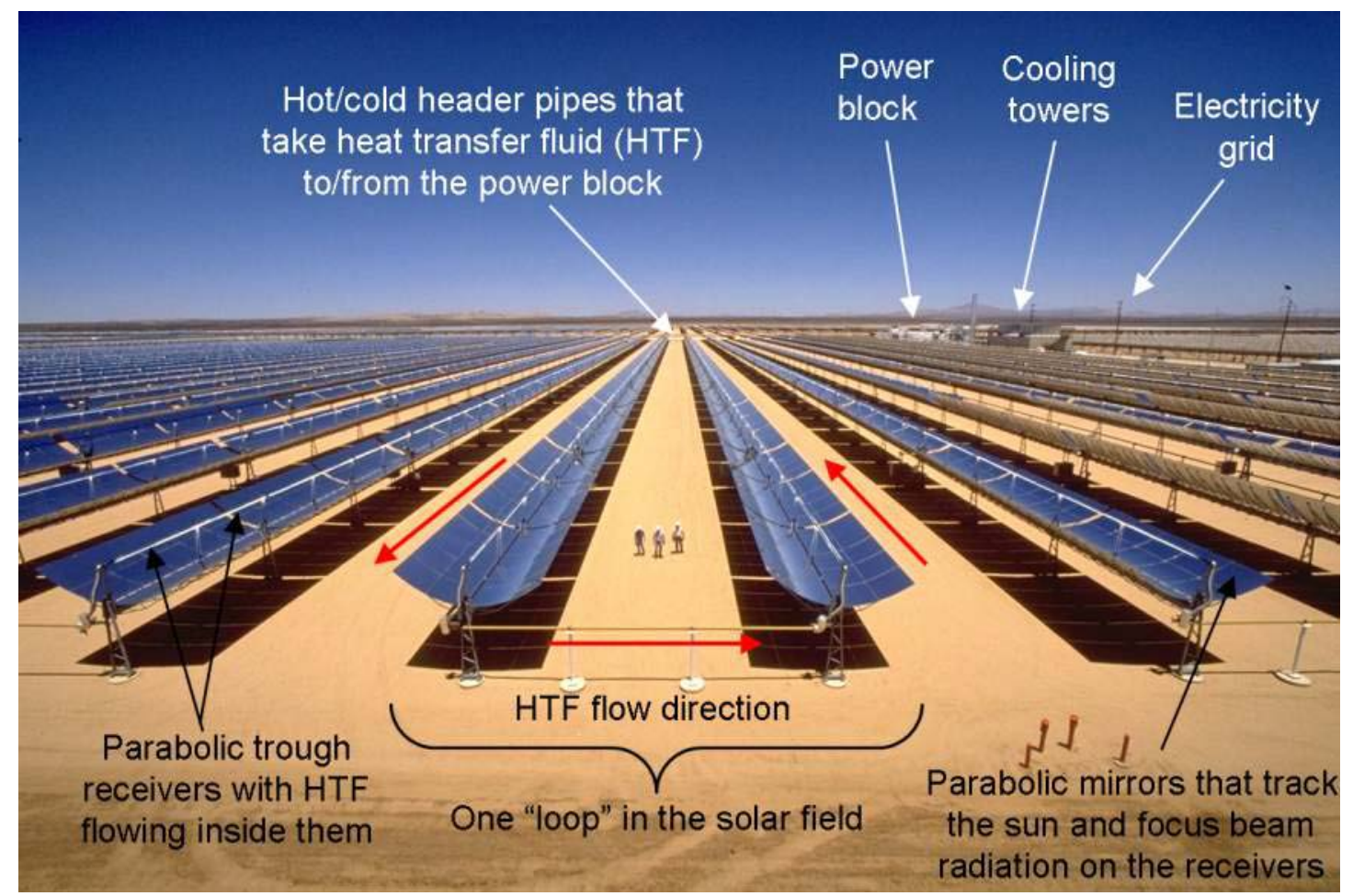

Figure 1. Parabolic trough receivers (also known as HCEs), mirrors, collectors, and "loops" in the solar field of a parabolic trough power plant. 
The electricity generated by the power block depends on the quantity and temperature of the HTF delivered by the solar field; larger HTF mass flow rates and/or higher temperatures lead to more power production. HCE heat loss has the effect of reducing one or both of these quantities. For a constant HTF mass flow rate, an increase in HCE heat loss from some baseline value decreases the loop HTF outlet temperature. Plant operators find this temperature fluctuation undesirable, so they decrease the mass flow rate to maintain the loop outlet temperature. In both cases, HCE heat loss adversely and significantly affects plant performance.

HCEs are designed to minimize heat loss to the environment while letting in and absorbing as much sunlight as possible. Figure 2 illustrates some of the design features that make this possible. The annulus between the absorber tube and the transparent glass cylindrical envelope is evacuated to prevent heat conduction/convection from the hot absorber tube to the cooler glass envelope. Radiative heat loss from the absorber is minimized by coating the absorber tube with a selective surface that has high solar absorption $(>0.95[1])$ but low thermal emittance. The effect of heat conduction at the ends is reduced by making long HCEs (4 meters and more.) Finally, the diameter of the absorber is small relative to the collecting aperture of the reflector, thereby decreasing the surface area associated with heat loss.

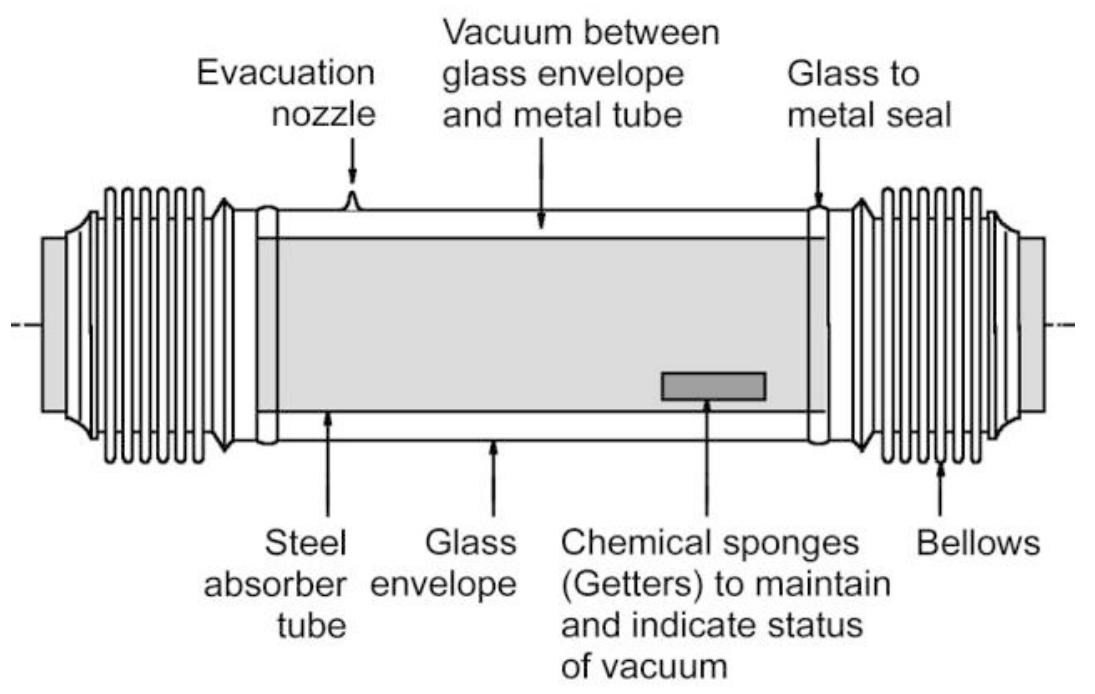

Figure 2. A shortened view of a parabolic trough receiver (HCE) source: Flagsol

This report presents heat loss results of Schott 2008 PTR70 HCE. It shows that Schott made improvements to its selective coating in 2008 that reduced heat losses compared to previous published values $[2,3,4]$, which already had low thermal losses relative to the state-of-the-art when the SEGS plants were built [5]. 


\section{Test Description}

Figure 3 is a photograph of the National Renewable Energy Laboratory (NREL) HCE Heat Loss Test Stand. This test stand is located indoors and uses electric resistance heaters on the inside of an HCE to bring the absorber surface up to desired test temperatures. Once a desired steadystate temperature is reached, power transducers measure the electrical power required to maintain the absorber temperature. The power required is the heat loss of the HCE at that temperature. The testing described here is that same as the tests described in $[3,6]$, except that more thermocouples were used to determine the average absorber and glass temperatures. These additional thermocouples allowed us to investigate how uniformly the HCE was heated. This investigation is presented in Appendix I.

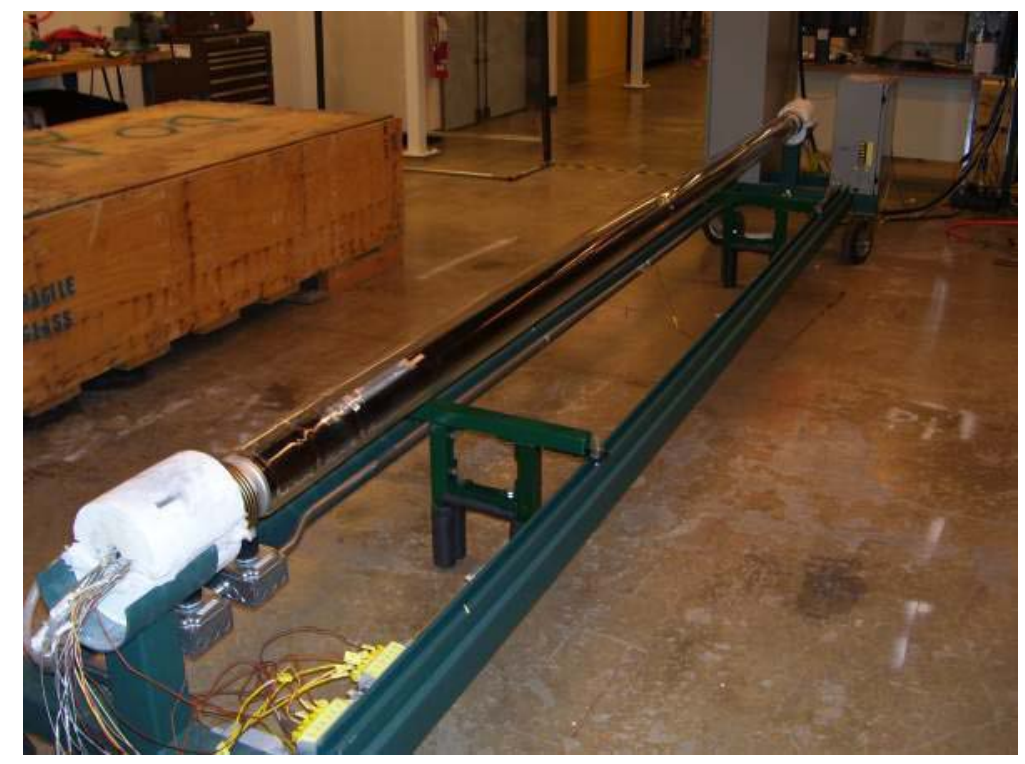

Figure 3. HCE heat-loss test stand at NREL

Present HCEs are $4.06 \mathrm{~m}$ long at $25^{\circ} \mathrm{C}\left(4.08 \mathrm{~m}\right.$ at $\left.400^{\circ} \mathrm{C}\right)$ with a stainless steel absorber inner/outer diameter of $6.6 / 7.0 \mathrm{~cm}$. To test HCE heat loss, two $2.17 \mathrm{~m}$ long, $5.4 \mathrm{~cm}$ outer diameter copper pipes with internal heaters are inserted into the ends of an HCE-one copper pipe per end. Spacers protruding from the copper pipe center it in the HCE and prevent it from touching the inner absorber surface. The copper pipe evens out the temperature distribution generated by three internal electric resistance heaters. Two of the heaters are 3-cm-long, stainless-steel-sheathed, coiled cable heaters whose surfaces contact the interior of the copper pipe. These heaters are referred to as "coil heaters" in the remainder of this report. The third heater is a $2.12 \mathrm{~m}$ (2.01 m heated-length) inconel-sheathed cartridge heater suspended along the cylindrical axis of the copper pipe using inconel spacers. The cartridge heater is fully inserted into the copper pipe so that its inner-most end, shown in Figure 4, is flush with the inner-most end of the copper pipe. When the copper pipe is inserted into the HCE, one coil heater ends up just inside the HCE while the other is adjacent to it but just outside the HCE. The inner coil heater compensates for end-loss effects, while the outer coil heater creates a zero temperature gradient on the copper pipe between the coil heaters. The cartridge heater supplies most of the thermal energy to the system, especially at increasing absorber temperatures. Power transducers 
measure heater output. The total heat loss is based on the sum of the powers of the two innermost coil heaters and the two cartridge heaters. Figure 4 is a photograph of the heaters inside one heating assembly, and Figure 5 shows the heating assembly ready for insertion into one end of an HCE. Table 1 lists heater and power transducer specifications.

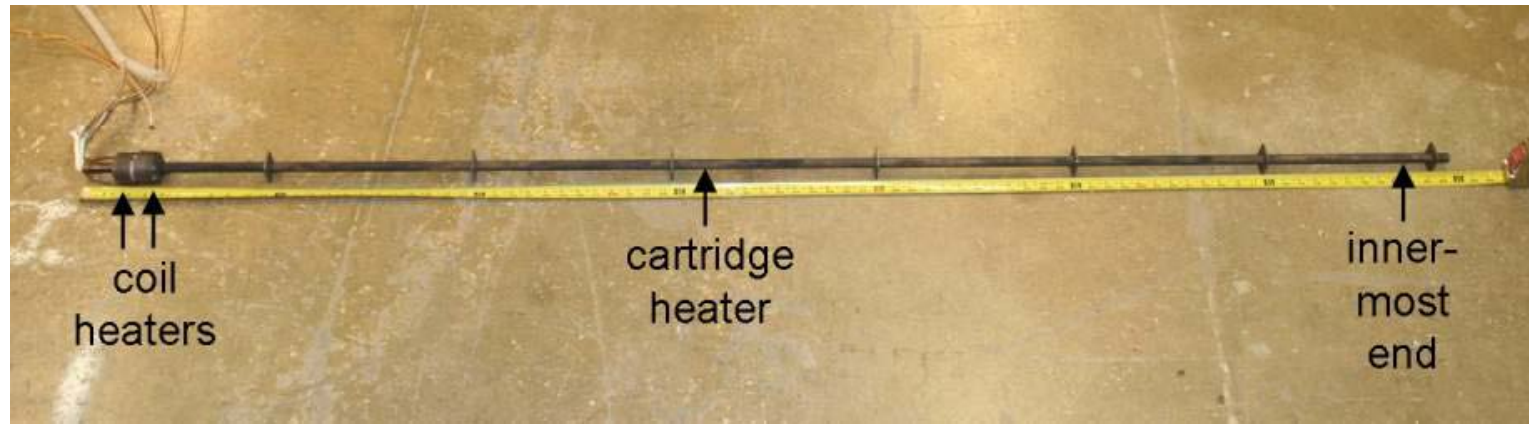

Figure 4. Heaters inside one heating assembly

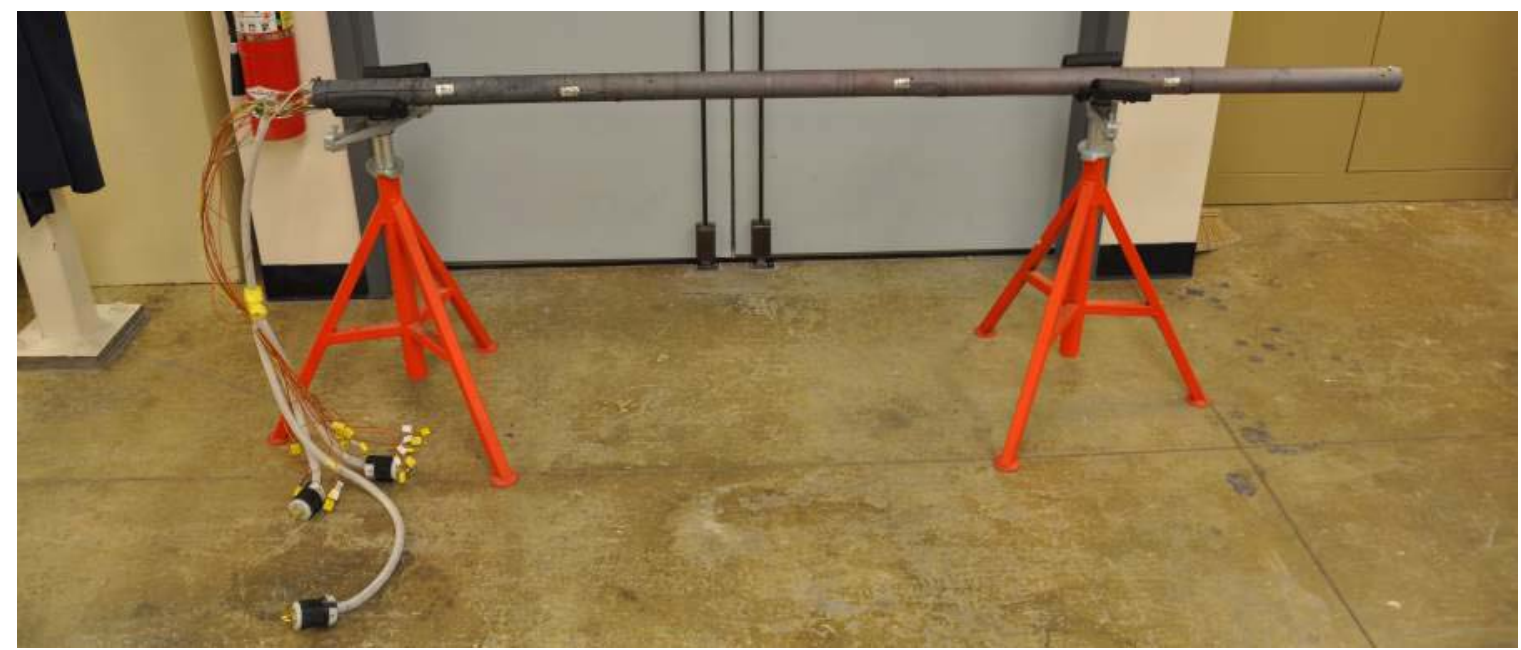

Figure 5. One heating assembly

Table 1. Heater and Power Transducer Specifications*

\begin{tabular}{|c|c|c|c|c|c|}
\hline & & & \multicolumn{2}{|c|}{ Error } \\
\cline { 4 - 6 } Heater Type & \# Used & $\begin{array}{c}\text { Max. Power of } \\
\text { each Heater (W) }\end{array}$ & $\begin{array}{c}\text { Transducer Full- } \\
\text { Scale Limit (W) }\end{array}$ & $\begin{array}{c}\text { \% of } \\
\text { Full } \\
\text { Scale }\end{array}$ & (W) \\
\hline $\begin{array}{c}\text { Coiled cable } \\
\text { heater }\end{array}$ & 4 & 600 & 500 & 0.5 & 2.5 \\
\hline $\begin{array}{c}\text { Cartridge } \\
\text { heater }\end{array}$ & 2 & 4800 & 5000 & 0.5 & 25 \\
\hline
\end{tabular}

* Transducers calibrated using instruments traceable to NIST, DOE\# 126410 and 01888C

Thermocouples measure the temperature of the copper pipe, stainless-steel absorber tube, and glass envelope at the locations shown in Figure 6. The copper temperature is measured at six 
locations, the absorber at eight locations, and the glass at three locations. The heating assembly and thermocouple locations for the other half are identical and symmetrical about the HCE center, with thermocouple naming conventions continuing from left to right though $\mathrm{Cu} 6, \mathrm{Abs} 8$, and Gl 3.

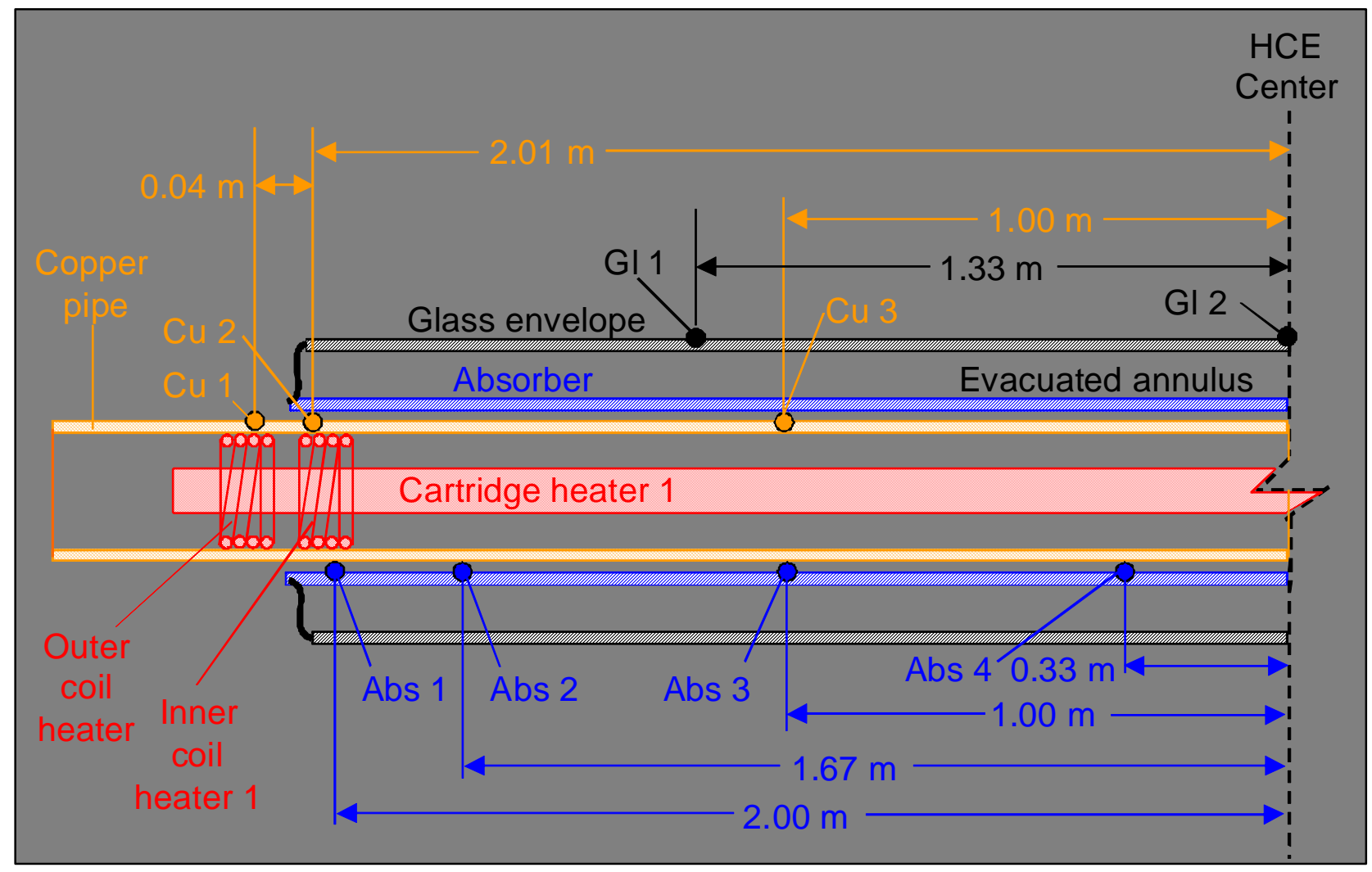

Figure 6. Glass (GI), Copper (Cu), and Absorber (Abs) thermocouple locations for one-half of the HCE. Labeling of thermocouples continues from left-to-right for other half (i.e. GI 3, Cu 6, and Abs 8 located farthest to right). Figure not to scale.

Inconel, copper, and stainless steel have different linear thermal expansion coefficients. Care must be taken to attach the copper and inconel-sheathed cartridge heater at only one point to avoid thermal stresses. The innermost end of the copper pipe and cartridge heater is the location of this attachment. Bolts thread through the copper pipe to rest on either side of an inconel spacer shrink-fitted to the end of the cartridge heater. Therefore the inconel cartridge heater, copper pipe, and stainless-steel absorber expand outward from the center of the HCE.

Wires attach the thermocouples to the copper and glass surfaces. The thermocouples measuring absorber temperatures spring out from the copper pipe to contact the inner absorber surface. Reliable absorber temperature measurements require good contact between the thermocouple and the absorber, as well as local radiation shielding to prevent radiant heating of the thermocouple by the copper pipe. Figure 7 shows the shielding underneath one thermocouple used to measure absorber temperature, and Table 2 lists the thermocouple specifications. Note that the uncertainty associated with the thermocouple temperature measurements is $\pm 1.1^{\circ} \mathrm{C}$ or $0.4 \% \cdot{ }^{\circ} \mathrm{C}$, whichever is greater [7]. A thermocouple also measures the air temperature. 


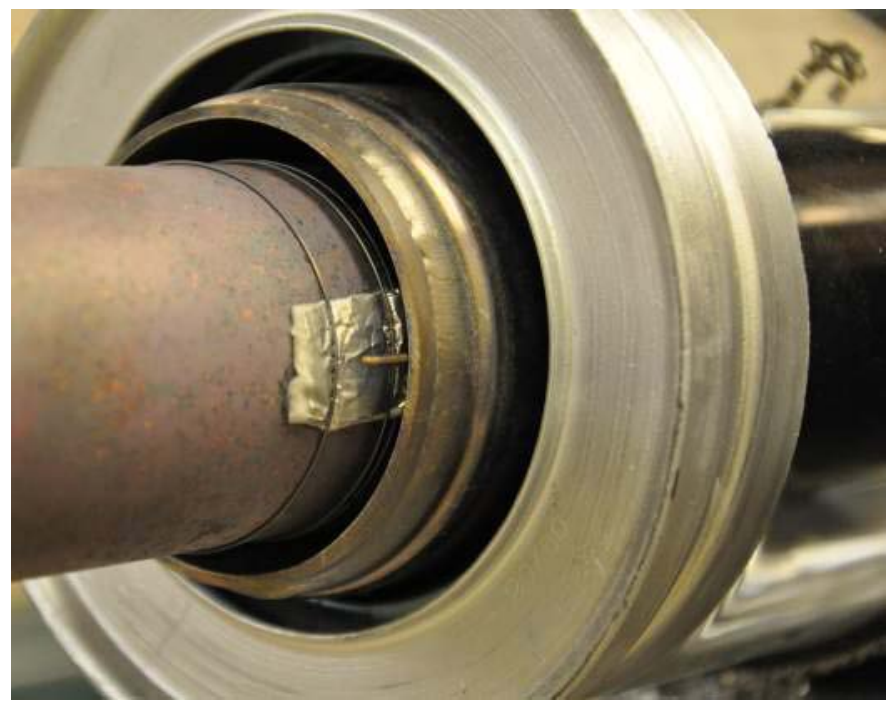

Figure 7. Absorber thermocouple with radiant shielding on copper pipe. Heating assembly in process of sliding into HCE.

Table 2. Thermocouple Specifications

\begin{tabular}{|c|c|c|c|c|}
\hline \multirow{2}{*}{ Thermocouple Description } & \multirow{2}{*}{$\begin{array}{c}\text { Calibration } \\
\text { Type }\end{array}$} & $\begin{array}{c}\text { Range } \\
{ }^{\circ} \mathrm{C}\end{array}$ & \multicolumn{2}{|c|}{$\begin{array}{c}\text { Temperature Error, } \\
\text { Maximum of: }\end{array}$} \\
\cline { 4 - 5 } & & $\begin{array}{c}\% \text { of value } \\
\left({ }^{\circ} \mathrm{C}\right)\end{array}$ & ${ }^{\circ} \mathrm{C}$ \\
\hline $\begin{array}{c}\text { Alloy 600 sheath, mineral } \\
\text { insulated, AF metal transition, } \\
\text { ungrounded }\end{array}$ & $\begin{array}{c}\mathrm{K} \text { - special } \\
\text { limits }\end{array}$ & $0-1250$ & $\pm 0.4 \% \cdot \mathrm{T}^{\circ} \mathrm{C}$ & \pm 1.1 \\
\hline
\end{tabular}

Testing proceeds once the heating assemblies are inserted and the HCE is supported in the test stand. Electrical power to the inner coil and cartridge heaters is increased slowly until all absorber temperatures approach a value of interest (e.g., $400^{\circ} \mathrm{C}$ ). The power to the outer coil heaters is adjusted so that the outer copper temperatures are equal to the inner copper temperatures (i.e., $\mathrm{Cu} 1=\mathrm{Cu} 2$ and $\mathrm{Cu} 5=\mathrm{Cu}$ 6), creating adiabatic boundaries between them. Temperatures and power values are logged every 5 seconds. Steady state is achieved when the glass and absorber temperatures remain constant (variation $\leq 0.5^{\circ} \mathrm{C}$ ) over a period of at least 15 minutes. The overall absorber temperature is calculated as the average temperature of Abs 2, 3, $4,5,6$, and 7 , and the overall glass temperature is the average of Gl 1, 2, and 3. Total heating power is the sum of that used by the inner coil heaters and the cartridge heaters. These calculations are described in Appendix I. 


\section{Results}

Two 2008 PTR70 $\mathrm{HCEs}$ were tested from $100^{\circ} \mathrm{C}$ to $500^{\circ} \mathrm{C}$ in roughly $50^{\circ} \mathrm{C}$ increments. Figure 8 shows the HCEs tested.

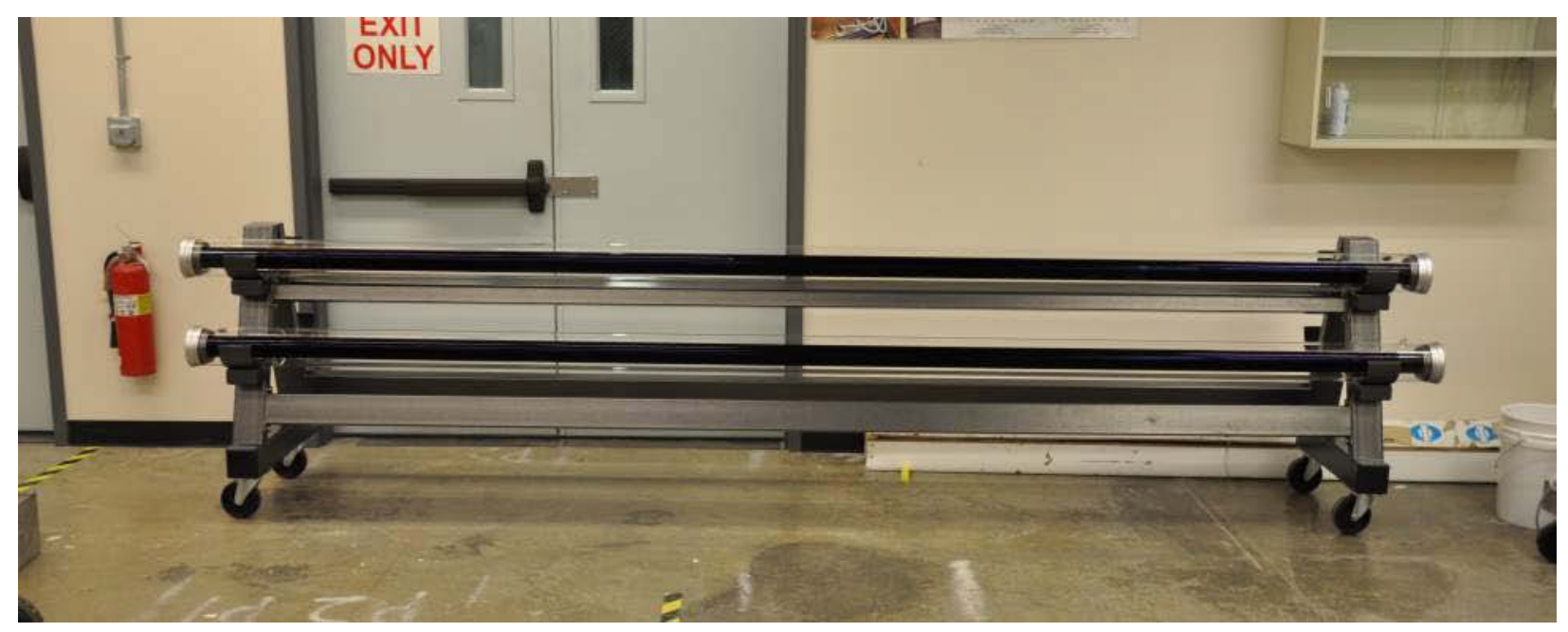

Figure 8. 2008 Schott PTR70 HCEs.

The HCEs were arbitrarily labeled $\# 1$ and $\# 2$. Each receiver was $4.06 \mathrm{~m}$ long at $25^{\circ} \mathrm{C}$, with absorber inner/outer diameters of $6.6 \mathrm{~cm} / 7.0 \mathrm{~cm}$ and glass envelope inner/outer diameters of about $11.5 \mathrm{~cm} / 12.0 \mathrm{~cm}$. Heat loss results are presented in Figure 9 and Table 3. Detailed data from one test near $400^{\circ} \mathrm{C}$ are presented in Appendix I. Uncertainties in the heat loss and temperature measurements are presented in Appendix II. In brief, the uncertainty associated with average temperatures and temperature differences is about $\pm 1^{\circ} \mathrm{C}$, and for heat loss it's \pm 10 $\mathrm{W} / \mathrm{m}$. 


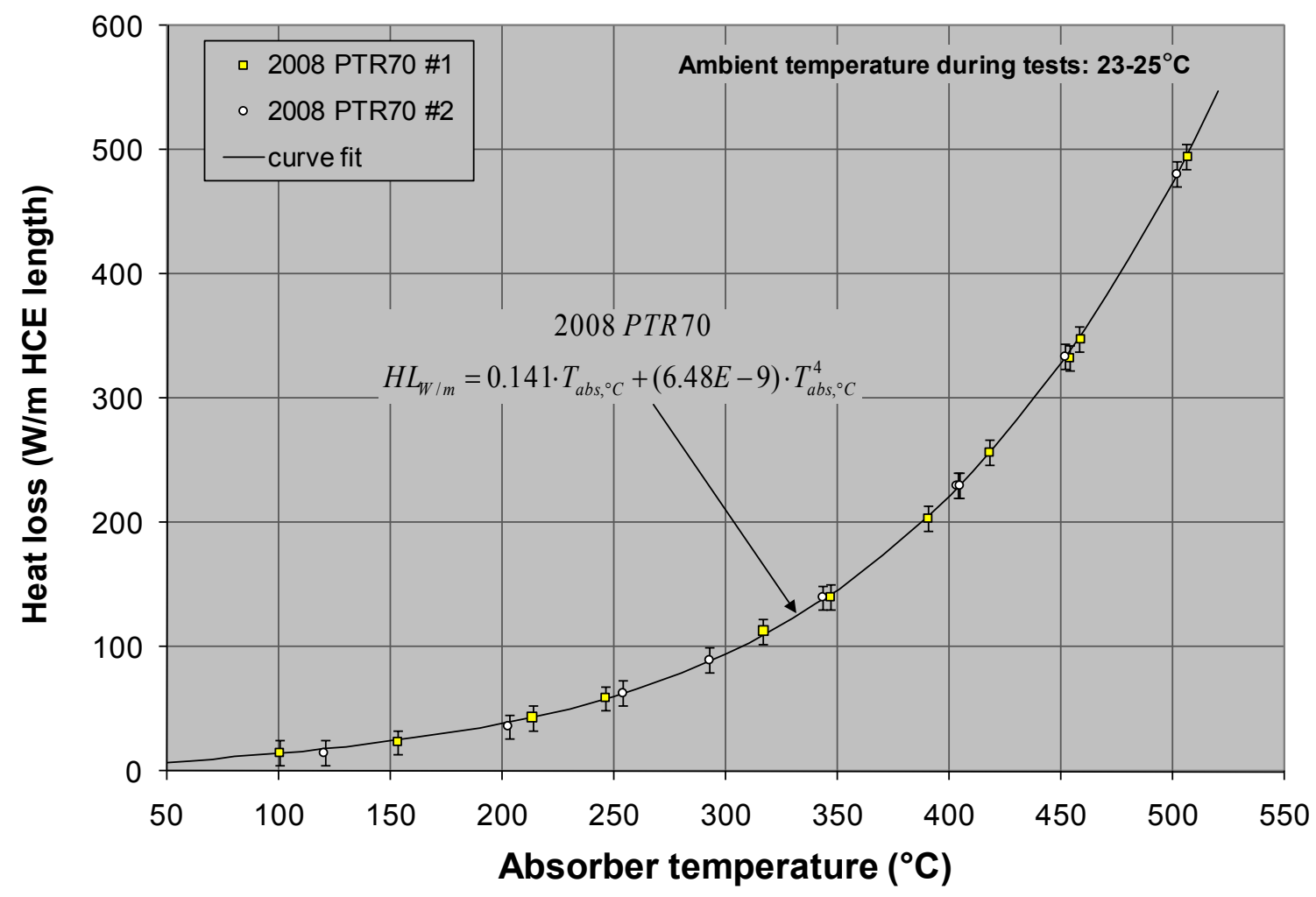

Figure 9. 2008 PTR70 heat loss results.

Instead of showing heat loss for the entire $4 \mathrm{~m}$ long HCE, heat loss per meter of HCE length is calculated and presented on the $y$-axis. The $\mathrm{x}$-axis is the average absorber temperature at the time of testing. Heat loss results are not presented versus the average absorber temperature above ambient because heat loss in these evacuated receivers is radiation dominated and therefore more dependent on the absolute absorber temperature than the difference between absorber and ambient temperatures. The sensitivity of the heat loss to HCE material properties, $\mathrm{HCE}$ and collector geometry, and environmental conditions is explored in Appendix III. 
Table 3. 2008 PTR70 heat loss results

2008 PTR70 \#1

\begin{tabular}{|c|c|c|c|c|c|c|}
\hline Test & $\begin{array}{c}\text { Average } \\
\text { absorber } \\
\text { temperature } \\
\left({ }^{\circ} \mathbf{C}\right)\end{array}$ & $\begin{array}{c}\text { Average glass } \\
\text { temperature } \\
\left({ }^{\circ} \mathrm{C}\right)\end{array}$ & $\begin{array}{c}\text { Average } \\
\text { ambient } \\
\text { temperature } \\
\left({ }^{\circ} \mathrm{C}\right)\end{array}$ & $\begin{array}{c}\text { Average } \\
\text { absorber } \\
\text { temp. above } \\
\left.\text { ambient }{ }^{\circ} \mathrm{C}\right)\end{array}$ & $\begin{array}{c}\text { Heat loss } \\
\text { (W/m HCE } \\
\text { length) }\end{array}$ & date of test \\
\hline 1 & $\mathbf{1 0 0}$ & 26 & 23 & 77 & $\mathbf{1 5}$ & $10 / 13 / 2008$ \\
\hline 2 & $\mathbf{1 5 3}$ & 30 & 23 & 130 & $\mathbf{2 3}$ & $10 / 13 / 2008$ \\
\hline 3 & $\mathbf{2 1 3}$ & 35 & 23 & 190 & $\mathbf{4 3}$ & $10 / 9 / 2008$ \\
\hline 4 & $\mathbf{2 4 6}$ & 38 & 23 & 222 & $\mathbf{5 9}$ & $10 / 14 / 2008$ \\
\hline 5 & $\mathbf{3 1 7}$ & 50 & 24 & 293 & $\mathbf{1 1 3}$ & $10 / 9 / 2008$ \\
\hline 6 & $\mathbf{3 4 6}$ & 55 & 24 & 323 & $\mathbf{1 4 1}$ & $10 / 14 / 2008$ \\
\hline 7 & $\mathbf{3 9 0}$ & 65 & 24 & 366 & $\mathbf{2 0 4}$ & $10 / 14 / 2008$ \\
\hline 8 & $\mathbf{4 1 8}$ & $\mathbf{7 3}$ & 24 & 393 & $\mathbf{2 5 7}$ & $10 / 9 / 2008$ \\
\hline 9 & $\mathbf{4 5 3}$ & 82 & 24 & 430 & $\mathbf{3 3 3}$ & $10 / 14 / 2008$ \\
\hline 10 & $\mathbf{4 5 8}$ & 84 & 24 & 434 & $\mathbf{3 4 8}$ & $10 / 9 / 2008$ \\
\hline 11 & $\mathbf{5 0 6}$ & 99 & 24 & 482 & $\mathbf{4 9 5}$ & $10 / 9 / 2008$ \\
\hline
\end{tabular}

2008 PTR70 \#2

\begin{tabular}{|c|c|c|c|c|c|c|}
\hline Test & $\begin{array}{c}\text { Average } \\
\text { absorber } \\
\text { temperature } \\
\left({ }^{\circ} \mathbf{C}\right)\end{array}$ & $\begin{array}{c}\text { Average glass } \\
\text { temperature } \\
\left({ }^{\circ} \mathrm{C}\right)\end{array}$ & $\begin{array}{c}\text { Average } \\
\text { ambient } \\
\text { temperature } \\
\left({ }^{\circ} \mathrm{C}\right)\end{array}$ & $\begin{array}{c}\text { Average } \\
\text { absorber } \\
\text { temp. above } \\
\text { ambient }\left({ }^{\circ} \mathrm{C}\right)\end{array}$ & $\begin{array}{c}\text { Heat loss } \\
\text { (W/m HCE } \\
\text { length) }\end{array}$ & date of test \\
\hline 1 & $\mathbf{1 2 0}$ & 27 & 22 & 98 & $\mathbf{1 5}$ & $11 / 5 / 2008$ \\
\hline 2 & $\mathbf{2 0 3}$ & 33 & 22 & 180 & $\mathbf{3 6}$ & $11 / 5 / 2008$ \\
\hline 3 & $\mathbf{2 5 4}$ & 39 & 23 & 231 & $\mathbf{6 3}$ & $11 / 5 / 2008$ \\
\hline 4 & $\mathbf{2 9 2}$ & 45 & 23 & 269 & $\mathbf{9 0}$ & $11 / 6 / 2008$ \\
\hline 5 & $\mathbf{3 4 3}$ & 54 & 23 & 320 & $\mathbf{1 4 0}$ & $11 / 6 / 2008$ \\
\hline 6 & $\mathbf{4 0 3}$ & 68 & 23 & 380 & $\mathbf{2 3 1}$ & $11 / 6 / 2008$ \\
\hline 7 & $\mathbf{4 0 4}$ & 67 & 22 & 382 & $\mathbf{2 3 0}$ & $11 / 7 / 2008$ \\
\hline 8 & $\mathbf{4 5 1}$ & 80 & 23 & 429 & $\mathbf{3 3 4}$ & $11 / 7 / 2008$ \\
\hline 9 & $\mathbf{5 0 1}$ & 95 & 23 & 478 & $\mathbf{4 8 1}$ & $11 / 7 / 2008$ \\
\hline
\end{tabular}

Current parabolic trough power plants operate between $293^{\circ} \mathrm{C}$ and $391{ }^{\circ} \mathrm{C}$. The average $\mathrm{HTF}$ temperature in each loop is about $340{ }^{\circ} \mathrm{C}$, and when the collectors are on-sun the HCE absorber walls are heated to an average temperature $5-10^{\circ} \mathrm{C}$ above the HTF temperature assuming current flow rates, as shown in Appendix III. Thus a simple estimation of HCE heat loss in parabolic trough solar fields corresponds to the heat loss that occurs at an absorber temperature of $350^{\circ} \mathrm{C}$. At this temperature on the $\mathrm{x}$-axis of Figure 9, the heat loss of the $2008 \mathrm{PTR} 70$ is $150 \mathrm{~W} / \mathrm{m}$. Studies of some previous generations of the PTR70 [2, 3, 4] found heat losses between 200 and $270 \mathrm{~W} / \mathrm{m}$ at an absorber temperature of $350^{\circ} \mathrm{C}$. The black chrome receivers installed at the SEGS plants in the $1980 \mathrm{~s}$ lost more than $350 \mathrm{~W} / \mathrm{m}$ at this temperature [5]. HCE heat loss has been decreased significantly. The next section describes the effect this decreased heat loss has on plant performance. 


\section{Estimating Field Performance}

The performance of a parabolic trough power plant is affected by HCE heat loss. Several methods predict the performance of parabolic trough solar fields [5, 8, 27]. This report uses the methodology developed by Price [9], and by extension, SAM [10].

Relating the heat loss acquired in the laboratory to heat loss in a solar field is a multi-step process:

1) The absorber emittance is deduced from laboratory testing.

2) A model of a collector and HCE with the lab-derived emittance is used to predict the heat loss of the HCE under a range of solar field operating conditions. This involves assumptions regarding the optical performance of the collector and HCE.

3) A correlation is developed for heat loss as a function of the operating conditions, and the coefficients of this correlation are determined.

4) The correlation is integrated relative to the HTF temperature so that the average HCE heat loss in the solar field can be related to solar field loop inlet and outlet temperatures.

5) A parabolic trough power plant model using the integrated heat loss equation developed in 4) calculates annual plant performance.

These steps are described in the following sections. 


\section{Calculating absorber emittance}

Figure 10 shows the heat loss that occurs during laboratory testing. The inner absorber surface is heated to a uniform temperature by the internal heaters. Energy then conducts through the absorber, radiates across the annulus, and conducts through the glass envelope. At steady-state the temperatures are constant, and the conducted and radiated powers are equal to the measured heat loss.

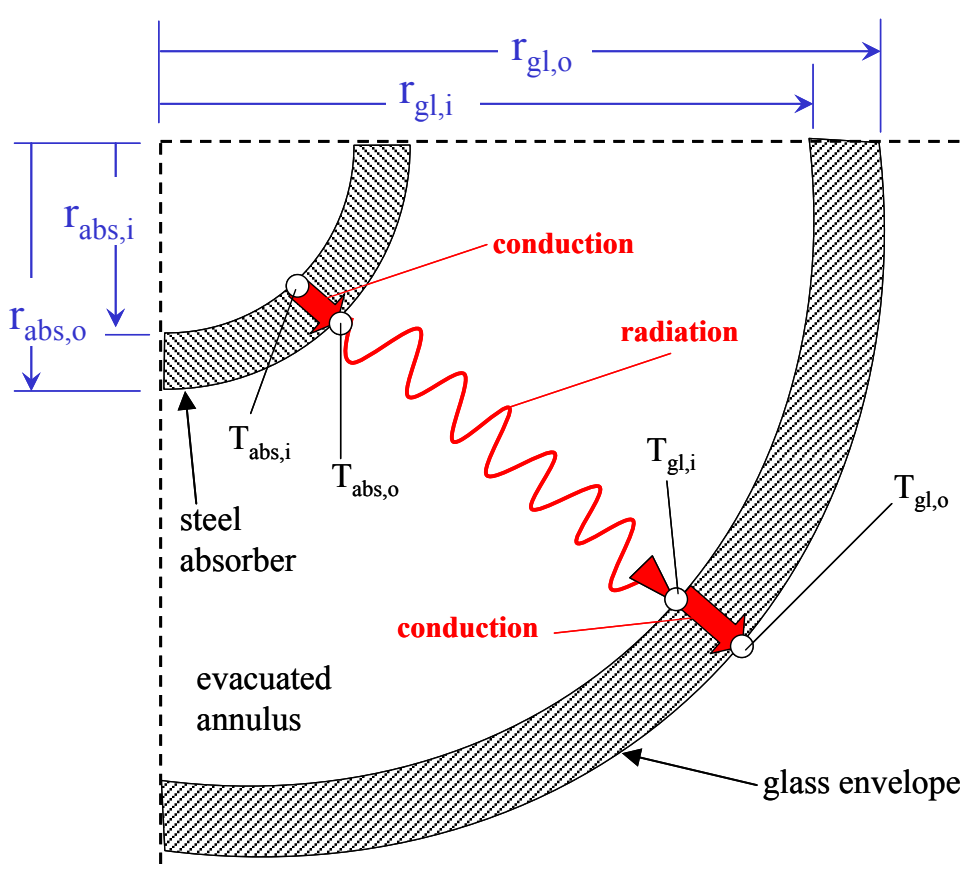

Figure 10. Schematic of 1-dimensional heat loss that occurs during laboratory testing

The absorber emittance, $\varepsilon_{a b s}$, is calculated from an iterative solution of the following equations [11]:

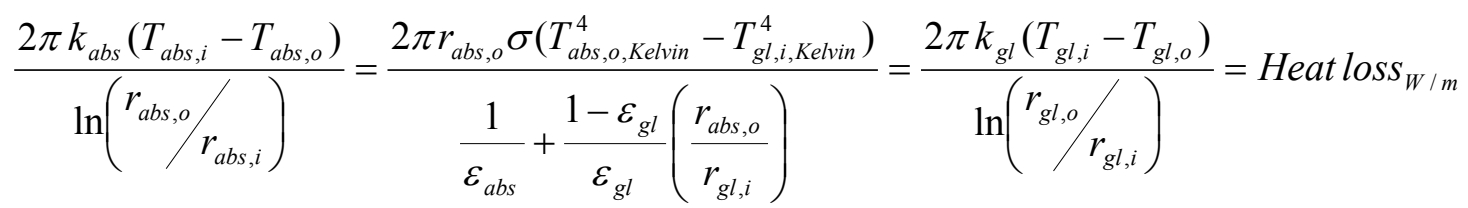

$\begin{array}{cccc}\begin{array}{c}\text { Heat conducted } \\ \text { through absorber }\end{array} & \begin{array}{c}\text { Heat radiated } \\ \text { across annulus }\end{array} & \begin{array}{c}\text { Heat conducted } \\ \text { through glass }\end{array} & \begin{array}{c}\text { Measured } \\ \text { heat loss }\end{array} \\ (\mathrm{W} / \mathrm{m}) & (\mathrm{W} / \mathrm{m}) & (\mathrm{W} / \mathrm{m}) & (\mathrm{W} / \mathrm{m})\end{array}$

All temperatures in the equations above are ${ }^{\circ} \mathrm{C}$, except for $T_{a b s, o, \text { Kelvin }}$ and $T_{a b s, o, \text { Kelvin }}$ which are $\mathrm{K}$. Known values in these equations are:

$$
\begin{aligned}
& k_{g l}=1.1 \mathrm{~W} / \mathrm{m} \cdot{ }^{\circ} \mathrm{C}[12] \\
& k_{a b s}=14.8+0.0153 \cdot \mathrm{T}_{\mathrm{abs}} \mathrm{W} / \mathrm{m} \cdot{ }^{\circ} \mathrm{C}[13] \\
& \varepsilon_{g l}=0.89[15] \\
& r_{a b s, i}=0.033 \mathrm{~m} \\
& r_{a b s, o}=0.035 \mathrm{~m}
\end{aligned}
$$


$r_{g l, i}=0.057 \mathrm{~m}$

$r_{g l, o}=0.06 \mathrm{~m}$

$T_{a b s, i}, T_{g l, o}$ and Heat $l_{o s s_{W / m}}$ are determined from testing and listed in Table 3.

The uncertainties associated with the preceding values are as follows:

$$
\begin{aligned}
& k_{g l}, k_{a b s}, r_{a b s, i}, r_{a b s, o}, r_{g l, i}, r_{g l, o}-\text { assumed zero. } \\
& \varepsilon_{g l}: \pm 0.05[15] \\
& T_{a b s, i}: \pm 1{ }^{\circ} \mathrm{C} \text { (see Appendix II) } \\
& \text { Heat } \operatorname{loss}_{\mathrm{W} / \mathrm{m}}: \pm 10 \mathrm{~W} / \mathrm{m} \text { (see Appendix II) } \\
& T_{g l, o}: \pm 20^{\circ} \mathrm{C} \text { (discussion below) }
\end{aligned}
$$

The uncertainty associated with the outer glass temperature isn't associated with its measurement, which Appendix II shows is $\pm 0.6^{\circ} \mathrm{C}$. Rather, it acknowledges that testing could have occurred under different ambient conditions that would result in different glass temperatures, as shown in Figures 11 and 12, and ensures that the calculated emittance is minimally dependent on ambient conditions.

Figures 11 and 12 were generated using the one dimensional (1D) HCE model described in Appendix III. Using this model, the heat loss and glass temperatures were determined for varying laboratory ambient and sky temperatures $\left(10^{\circ} \mathrm{C}\right.$ to $\left.30^{\circ} \mathrm{C}\right)$ and wind speeds $(0 \mathrm{~m} / \mathrm{s}$ to 2 $\mathrm{m} / \mathrm{s}$ ). Ambient and sky temperatures were assumed equal in the laboratory.

The figures show that the ambient/sky temperatures and wind speed can affect the glass temperature by $\pm 20^{\circ} \mathrm{C}$ from its average value. However, the heat loss varies little with changes in these parameters: $\pm 2 \mathrm{~W} / \mathrm{m}$ for the $250^{\circ} \mathrm{C}$ case, and $\pm 5 \mathrm{~W} / \mathrm{m}$ for the $450^{\circ} \mathrm{C}$ case. 


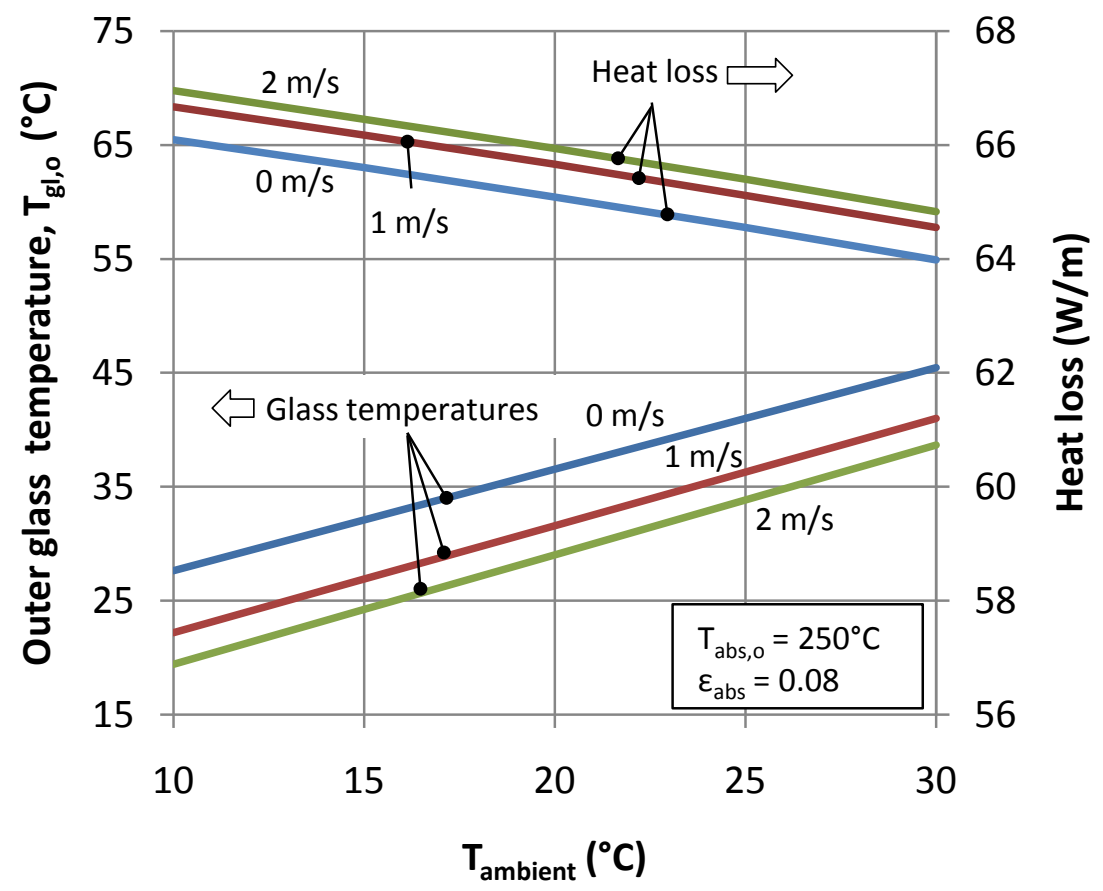

Figure 11. Modeled glass temperatures and heat loss for ambient and sky temperatures $10-30^{\circ} \mathrm{C}$, wind speeds $0-2 \mathrm{~m} / \mathrm{s}$. Assumed absorber temperature of $250^{\circ} \mathrm{C}$ and absorber emittance of 0.08 . Calculation from the 1D HCE model (Appendix III).

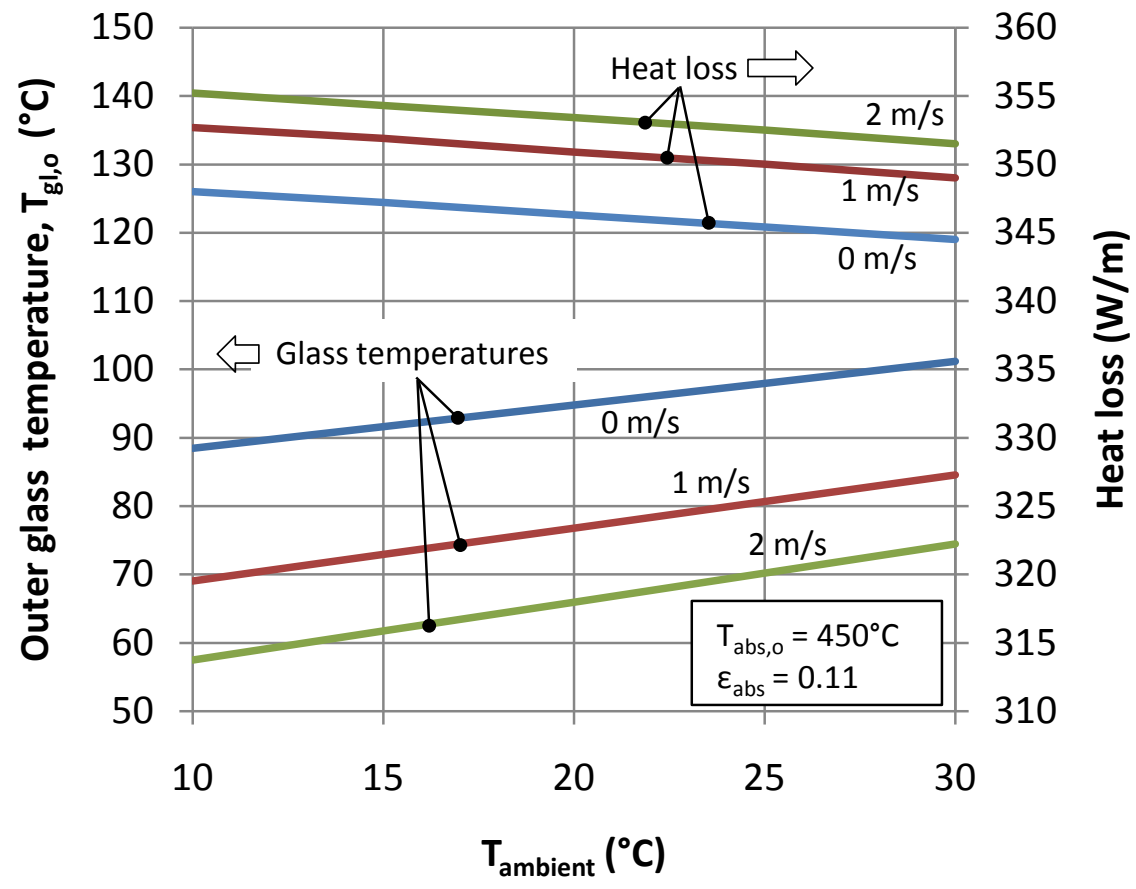

Figure 12. Modeled glass temperatures and heat loss for ambient and sky temperatures $10-30^{\circ} \mathrm{C}$, wind speeds $0-2 \mathrm{~m} / \mathrm{s}$. Assumed absorber temperature of $450^{\circ} \mathrm{C}$ and absorber emittance of 0.11 . Calculation from the 1D HCE model (Appendix III). 
The fact that heat loss in these evacuated receivers is insensitive to ambient conditions means that the calculated emittance is insensitive to ambient conditions as well. Figure 13 shows the variation of calculated emittance with respect to ambient conditions. This calculation used the glass temperatures presented in Figure 11 for the $250^{\circ} \mathrm{C}$ case and the glass temperatures in Figure 12 for the $450^{\circ} \mathrm{C}$ case. The heat loss was assumed to be $65.5 \mathrm{~W} / \mathrm{m}$ for all the $250^{\circ} \mathrm{C}$ absorber calculations, and $350 \mathrm{~W} / \mathrm{m}$ for all the $450^{\circ} \mathrm{C}$ absorber calculations. The largest differences in the calculated emittance are about \pm 0.002 for both cases. This variation is small compared to the uncertainty in the emittance caused by the $\pm 10 \mathrm{~W} / \mathrm{m}$ uncertainty in the heat loss measurement, as shown in Table 4. However, the uncertainty associated with the outer glass temperature, $T_{g l, o}$, is set at $\pm 20^{\circ} \mathrm{C}$ to preserve the small uncertainty induced in the calculated emittance by variation in ambient conditions and consequently the outer glass temperature.

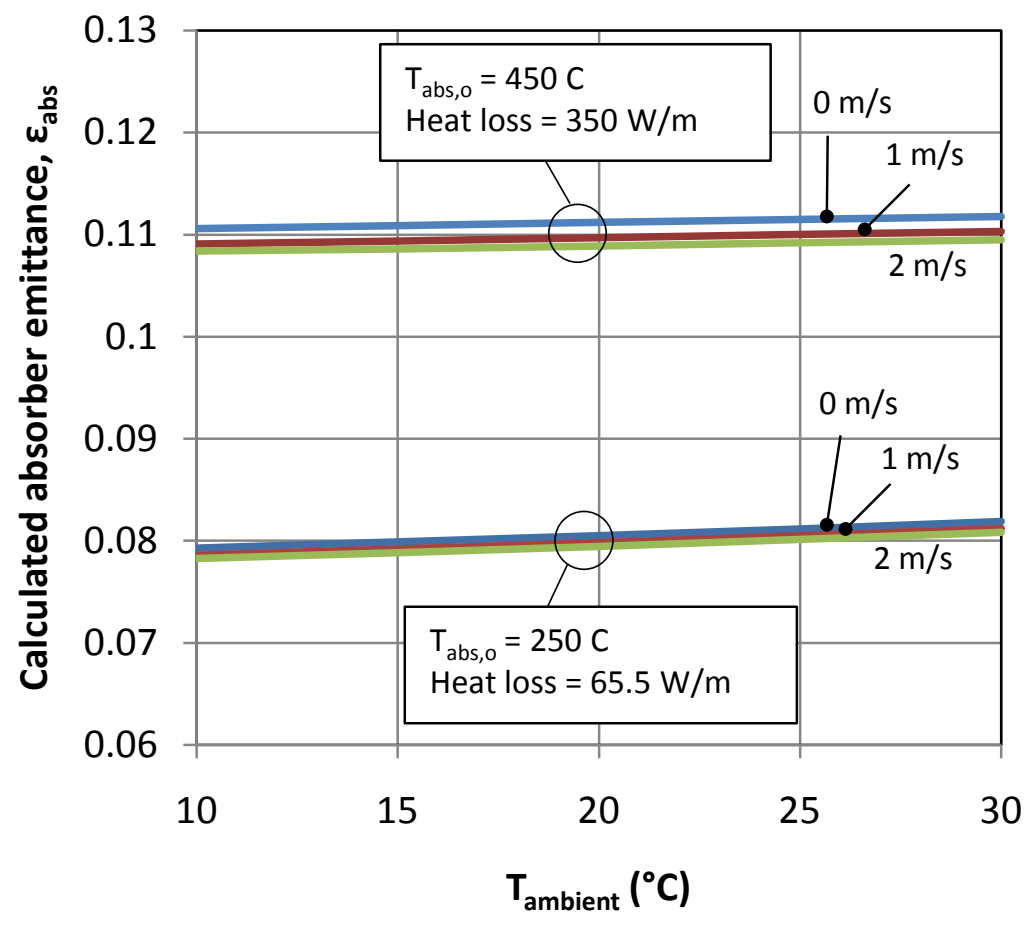

Figure 13. Variation of calculated emittance due to changes in laboratory ambient conditions. The glass temperatures presented in Figures 11 and 12 were used in this calculation. All $450^{\circ} \mathrm{C}$ calculations used $350 \mathrm{~W} / \mathrm{m}$ heat loss, and all $250^{\circ} \mathrm{C}$ calculations used $65.5 \mathrm{~W} / \mathrm{m}$ heat loss.

Emittance results and uncertainties are presented in Figure 14. The $\pm 10 \mathrm{~W} / \mathrm{m}$ heat loss uncertainty causes most of the calculated emittance uncertainty, as shown in Table 4 for two tested absorber temperatures. Emittance uncertainty increases with decreasing absorber temperature because the $\pm 10 \mathrm{~W} / \mathrm{m}$ becomes a larger proportion of the heat loss as the temperature decreases. For instance, the heat loss at $390{ }^{\circ} \mathrm{C}$ is about $200 \mathrm{~W} / \mathrm{m}$. The uncertainty in the heat loss is only $5 \%$ of this value $( \pm 10 / 200=5 \%)$, and the emittance uncertainty is about $\pm 5 \%$ the calculated value. However, at $100^{\circ} \mathrm{C}$ the uncertainty is $66 \%$ of the heat loss value $( \pm 10 / 15)$, which results in a similar uncertainty in the calculated emittance. 
Table 4. Contributions to the uncertainty in the absorber emittance

\begin{tabular}{|c|c|c|c|c|}
\hline & $\begin{array}{c}2008 \text { PTR70 \#2 } \\
\text { Test } 3\end{array}$ & $\begin{array}{c}\text { Contribution to } \\
\varepsilon_{\text {abs }} \text { uncertainty }\end{array}$ & $\begin{array}{c}2008 \text { PTR70 \#2 } \\
\text { Test } 8\end{array}$ & $\begin{array}{c}\text { Contribution to } \\
\varepsilon_{\text {abs }} \text { uncertainty }\end{array}$ \\
\hline $\mathrm{T}_{\mathrm{abs}, \mathrm{i}}\left({ }^{\circ} \mathrm{C}\right)$ & $253.6 \pm 1$ & $\mathbf{0 . 3 \%}$ & $451.4 \pm 1$ & $\mathbf{3 . 0 \%}$ \\
\hline $\mathrm{T}_{\mathrm{gl}, \mathrm{o}}\left({ }^{\circ} \mathrm{C}\right)$ & $39.0 \pm 20$ & $\mathbf{5 . 0 \%}$ & $80.1 \pm 20$ & $\mathbf{1 6 . 8 \%}$ \\
\hline$\varepsilon_{\mathrm{gl}}$ & $0.89 \pm 0.05$ & $\mathbf{0 . 0 \%}$ & $0.89 \pm 0.05$ & $\mathbf{1 . 4 \%}$ \\
\hline Heat loss $(\mathrm{W} / \mathrm{m})$ & $63.3 \pm 10$ & $\mathbf{9 4 . 7 \%}$ & $333.8 \pm 10$ & $\mathbf{7 8 . 8 \%}$ \\
\hline$\varepsilon_{\mathrm{abs}}$ & $\mathbf{0 . 0 7 6} \pm \mathbf{0 . 0 1 2}$ & & $\mathbf{0 . 1 0 4} \pm \mathbf{0 . 0 0 4}$ & \\
\hline
\end{tabular}

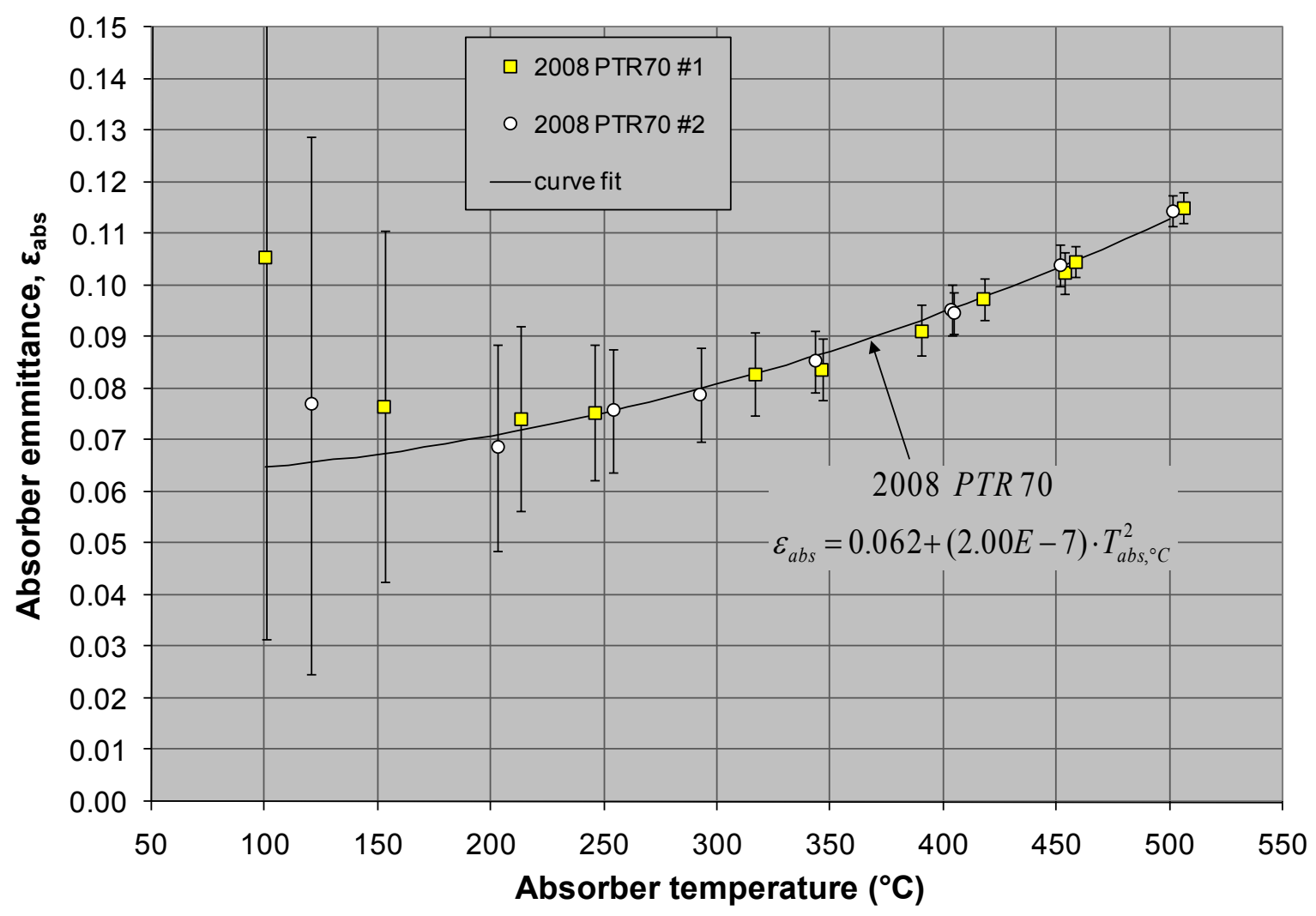

Figure 14. Absorber emittance calculated from heat loss testing

Figure 14 shows that the emittance of the selective coating increases with increasing temperature. This is expected. As the absorber temperature increases more of the thermal radiation is emitted at shorter wavelengths, and the solar selective coating must have low reflectance (consequently, higher emittance) at shorter wavelengths to have high solar absorption. However, the curve fits of the emittance in Figure 14 have shallower slopes than might be expected from direct calculation of the emittance from spectral reflectance data [16]. One reason for this is that the proportion of heat loss that is due to conduction at the ends of the HCE increases with decreasing absorber temperature. The $400^{\circ} \mathrm{C}$ test described in Appendix I shows that the total power that the inner coil heaters require to keep the ends at the same temperature as the bulk of the absorber is only $3 \%$ of the total heat loss value $(25 \mathrm{~W} / 900 \mathrm{~W})$. 
This $25 \mathrm{~W}$ is most likely conduction, not radiation, but its value is so small relative to the total heating power that it affects the emittance calculation slightly -0.096 including the $25 \mathrm{~W}, 0.093$ without it. At lower temperatures end conduction can be up to $15 \%$ of the total heat loss, so an emittance calculation that lumps end conduction in with radiation will give higher values than the actual emittance of the absorber surface. Therefore the emittances on the left hand side of Figure 14 are inflated slightly by end conduction, resulting in a flatter emittance curve than what might be calculated from a spectral reflectance curve for the selective coating of the absorber.

Table 5 presents the emittance results in tabular form.

Table 5. 2008 PTR70 emittance calculation

\begin{tabular}{|c|c|c|c|c|c|}
\hline Test & $\begin{array}{c}\text { Average } \\
\text { absorber } \\
\text { temperature, } \\
\mathrm{T}_{\mathrm{abs}, \mathrm{i}}\left({ }^{\circ} \mathrm{C}\right)\end{array}$ & $\begin{array}{c}\text { Average } \\
\text { glass } \\
\text { temperature, } \\
\mathrm{T}_{\mathrm{gl}, \mathrm{o}}\left({ }^{\circ} \mathrm{C}\right)\end{array}$ & $\begin{array}{l}\text { Heat loss } \\
(\mathrm{W} / \mathrm{m})\end{array}$ & $\begin{array}{l}\text { Calculated } \\
\text { emittance }\end{array}$ & $\begin{array}{c}\text { Uncertainty } \\
\text { in } \\
\text { emittance }\end{array}$ \\
\hline 1 & 100 & 26 & 15 & 0.106 & 0.074 \\
\hline 2 & 153 & 30 & 23 & 0.077 & 0.034 \\
\hline 3 & 213 & 35 & 43 & 0.074 & 0.018 \\
\hline 4 & 246 & 38 & 59 & 0.075 & 0.013 \\
\hline 5 & 317 & 50 & 113 & 0.083 & 0.008 \\
\hline 6 & 346 & 55 & 141 & 0.084 & 0.006 \\
\hline 7 & 390 & 65 & 204 & 0.091 & 0.005 \\
\hline 8 & 418 & 73 & 257 & 0.097 & 0.004 \\
\hline 9 & 454 & 82 & 333 & 0.103 & 0.004 \\
\hline 10 & 458 & 84 & 349 & 0.105 & 0.003 \\
\hline 11 & 506 & 99 & 495 & 0.115 & 0.003 \\
\hline
\end{tabular}

2008 PTR70 \#2

\begin{tabular}{|c|c|c|c|c|c|}
\hline & $\begin{array}{c}\text { Average } \\
\text { absorber } \\
\text { temperature, } \\
\mathrm{T}_{\text {abs, }, \mathrm{i}}\left({ }^{\circ} \mathrm{C}\right)\end{array}$ & $\begin{array}{c}\text { Average } \\
\text { glass } \\
\text { temperature, } \\
\mathrm{T}_{\mathrm{gl}, \mathrm{o}}\left({ }^{\circ} \mathrm{C}\right)\end{array}$ & $\begin{array}{c}\text { Heat loss } \\
(\mathrm{W} / \mathrm{m})\end{array}$ & $\begin{array}{c}\text { Calculated } \\
\text { emittance }\end{array}$ & $\begin{array}{c}\text { Uncertainty } \\
\text { in } \\
\text { emittance }\end{array}$ \\
\hline 1 & 120 & 27 & 15 & $\mathbf{0 . 0 7 7}$ & 0.052 \\
\hline 2 & 203 & 33 & 36 & $\mathbf{0 . 0 6 9}$ & 0.020 \\
\hline 3 & 254 & 39 & 63 & $\mathbf{0 . 0 7 6}$ & 0.012 \\
\hline 4 & 292 & 45 & 90 & $\mathbf{0 . 0 7 9}$ & 0.009 \\
\hline 5 & 343 & 54 & 140 & $\mathbf{0 . 0 8 5}$ & 0.006 \\
\hline 6 & 403 & 68 & 231 & $\mathbf{0 . 0 9 5}$ & 0.005 \\
\hline 7 & 404 & 67 & 230 & $\mathbf{0 . 0 9 5}$ & 0.004 \\
\hline 8 & 451 & 80 & 334 & $\mathbf{0 . 1 0 4}$ & 0.004 \\
\hline 9 & 501 & 95 & 481 & $\mathbf{0 . 1 1 4}$ & 0.003 \\
\hline
\end{tabular}




\section{Modeling the HCE in a parabolic trough collector}

With the absorber emittance estimated by the curve fit in Figure 14, the heat loss from an HCE in a solar field can be estimated by Forristall's parabolic trough collector model $[13,14]$. This validated model calculates HCE heat loss given collector and HCE optical properties and geometry, heat transfer fluid properties, and environmental conditions. It also accommodates heat conduction/convection due to gases in the HCE annulus, and heat transfer that occurs when an HCE has lost its glass envelope. Space considerations limit explanation of this model here, though a simplified evacuated 1D HCE model tailored to the PTR70 geometry with VP1 as the heat transfer fluid is presented in Appendix III. A full description of Forristall's model is available for download [13].

Model inputs are listed below. The parametric inputs were varied according to the values indicated, while the fixed inputs were unchanged for all simulations.

\section{$\underline{\text { Parametric inputs }}$}

Direct normal insolation, $\mathrm{I}_{\mathrm{b}}: \mathbf{0 , 8 0 0 , 1 0 0 0 ~ W / \mathbf { m } ^ { 2 }}$

Windspeed, $\mathrm{V}_{\mathrm{w}}: \mathbf{1}, \mathbf{2}, \mathbf{4}, 8 \mathrm{~m} / \mathrm{s}$

Ambient temperature, $\mathrm{T}_{\mathrm{amb}}: \mathbf{1 5}, 35^{\circ} \mathrm{C}$

Incidence angle, $\theta_{\text {deg }}: \mathbf{0}^{\circ}, \mathbf{1 5}^{\circ}, \mathbf{3 0}^{\circ}, \mathbf{4 5}^{\circ}, \mathbf{6 0}^{\circ}$

HTF temperature, $\mathrm{T}_{\mathrm{HTF}}: 100,150,200,250,300,350,400,450,500{ }^{\circ} \mathrm{C}$

Combinations of all the above variables requires $3 \cdot 4 \cdot 2 \cdot 5 \cdot 9=1080$ parametric runs.

Fixed inputs

\section{HTF: Therminol VP1 ${ }^{1}$ \\ Collector aperture: $\mathbf{5 . 7 5} \mathbf{~ m}$}

Collector optical efficiency: $\mathbf{0 . 7 5}$

Incident angle modifier ${ }^{2}, K=\operatorname{COS}\left(\boldsymbol{\theta}_{\text {deg }}\right)+\mathbf{0 . 0 0 0 8 8 4} \cdot \boldsymbol{\theta}_{\text {deg }}-\mathbf{0 . 0 0 0 0 5 3 6 9}\left(\boldsymbol{\theta}_{\text {deg }}\right)^{2}$

Fraction HCE length unshaded by bellows: 0.96 [24, Appendix IV]

Assumed HCE glass envelope transmittance: 0.963 [24]

Assumed HCE absorber absorptance: 0.96 [16]

HCE absorber emittance: per curve fit in Figure 14

Desired temperature rise per 1 meter HCE length, if DNI available: $\mathbf{0 . 2}{ }^{\circ} \mathbf{C}$

The flow rate was controlled to deliver the desired temperature rise.

The desired output from the model was the heat loss from the absorber $(\mathrm{W} / \mathrm{m})$ for each of the parametric runs.

Both the Calculating Absorber Emittance section and Appendix III show that an evacuated HCE's heat loss is not changed much by ambient conditions. This is not true for an HCE that

\footnotetext{
${ }^{1}$ Though the working limit of VP1 is about $400^{\circ} \mathrm{C}$, higher HTF temperatures are explored to estimate HCE heat loss at these temperatures.

${ }^{2}$ From Dudley et al. [5].
} 
has lost its vacuum, lost its glass envelope, or whose annulus has been infiltrated with hydrogen. This is why ambient conditions are included in the parametric inputs above.

\section{Determining the heat loss correlation coefficients}

Five inputs/outputs of the model were of interest for use in the heat loss correlation:

$\boldsymbol{T}_{\boldsymbol{H} \boldsymbol{T F}}$ - Temperature of the $\operatorname{HTF}\left({ }^{\circ} \mathrm{C}\right)$

$\boldsymbol{V}_{\boldsymbol{w}}-$ Wind speed $(\mathrm{m} / \mathrm{s})$

$\boldsymbol{I}_{\boldsymbol{b}} \boldsymbol{I} \boldsymbol{A M} \boldsymbol{C O S} \boldsymbol{T h}=\mathrm{I}_{\mathrm{b}} \mathrm{K}$ - Insolation that could reach the absorber tube $\left(\mathrm{W} / \mathrm{m}^{2}\right)$. This term is the product of the beam radiation $\left(\mathrm{I}_{\mathrm{b}}\right)$, the incidence angle modifier (IAM), and the cosine of the incidence angle $(\cos \theta)$.

$\left(\boldsymbol{T}_{\boldsymbol{H} \boldsymbol{T F}}-\boldsymbol{T}_{\boldsymbol{a m b}}\right)$ - Difference between the HTF temperature and ambient $\left({ }^{\circ} \mathrm{C}\right)$

$\boldsymbol{H} \boldsymbol{L}=$ Modeled heat loss from the absorber $(\mathrm{W} / \mathrm{m})$

The correlation used to match the modeled results is

$H L=A 0+A 1 \cdot\left(T_{H T F}-T_{a m b}\right)+A 2 \cdot T_{H T F}^{2}+A 3 \cdot T_{H T F}^{3}+A 4 \cdot I_{b} I A M \operatorname{Cos} T h \cdot T_{H T F}^{2}+\sqrt{V_{w}} \cdot\left(A 5+A 6 \cdot\left(T_{H T F}-T_{a m b}\right)\right)$

Price [9] developed this correlation for Excelergy, and it's still used in SAM. It correlates the heat loss to the HTF temperature (A2 and A3), the heating of the absorber tube above the HTF temperature by the sun (A4), and the effect of the ambient temperature and wind speed (A1, A5, and A6). For evacuated HCEs whose limiting thermal resistance is radiation across the annulus, ambient conditions affect heat loss slightly and coefficients A1, A5, and A6 are small. However, some small percentage of the HCEs in the field may have lost their vacuum due to a crack in the glass envelope, have lost their glass envelope entirely, or be filled with hydrogen $[17,18]$. In these cases the glass envelope temperature is better coupled to the HTF temperature, and the magnitudes of these coefficients increase.

Table 6 presents the heat loss correlation coefficients for the 2008 PTR70 HCEs tested in this report. SigmaPlot[19] calculated these coefficients using the Levenberg-Marquardt algorithm for least squares curve fitting. This algorithm is described by Press et al. [20]. Other software programs such as Octave [21] can generate identical coefficients [22].

Table 6. Evacuated 2008 PTR70 heat loss coefficients

\begin{tabular}{|c|c|}
\hline $\begin{array}{c}\text { SAM/Excelergy } \\
\text { coefficients }\end{array}$ & $\begin{array}{c}\text { Vacuum } \\
\text { 2008 PTR70 }\end{array}$ \\
\hline A0 & 4.05 \\
\hline A1 & 0.247 \\
\hline A2 & -0.00146 \\
\hline A3 & $5.65 \mathrm{E}-06$ \\
\hline A4 & $7.62 \mathrm{E}-08$ \\
\hline A5 & -1.70 \\
\hline A6 & 0.0125 \\
\hline
\end{tabular}


The correlation fits the modeled results well, as shown in Figure 15.

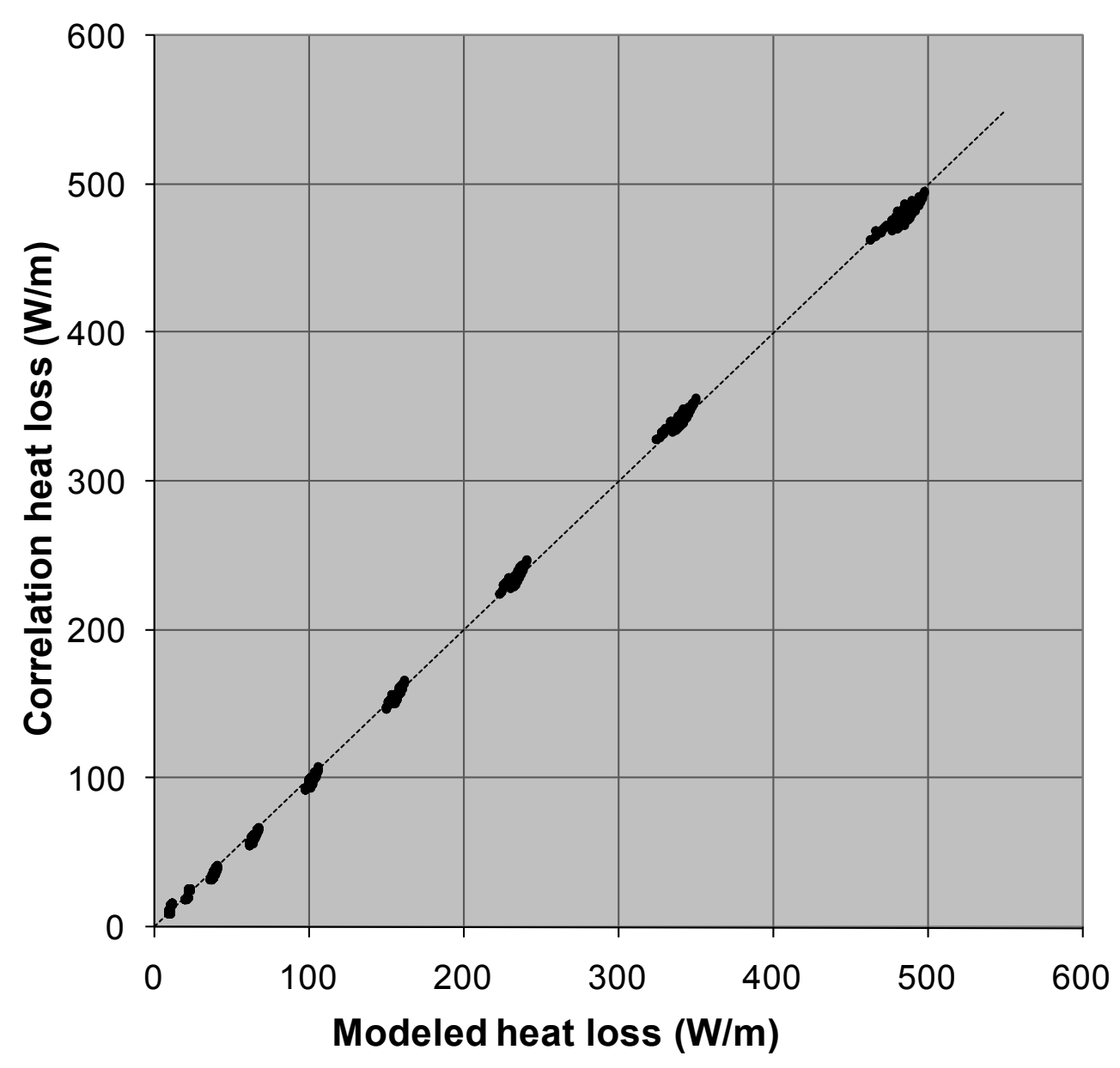

Figure 15. Agreement between the correlated and modeled heat loss

Nine groupings of heat loss results are visible in the graph. These groupings correspond to the nine simulated HTF temperatures. The spread of the points in each grouping show that permutations of the other parameters can cause differences of almost $50 \mathrm{~W} / \mathrm{m}$ for a given HTF temperature.

One obvious question is how dependent the coefficients in Table 6 are on the choice of the parametric runs used to derive them. Previous to this report, all heat loss coefficients were based on 128 parametric runs:

Direct normal insolation, $\mathrm{I}_{\mathrm{b}}: \mathbf{0 , 1 0 0 0 ~} \mathbf{W} / \mathbf{m}^{2}$

Windspeed, $\mathrm{V}_{\mathrm{w}}: \mathbf{1}, \mathbf{2}, \mathbf{4}, \mathbf{8} \mathrm{m} / \mathrm{s}$

Ambient temperature, $\mathrm{T}_{\mathrm{amb}}$ : $\mathbf{1 5}, \mathbf{3 5}^{\circ} \mathrm{C}$

Incidence angle, $\theta_{\text {deg }}: 0^{\circ}$

HTF temperatures, $\mathrm{T}_{\mathrm{HTF}}: \mathbf{5 0}, \mathbf{1 0 0}, \mathbf{1 5 0}, \mathbf{2 0 0}, \mathbf{2 5 0}, \mathbf{3 0 0}, \mathbf{3 5 0}, \mathbf{4 0 0}^{\circ} \mathrm{C}$

with identical fixed inputs except for 


\section{Collector aperture: $\mathbf{5} \mathbf{~ m}$}

HTF flow rate $\approx \mathbf{8} \mathbf{~ k g} / \mathbf{s}$

450 and $500{ }^{\circ} \mathrm{C}$ were added to this test suite (160 parametric runs) and the coefficients were determined again. Table 7 compares the coefficients determined by correlating to 160 parametric runs instead of the 1080 parametric runs described previously.

Table 7. Comparision of heat loss correlation coefficients, 160 versus 1080 parametric runs

\begin{tabular}{|c|c|c|}
\hline $\begin{array}{c}\text { SAM/Excelergy } \\
\text { coefficients }\end{array}$ & $\begin{array}{c}\text { Vacuum } \\
2008 \text { PTR70 } \\
160 \text { parametric runs }\end{array}$ & $\begin{array}{c}\text { Vacuum } \\
\text { 2008 PTR70 } \\
1080 \text { parametric runs }\end{array}$ \\
\hline A0 & 1.67 & 4.05 \\
\hline A1 & 0.262 & 0.247 \\
\hline A2 & -0.00148 & -0.00146 \\
\hline A3 & $5.63 \mathrm{E}-06$ & $5.65 \mathrm{E}-06$ \\
\hline A4 & $5.34 \mathrm{E}-08$ & $7.62 \mathrm{E}-08$ \\
\hline A5 & -1.12 & -1.70 \\
\hline A6 & 0.0106 & 0.0125 \\
\hline
\end{tabular}

The coefficients are similar and yield heat losses with differences less than the heat loss uncertainty of this report $( \pm 10 \mathrm{~W} / \mathrm{m})$. The coefficients aren't that sensitive to the parametric run inputs, assuming the inputs are reasonably chosen. They can be used with confidence for operating configurations different from those for which they were derived. This statement is reinforced by the heat loss sensitivity study presented in Appendix III.

As mentioned earlier, the glass envelope and vacuum of HCEs in the field can be compromised. Although these HCEs will likely represent a small fraction of the total HCEs in the field, their increased heat loss makes it important to include them in a solar field model. SAM and Excelergy include three "compromised" HCEs:

Broken glass - The HCE's glass envelope is completely missing. The selective coating has oxidized leaving it with a similar absorptance but an emittance based on oxidized steel $\left(\varepsilon_{\mathrm{abs}} \approx 0.65[11]\right)$, not the emittance presented in this report. The absorber radiates and convects energy directly to the environment.

Lost vacuum - The glass envelope has a leak and air has leaked through it and resides in the annulus at atmospheric pressure. The selective coating oxidizes as above, but the absorber exchanges energy with the glass envelope, not directly with the environment.

Hydrogen - A sufficient quantity of hydrogen has permeated through the absorber to saturate the getters and reside in the annulus at about 1 torr. The selective surface is uncompromised, but hydrogen conducts a significant amount of heat from the absorber to the glass envelope, increasing heat loss. 
The heat loss correlation coefficients for these "compromised" HCEs were determined in the same manner as the coefficients for the evacuated (vacuum) PTR70. Table 8 presents all heat loss correlation coefficients for the 2008 PTR70.

Table 8. SAM/Excelergy Heat loss correlation coefficients for the 2008 PTR70

\begin{tabular}{|c|c|c|}
\hline Case & $\begin{array}{l}\text { Heat loss } \\
\text { coefficient }\end{array}$ & 2008 PTR70 \\
\hline \multirow{7}{*}{ Vacuum } & $\mathrm{A} 0$ & 4.05 \\
\hline & A1 & 0.247 \\
\hline & A2 & -0.00146 \\
\hline & A3 & $5.65 \mathrm{E}-06$ \\
\hline & A4 & 7.62E-08 \\
\hline & A5 & -1.70 \\
\hline & A6 & 0.0125 \\
\hline \multirow{7}{*}{ Hydrogen } & $\mathrm{A} 0$ & 11.8 \\
\hline & A1 & 1.35 \\
\hline & A2 & $7.50 \mathrm{E}-04$ \\
\hline & A3 & $4.07 \mathrm{E}-06$ \\
\hline & A4 & $5.85 \mathrm{E}-08$ \\
\hline & A5 & -4.48 \\
\hline & A6 & 0.285 \\
\hline \multirow{7}{*}{ Lost vacuum } & A0 & 50.8 \\
\hline & A1 & 0.904 \\
\hline & $\mathrm{A} 2$ & 5.79E-04 \\
\hline & A3 & $1.13 \mathrm{E}-05$ \\
\hline & A4 & $1.73 \mathrm{E}-07$ \\
\hline & A5 & -43.2 \\
\hline & A6 & 0.524 \\
\hline \multirow{7}{*}{ Broken } & $\mathrm{A} 0$ & -9.95 \\
\hline & A1 & 0.465 \\
\hline & A2 & $-8.54 \mathrm{E}-04$ \\
\hline & A3 & $1.85 \mathrm{E}-05$ \\
\hline & A4 & $6.89 \mathrm{E}-07$ \\
\hline & A5 & 24.7 \\
\hline & A6 & 3.37 \\
\hline
\end{tabular}

The "heat loss factor" for these coefficients is 1 . This factor is described in the following section. 


\section{Solar field heat loss}

The correlation presented in the previous section calculates the HCE heat loss occurring in a loop per meter length. One entire loop in the solar field could be modeled meter-by-meter. This entails:

1) Starting with an inlet temperature $T_{H T F, i n}$, HTF heat capacity $\left(c_{H T F}\right)$, and mass flow rate $(\dot{m})$. Appendix III presents a correlation for the heat capacity of VP1.

2) Finding the solar energy absorbed by 1 meter length of absorber:

$$
Q_{\text {sol }, a b s}=I_{b} \cdot \cos \theta \cdot A p \cdot \eta_{o p t} \cdot I A M
$$

This equation is described in Appendix III.

3) Finding the heat loss of the 1 meter length with the heat loss correlation presented in the previous section. This requires the correlation coefficients A0-A6, $T_{H T F, i n}, V_{w}$, $I_{b} I A M C O S T h$, and $\left(T_{H T F, i n}-T_{a m b}\right)$.

4) Calculating the net power gain to the fluid, $Q_{\text {net }}$, by subtracting 3) from 2) and multiplying by 1 meter.

5) Finding the outlet temperature of the 1 meter section with

$$
T_{H T F, \text { out }}=T_{H T F, \text { in }}+\frac{Q_{\text {net }}}{\dot{m} \cdot c_{H T F}}
$$

6) Repeating steps 1 through 5 until the entire loop distance is simulated.

The mass flow rate is varied to get the outlet temperature of the loop to the desired value.

This procedure was followed for an LS3 loop containing 144 HCEs. The inputs were:

\begin{tabular}{|r|c|}
\hline HCE length $(\mathrm{m}):$ & 4.08 \\
\hline Number of HCEs in loop: & 144 \\
\hline Total loop length $(\mathrm{m}):$ & 588 \\
\hline Mass flow rate $(\mathrm{kg} / \mathrm{s}):$ & 9.00 \\
\hline $\mathrm{I}_{\mathrm{b}}\left(\mathrm{W} / \mathrm{m}^{2}\right):$ & 950 \\
\hline Incidence angle, $\theta(\mathrm{deg}):$ & 20 \\
\hline Optical efficiency, $\eta_{\mathrm{o}}:$ & 0.75 \\
\hline $\mathrm{IAM:}$ & 1.00 \\
\hline Aperture $(\mathrm{m}):$ & 5.75 \\
\hline $\mathbf{Q}_{\text {sol, abs }}(\mathrm{W} / \mathrm{m}):$ & 3834 \\
\hline Loop inlet temp $\left({ }^{\circ} \mathrm{C}\right):$ & 293 \\
\hline $\boldsymbol{I}_{\mathbf{b}} \cdot \mathbf{I A M} \cdot \operatorname{Cos} \boldsymbol{\vartheta}\left(\mathbf{W} / \mathbf{m}^{2}\right):$ & 889 \\
\hline Wind speed $(\mathrm{m} / \mathrm{s}):$ & 2 \\
\hline Ambient temp. $\left({ }^{\circ} \mathrm{C}\right)$ & 30 \\
\hline
\end{tabular}


The meter-by-meter simulation used the vacuum PTR70 heat loss correlation coefficients presented in Table 8.

Figure 16 shows the temperature rise of the HTF. Although the temperature rise looks linear, it actually curves down slightly - the temperature rise per meter decreases from $0.18^{\circ} \mathrm{C}$ at $T_{H T F}=$ $293^{\circ} \mathrm{C}$ to $0.16^{\circ} \mathrm{C}$ at $T_{H T F}=391^{\circ} \mathrm{C}$. The net gain of energy decreases as the fluid progresses through the loop because heat loss increases as the HTF temperature increases. The heat loss in the loop is shown in Figure 17.

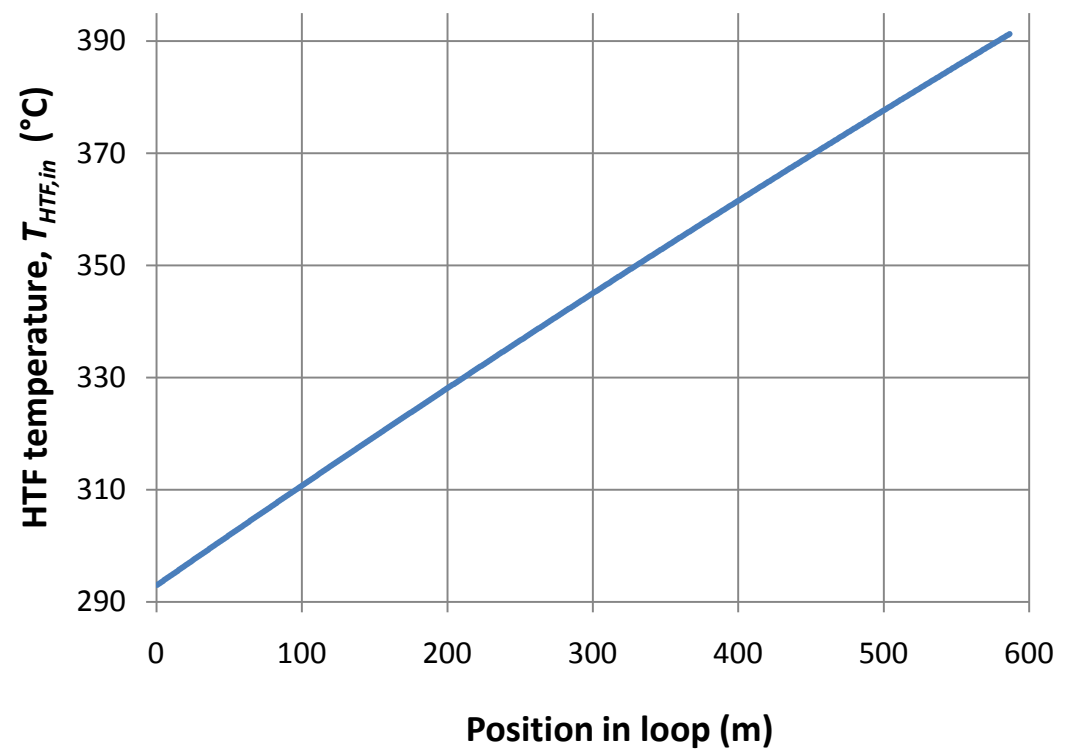

Figure 16. HTF temperature increase as it flows through one loop

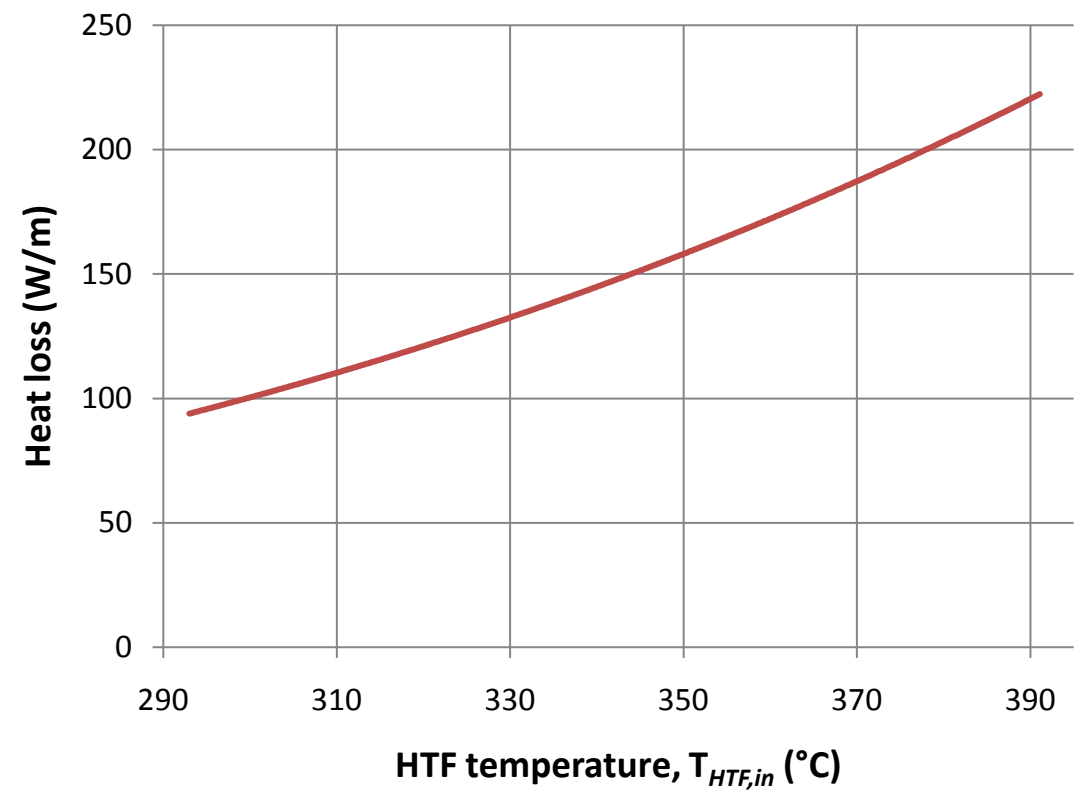

Figure 17. Heat loss as a function of HTF temperature 
The difficulty with this meter-by-meter method is that many calculations are required to simulate a loop. SAM and Excelergy use a simpler method for the entire solar field on an hour-by-hour basis:

$$
Q_{\text {deliveredbySF }, W / m^{2}}=Q_{a b s o r b e d, W / m^{2}}-H L_{\text {avg, }, / m^{2}}-\text { PipingHeatLoss }{ }_{W / m 2}
$$

where

$Q_{\text {deliveredbySF,W/m2 }}$ is the power delivered by the solar field per $\mathrm{m}^{2}$ solar field collector aperture area $\left(\mathrm{W} / \mathrm{m}^{2}\right)$.

$Q_{a b s o r b e d, W / m 2}$ is the power absorbed by the solar field per $\mathrm{m}^{2}$ solar field collector aperture area $\left(\mathrm{W} / \mathrm{m}^{2}\right)$.

The reader is referred to the SAM User's Manual [10] for information regarding the two quantities above.

$H L_{\text {avg, } W / m 2}$ is the average heat loss from the HCEs in the solar field, normalized per $\mathrm{m}^{2}$ solar field collector aperture area $\left(\mathrm{W} / \mathrm{m}^{2}\right)$.

PipingHeatLoss $\mathrm{W}_{\mathrm{m} 2}$ is the heat loss from other pipes in the solar field normalized per $\mathrm{m}^{2}$ solar field collector aperture area $\left(\mathrm{W} / \mathrm{m}^{2}\right)$. Kelly and Kearney [23] describe how to calculate this parameter. SAM 2.5 uses $10 \mathrm{~W} / \mathrm{m}^{2}$.

This method requires $H L_{a v g, W / m 2}$, which is the average heat loss that occurs in a loop, $H L_{a v g, W / m}$, divided by the aperture width of the collector. $H L_{a v g, W / m}$ is calculated by integrating the heat loss presented in Figure 17 and then dividing by the temperature span. This approach works because the temperature rise per meter HCE is nearly linear, as shown in Figure 16.

The integration proceeds as follows:

$H L_{a v g, W / m}=\frac{\int_{T_{i}}^{T_{o}}\left(A 0+A 1 \cdot\left(T_{H T F}-T_{a m b}\right)+A 2 \cdot T_{H T F}^{2}+A 3 \cdot T_{H T F}^{3}+A 4 \cdot I_{b} I A M C o s T h \cdot T_{H T F}^{2}+\sqrt{V_{w}} \cdot\left(A 5+A 6 \cdot\left(T_{H T F}-T_{a m b}\right)\right)\right) \cdot d T_{H T F}}{\left(T_{o}-T_{i}\right)}$

where

$T_{i}$ is the loop inlet temperature, ${ }^{\circ} \mathrm{C}$

$T_{o}$ is the loop outlet temperature, ${ }^{\circ} \mathrm{C}$

The integrated result simplifies to

$$
H L_{\text {avg }, W / m}=\frac{H L T e r m 1+H L T e r m 2+H L T e r m 3+H L T e r m 4}{\left(T_{o}-T_{i}\right)}
$$

where

$$
H L T e r m 1=(A 0+A 5 \cdot \sqrt{V})\left(T_{o}-T_{i}\right)
$$




$$
\begin{aligned}
& \text { HLTerm } 2=\left(A 1+A 6 \cdot \sqrt{V_{w}}\right)\left(\frac{T_{o}^{2}-T_{i}^{2}}{2}-T_{a m b} \cdot\left(T_{o}-T_{i}\right)\right) \\
& \text { HLTerm } 3=\frac{\left(A 2+A 4 \cdot I_{b} I A M \operatorname{Cos} T h\right)}{3}\left(T_{o}^{3}-T_{i}^{3}\right) \\
& \text { HLTerm } 4=\frac{A 3}{4}\left(T_{o}^{4}-T_{i}^{4}\right)
\end{aligned}
$$

$H L_{\text {avg }, W / m}$ is the average amount of heat per HCE length $(\mathrm{W} / \mathrm{m})$ that is lost in the solar field. SAM and Excelergy normalize this heat loss by the collecting aperture with

$$
H L_{\text {avg }, W / m^{2}}=\text { HeatLossFactor } \cdot \frac{H L_{\text {avg }, W / m}}{\text { Collector Aperture }}
$$

The Heat Loss Factor in SAM and Excelergy provides an easy means to scale HCE heat loss. This value is 1 for the HCEs presented in Table 8. However, a program user may wish to be conservative in the estimation of heat loss by increasing this factor from 1 to 1.1 or 1.2. This increases heat loss from the HCEs by $10 \%$ and $20 \%$, respectively.

Finally, the total thermal energy $\left(\mathrm{MW}_{\text {th }}\right)$ delivered by the solar field is

$$
Q_{S F}=\frac{Q_{\text {deliveredbySF, } / \mathrm{m}^{2}} \cdot \text { NetArea }_{S F}}{1,000,000}
$$

$Q_{S F}$ is divided by $1,000,000$ to convert $\mathrm{W}_{\text {th }}$ to $\mathrm{MW}_{\text {th }}$.

where

NetArea $_{S F}$ is the net area of the solar field $\left(\mathrm{m}^{2}\right)$ 


\section{Demonstrating improved plant performance}

With the heat loss correlation coefficients determined, SAM can calculate the effect of HCE heat loss on plant performance. A $100 \mathrm{MW}_{\text {e }}$ parabolic trough power plant is simulated with the 2008 PTR70 HCE, and the results of this simulation are compared to the results of an identical plant simulation that uses the previous, default Schott PTR70 in SAM [2,3,4]. The previous PTR70 is referred to as the default PTR70 in the remainder of this section. The parabolic trough power plant had the following characteristics:

\section{Configuration/Solar Field/Power Block/Parasitics}

Size: $100 \mathrm{MW}_{\mathrm{e}}$

Thermal energy storage: 6 hours, 2 tank molten salt

Solar field size: $875,000 \mathrm{~m}^{2}$

Solar field inlet/outlet temperature: $293{ }^{\circ} \mathrm{C} / 391{ }^{\circ} \mathrm{C}$

Heat transfer fluid: VP1

Condenser: Wet-cooling

No fossil fuel backup

Location: Daggett, CA

Solar Collector Assembly: Solargenix SGX-1

HCE heat loss correlation coefficients: default PTR70 or 2008 PTR70

HCE bellows shading: 0.96 [see Appendix IV, 24]

HCE glass transmittance: 0.96 [24]

HCE absorber absorptance: 0.96 [16]

HCE conditions in the field: $98 \%$ Vacuum, $1 \%$ Lost vacuum, $0.5 \%$ Broken glass, $0.5 \%$ Hydrogen

Turbine gross/net output: 110/100 $\mathrm{MW}_{\mathrm{e}}$

Design turbine gross efficiency: 0.3774

Total design point parasitics: $20 \mathrm{MW}_{\mathrm{e}}$ (These are total plant parasitics, which are not concurrent.

Parasitics during operation are roughly half this value)

\section{$\underline{\text { Costs/Maintenance }}$}

Direct

Site improvements: $\$ 3 / \mathrm{m}^{2}$

Solar field: $\$ 300 / \mathrm{m}^{2}$

HTF system: $\$ 150 / \mathrm{kW}_{\mathrm{e}}$

Storage: $\$ 40 / \mathrm{kW}_{\text {th }}$

Power plant: $\$ 850 / \mathrm{kW}_{\mathrm{e}}$

Contingency: $8 \%$

Indirect

Engineer, procure, construct: $16 \%$ of direct costs

Project, land, miscellaneous: $3.5 \%$ of direct costs

Sales tax: $7.75 \%$ applied to $80 \%$ of the direct costs

Maintenance: $\$ 50 / \mathrm{kW}-\mathrm{yr}$

Note: These default values distributed with SAM 2.5 are not necessarily representative of actual costs. 
Financial/Incentives

$30 \%$ investment tax credit

$8 \%$ real discount rate

30 year plant life

$15 \%$ internal rate of return

1.4 minimum debt service cover ratio (DSCR)

20 year loan

Loan rate: $8 \%$

Federal and state depreciation: MACRS Mid-Quarter convention

$40 \%$ loan debt fraction

Two SAM simulations were performed. One simulation used the default PTR70 heat loss correlation coefficients presented in Figure 18, and the other used the 2008 PTR70 heat loss correlation coefficients presented in Figure 19.

\begin{tabular}{|c|c|c|c|c|}
\hline & $\begin{array}{c}\text { Default } \\
\text { PTR70 } \\
\text { Vacuum }\end{array}$ & $\begin{array}{c}\text { Default } \\
\text { PTR70 } \\
\text { Lost vacuum }\end{array}$ & $\begin{array}{c}\text { Default } \\
\text { PTR70 } \\
\text { Broken glass }\end{array}$ & $\begin{array}{c}\text { Default } \\
\text { PTR70 } \\
\text { Hydrogen }\end{array}$ \\
\hline \multicolumn{5}{|l|}{ Heat Loss Parameters } \\
\hline A0 Heat Loss Coefficient & 1.8615 & -0.16634 & 116.25 & 9.2419 \\
\hline A1 Heat Loss Coefficient & 0.18741 & 0.87716 & -0.97124 & 1.3648 \\
\hline A2 Heat Loss Coefficient & -0.0011594 & -0.00075942 & -0.010638 & 0.0010516 \\
\hline A3 Heat Loss Coefficient & $6.6026 \mathrm{E}-6$ & $5.7723 \mathrm{E}-6$ & $2.9254 \mathrm{E}-5$ & $4.8011 \mathrm{E}-6$ \\
\hline A4 Heat Loss Coefficient & $8.8034 \mathrm{E}-8$ & $4.4504 \mathrm{E}-8$ & $7.352 \mathrm{E} \cdot 7$ & $9.2562 \mathrm{E}-8$ \\
\hline A5 Heat Loss Coefficient & -0.91215 & -4.2159 & -100.51 & -3.7595 \\
\hline A6 Heat Loss Coefficient & 0.011763 & 0.13313 & 5.2682 & 0.33064 \\
\hline Heat Loss Factor & 1.25 & 1.25 & 1.25 & 1.25 \\
\hline Minimum Windspeed $[\mathrm{m} / \mathrm{s}]$ & $\overline{0}$ & 0 & 0.5 & $\overline{0}$ \\
\hline
\end{tabular}

Figure 18. SAM default PTR70 heat loss correlation coefficients

\begin{tabular}{|c|c|c|c|c|}
\hline & $\begin{array}{c}2008 \\
\text { PTR70 } \\
\text { Vacuum }\end{array}$ & $\begin{array}{c}2008 \\
\text { PTR70 } \\
\text { Lost vacuum }\end{array}$ & $\begin{array}{c}2008 \\
\text { PTR70 } \\
\text { Broken glass }\end{array}$ & $\begin{array}{c}2008 \\
\text { PTR70 } \\
\text { Hydrogen }\end{array}$ \\
\hline \multicolumn{5}{|l|}{ Heat Loss Parameters } \\
\hline A0 Heat Loss Coefficient & 4.05 & 50.8 & -9.95 & 11.8 \\
\hline A1 Heat Loss Coefficient & 0.247 & 0.904 & 0.465 & 1.35 \\
\hline A.2 Heat Loss Coefficient & -0.00146 & 0.000579 & -0.000854 & 0.00075 \\
\hline A3 Heat Loss Coefficient & $5.65 \mathrm{E}-6$ & $1.13 \mathrm{E}-5$ & $1.85 \mathrm{E}-5$ & $4.07 \mathrm{E}-6$ \\
\hline A4 Heat Loss Coefficient & $7.62 \mathrm{E}-8$ & $1.73 \mathrm{E} \cdot 7$ & $6.89 \mathrm{E} \cdot 7$ & $5.85 \mathrm{E}-8$ \\
\hline A5 Heat Loss Coefficient & -1.7 & -43.2 & 24.7 & -4.48 \\
\hline A6 Heat Loss Coefficient & 0.0125 & 0.524 & 3.37 & 0.285 \\
\hline Heat Loss Factor & 1 & 1 & 1 & 1 \\
\hline Minimum Windspeed $[\mathrm{m} / \mathrm{s}]$ & 0 & $\overline{0}$ & $\overline{0}$ & 0 \\
\hline
\end{tabular}

Figure 19. 2008 PTR70 heat loss correlation coefficients 
The default PTR70 heat loss correlation coefficients were not based on an emittance that was derived from heat loss testing. When heat loss results become available, we discovered that the heat loss determined by the coefficients needed to be scaled up by 1.25 to be consistent with values in the literature $[2,3,4]$. This is why the heat loss factor for the default PTR70 is 1.25 .

SAM simulation results are presented in Table 9.

Table 9. SAM simulation results for the default and 2008 PTR70

\begin{tabular}{|c|c|c|c|}
\hline Simulation result & $\begin{array}{c}\text { Default PTR70 heat } \\
\text { loss coefficients }\end{array}$ & $\begin{array}{c}\text { 2008 PTR70 heat } \\
\text { loss coefficients }\end{array}$ & $\begin{array}{c}\text { 2008 PTR 70 } \\
\text { Default PTR 70 }\end{array}$ \\
\hline $\begin{array}{c}\text { Real levelized cost of } \\
\text { energy }(\mathrm{LCOE}), \\
\phi / \mathrm{kWh}\end{array}$ & 11.4 & 10.8 & $95 \%$ \\
\hline $\begin{array}{c}\text { Nominal LCOE, } \\
\varnothing / \mathrm{kWh}\end{array}$ & 14.4 & 13.7 & $95 \%$ \\
\hline $\begin{array}{c}\text { Annual electricity } \\
\text { production }\left(\mathrm{MWh}_{\mathrm{e}}\right)\end{array}$ & 348,000 & 367,000 & $105 \%$ \\
\hline
\end{tabular}

As described in the SAM User's Manual [10], "The levelized cost of energy (LCOE) is an economic measure that is useful for comparing and ranking technology options because it is a cost that accounts for the purchase, financing, tax, and operation costs of a power system over its lifetime. Analysts can use the LCOE to evaluate renewable energy projects and to compare them to energy efficiency and conventional fossil fuel projects."

In these utility scale projects, the revenue based on a desired internal rate of return (IRR) is considered a cost of the system and is included in the LCOE calculation. The difference between real and nominal LCOEs is the discount rate used to levelize the present value of a nominal power purchase agreement over the lifetime of the plant. The reader is referred to the SAM User's Manual for details.

Table 9 shows that the 2008 PTR70 decreases the LCOE by about $0.5 \phi / \mathrm{kWh}$ and increases annual electricity production by $5 \%$ relative to the previous PTR70. This assumes that the HCEs are the same in all other respects. 


\section{Conclusion}

Two Schott 2008 model year PTR70 HCEs were tested on NREL's heat loss test stand from 100 $-500^{\circ} \mathrm{C}$ in $50^{\circ} \mathrm{C}$ increments. Absorber emittance was determined from the laboratory testing so that the performance of the HCEs could be modeled in a parabolic trough collector. Collector/HCE simulation results for many different field operation conditions were used to create heat loss correlation coefficients for Excelergy and SAM. SAM estimates that the decreased emittance of the 2008 PTR70 will decrease the LCOE for parabolic trough power plants by $0.5 \phi / \mathrm{kWh}$ and increase the electricity generated by $5 \%$ relative to previous PTR $70 \mathrm{~s}$. These conclusions assume that the 2008 PTR70 is supplied at the same cost and with the same optical performance as earlier PTR70 models.

\section{Acknowledgements}

We are thankful to Mark Mehos, Craig Turchi, and Mike Wagner (NREL) and Hank Price (Abengoa Solar) for content suggestions as well as review of preliminary versions of this report. We would also like to acknowledge the technical assistance provided by Judy Netter, Mark Bernardi, and Mark Depaul (NREL). 


\section{References}

[1] Price, H., E. Lüpfert, D. Kearney, E. Zarza, G. Cohen, R. Gee, R. Mahoney, “Advances in Parabolic Trough Solar Power Technology,” J. Sol. Energy Eng. 124, 109-125, 2002.

[2] Moss, T., D. Brousseau, "Test Results of a Schott Trough Receiver using a LS-2 Collector," Proceedings of ISEC: ASME 2005, Orlando, Florida, August 6-12, 2005.

[3] Burkholder, F., H. Price, C. Kutscher, M. Brandemuehl, J. Netter, "Parabolic Trough Receiver Thermal Testing," Proceedings of the ASME Energy Sustainability Conference, Long Beach, California, June 27-30, 2007.

[4] Lüpfert, E., K.J. Riffelmann, H. Price, F. Burkholder, R. T. Moss, "Experimental Analysis of Overall Thermal Properties of Parabolic Trough Receivers," J. Sol. Energy Eng. 130, 021007, 2008.

[5] Dudley, V., G. Kolb, A. R. Mahoney, T. Mancini, C. Matthews, M. Sloan, D. Kearney, “Test Results SEGS LS-2 Solar Collector," SAND94-1884, December 1994. Available electronically at $<$ http://www.nrel.gov/csp/troughnet/pdfs/segs_1s2_solar_collector.pdf $>$

[6] Burkholder, F., C. Kutscher, "Heat-Loss Testing of Solel's UVAC3 Parabolic Trough Receiver," National Renewable Energy Laboratory Technical Report, NREL/TP-550-42394, 2008. Available electronically at $<\underline{\text { http://www.nrel.gov/csp/troughnet/pdfs/42394.pdf }>}$

[7] Omega.com Thermocouples. 10 Apr. 2009

<http://www.omega.com/guides/thermocouples.html $>$

[8] Lüpfert, E., U. Herrmann, H. Price, E. Zarza, R. Kistner, "Towards standard performance analysis for parabolic trough collector fields," Proceedings of $12^{\text {th }}$ International SolarPACES Symposium. Oaxaca, Mexico, 6-8 October 2004.

[9] Price, H., “A Parabolic Trough Solar Power Plant Simulation Model,” National Renewable Energy Laboratory Technical Report, NREL/CP-550-33209, January 2003. Available electronically at $<$ http://www.nrel.gov/docs/fy03osti/33209.pdf $>$

[10] SAM (Solar Advisor Model) Version 2.5.0.2 developed by the National Renewable Energy Laboratory. Available electronically at $<$ www.nrel.gov/analysis/sam $>$

[11] Incropera, F., D. Dewitt, Introduction to Heat Transfer, John Wiley \& Sons, New York, 2002.

[12] MatWeb Material Property Data, Schott Thin Borosilicate Glass. 10 Apr. 2009. $<\underline{\text { http://www.matweb.com/search/datasheet.aspx?matguid=8df9f3e0106d43818ebe1862e76a1107> }}$ 
[13] Forristall, R., "Heat Transfer Analysis and Modeling of a Parabolic Trough Solar Receiver Implemented in Engineering Equation Solver," National Renewable Energy Laboratory Technical Report, NREL/TP-550-34169, 2003. Available electronically at $<$ http://www.nrel.gov/csp/troughnet/pdfs/34169.pdfs

[14] Forristall, R., "EES Heat Transfer Model for Solar Receiver Performance," Proceedings of ISEC, Solar 2004, Portland, Oregon, July 11-14, 2004.

[15] Touloukian, Y. S., D. P. DeWitt, eds. Radiative Properties, Nonmetalic Solids. Thermophysical Properties of Matter, Vol. 8, New York: Plenum Publishing, 1972.

[16] Benz., N., W. Graf, Z. Hacker, Ch. Hildebrandt, M. Möllenhoff, J. Schulte-Fischedick, K. Silmy, "Advances in Receiver Technology for Parabolic Troughs," Proceedings of the $14^{\text {th }}$ Biennial CSP SolarPACES Symposium, Las Vegas, NV, March 4-7, 2008.

[17] Price, H., R. Forristall, T. Wendelin, A. Lewandowski, T. Moss, C. Gummo, "Field Survey of Parabolic Trough Receiver Performance," Proceedings of ISEC: ASME 2006, Denver, Colorado, July 8-13, 2006.

[18] Moens, L., D. Blake, "Mechanism of Hydrogen Formation in Solar Parabolic Trough Receivers," National Renewable Energy Lab Technical Report NREL/TP-510-42468, February 2008. Available electronically at $<$ http://www.nrel.gov/csp/troughnet/pdfs/42468.pdf $>$

[19] SigmaPlot for Windows Version 9.01 (2004) Systat Software, Inc.

[20] Press, W., B. Flannery, S. Teukolsky, W. Vetterling Numerical Recipes, Cambridge University Press, New York, 1987.

[21] Octave for Windows Version 3.0.4 (2009). J. Eaton and the University of Wisconsin, Madison. Open source code available at $<\underline{\mathrm{http}}$ ///www.gnu.org/software/octave/download.html $>$

[22] Personal communication, Diego A. Arias, Abengoa Solar, 13 Mar. 2009.

[23] Kelly, B., D. Kearney, "Parabolic Trough Solar System Piping Model - Final Report," National Renewable Energy Laboratory Subcontract Report NREL/SR-550-40165, July 2006. Available electronically at $<$ http://www.nrel.gov/csp/troughnet/pdfs/40165.pdf $>$

[24] Benz, N. "Next Generation Receivers," Presentation given at Trough Workshop at NREL, March 8-9, 2007. Available electronically at

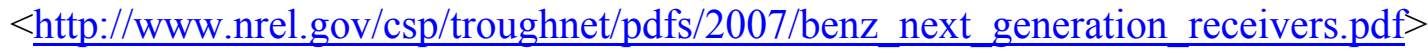

[25] Dieck, R.H., Measurement Uncertainty, Methods and Applications. North Carolina: Instrument Society of America, 1992

[26] Klein, S. A. (2002). Engineering Equation Solver (EES) for Microsoft Windows Operating System: Commercial and Professional Versions. Madison, WI: F-Chart Software. 
[27] Listing of other parabolic trough models:

Stoddard, M., S. Faas, C. Chiang, J. Dirks, 1987, "SOLERGY - A Computer Code for Calculating the Annual Energy from Central Receiver Power Plants," SAND86-8060, Sandia National Laboratories, Livermore, California.

KJC Operating Company, 1993, "Final Report on HCE Heat Transfer Analysis Code," as part of Sandia National Labs Contract No. AB-0227, O\&M Cost Reduction in Solar Thermal Electric Plants, 15 December 1993, Boron, California. Report describes HCE-HTX code written by M. Sloan based on analysis by T. Mancini of Sandia National Laboratory.

Price, H., P. Svoboda, D. Kearney, 1994, "Validation of the FLAGSOL Parabolic Trough Solar Power Plant Performance Model", National Renewable Energy Lab Technical Report NREL/TP471-7297, October 1994.

Lippke, F., 1995 "Simulation of the Part-Load Behavior of a 30 MWe SEGS Plant," SAND951293, Sandia National Laboratories, Albuquerque, NM.

Odeh, S.D., G.L. Morrison, M. Behnia, 1996, "Thermal analysis of parabolic trough solar collector for power generation," Proceedings of ANZSES $34^{\text {th }}$ Annual Conference, Darwin, Australia, p 460-467.

Fraidenraich, N., J.M. Gordon, R.C.F. Lima, 1997, "Improved solutions for temperature and thermal power delivery profiles in linear solar collectors," Solar Energy 61, p. 141-145.

Nelson, R., R. Cable, 1999, "Improved SEGS Plant Modeling: Description and Comparison," American Solar Energy Society 1999 Annual Conference, Albuquerque, NM.

Jones, S., R. Pitz-Paal, P. Schwarzboezl, N. Blair, R. Cable, 2001, "TRNSYS Modeling of the SEGS VI Parabolic Trough Solar Electric Generating System," Proceedings of the Solar Forum 2001: Solar Energy: The Power to Choose, April 21-25, 2001, Washington, D.C.

Stuetzle, T. A., 2002, Automatic Control of the 30 MWe SEGS VI Parabolic Trough Plant. M.S. Thesis, University of Wisconsin, Madison, 2002. Available electronically at $<\underline{\text { http://sel.me.wisc.edu/publications-theses.shtml }>}$

Odeh, S.D., 2003, "Unified model of solar thermal electric generation systems," Renewable Energy 28, p. 755-767.

Hermann, U., B. Kelly, H. Price, 2004, “Two-tank molten salt storage for parabolic trough solar power plants," Energy 29, p. 883-893.

Patnode, A. M., 2006, Simulation and Performance Evaluation of Parabolic Trough Solar Power Plants. M.S. Thesis, University of Wisconsin, Madison. Available electronically at $<$ http://sel.me.wisc.edu/publications-theses.shtml $>$ 
McMahan, A. C., 2006, Design \& Optimization of Organic Rankine Cycle Solar-Thermal Powerplants. M.S. Thesis, University of Wisconsin, Madison. Available electronically at $<$ http://sel.me.wisc.edu/publications-theses.shtml $>$

Relloso, S., B. Olabarri, 2008, "SENSOL as a Key Tool for Solar Commercial Projects," Proceedings of the $14^{\text {th }}$ Biennial CSP SolarPACES Symposium, Las Vegas, NV, March 4-7, 2008.

Rheinländer, J., S. Bergmann, M.R. Erbes, 2008, "Technical and Economic Performance of Parabolic Trough Solar Power Plants - A Computational Tool for Plant Feasibility Studies," Proceedings of the $14^{\text {th }}$ Biennial CSP SolarPACES Symposium, Las Vegas, NV, March 4-7, 2008.

Rolim, M.M., N. Fraidenraich, C. Tiba, 2009, "Analytic Modeling of a Solar Power Plant with Parabolic Linear Collectors," Solar Energy 83, p. 126-133. 


\section{Appendix I - Detailed data from one test near $400{ }^{\circ} \mathrm{C}$}

This section shows the data gathered during one heat loss test and explains how this data is used to calculate the values presented in Figure 9 and Table 3. The data presented in this section was gathered during Test 6 in the table below.

2008 PTR70 \#2
\begin{tabular}{|c|c|c|c|c|c|c|}
\hline & $\begin{array}{c}\text { Average } \\
\text { absorber } \\
\text { temperature } \\
\left({ }^{\circ} \mathbf{C}\right)\end{array}$ & $\begin{array}{c}\text { Average glass } \\
\text { temperature } \\
\left({ }^{\circ} \mathrm{C}\right)\end{array}$ & $\begin{array}{c}\text { Average } \\
\text { ambient } \\
\text { temperature } \\
\left({ }^{\circ} \mathrm{C}\right)\end{array}$ & $\begin{array}{c}\text { Average } \\
\text { absorber } \\
\text { temp. above } \\
\text { ambient }\left({ }^{\circ} \mathrm{C}\right)\end{array}$ & $\begin{array}{c}\text { Heat loss } \\
(\mathbf{W} / \mathbf{m} \text { HCE } \\
\text { length) }\end{array}$ & date of test \\
\hline 1 & $\mathbf{1 2 0}$ & 27 & 22 & 98 & $\mathbf{1 5}$ & $11 / 5 / 2008$ \\
\hline 2 & $\mathbf{2 0 3}$ & 33 & 22 & 180 & $\mathbf{3 6}$ & $11 / 5 / 2008$ \\
\hline 3 & $\mathbf{2 5 4}$ & 39 & 23 & 231 & $\mathbf{6 3}$ & $11 / 5 / 2008$ \\
\hline 4 & $\mathbf{2 9 2}$ & 45 & 23 & 269 & $\mathbf{9 0}$ & $11 / 6 / 2008$ \\
\hline 5 & $\mathbf{3 4 3}$ & 54 & 23 & 320 & $\mathbf{1 4 0}$ & $11 / 6 / 2008$ \\
\hline 6 & $\mathbf{4 0 3}$ & 68 & 23 & 380 & $\mathbf{2 3 1}$ & $11 / 6 / 2008$ \\
\hline 7 & $\mathbf{4 0 4}$ & 67 & 22 & 382 & $\mathbf{2 3 0}$ & $11 / 7 / 2008$ \\
\hline 8 & $\mathbf{4 5 1}$ & 80 & 23 & 429 & $\mathbf{3 3 4}$ & $11 / 7 / 2008$ \\
\hline 9 & $\mathbf{5 0 1}$ & 95 & 23 & 478 & $\mathbf{4 8 1}$ & $11 / 7 / 2008$ \\
\hline
\end{tabular}

Figure I-1 shows the absorber temperatures (Abs 1 through Abs 8) and heater powers (Inner coil heater 1, Cartridge heater 1, Cartridge heater 2, Inner coil heater 2) during the 15 minute steadystate period.

Data from 2008 PTR70 \#2, average absorber temperature at $403^{\circ} \mathrm{C}$ Absorber temperatures and heater powers

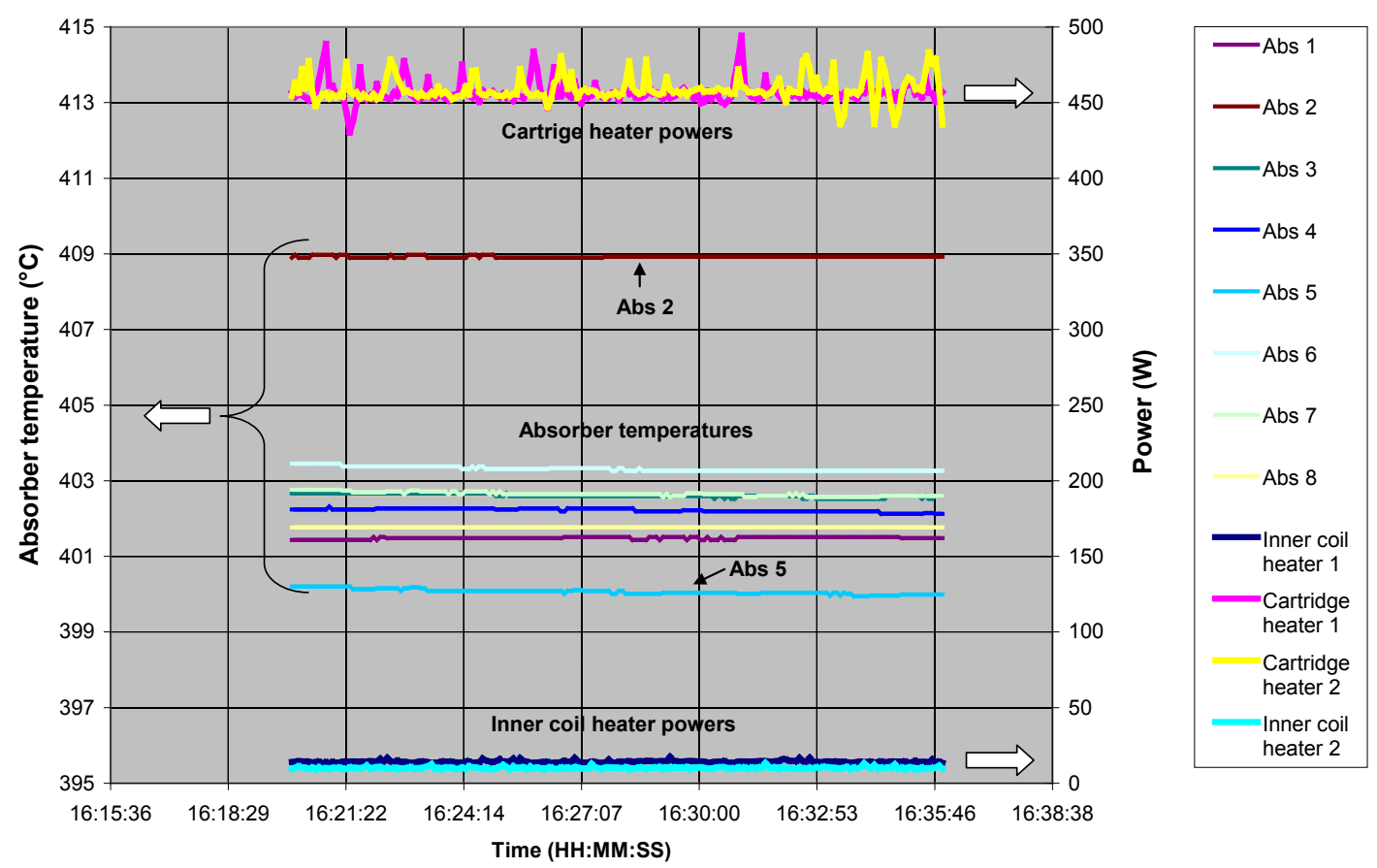

Figure l-1. Absorber temperatures and heater powers during Test 6 of 2008 PTR70 \#2 
Figure I-1 shows that absorber temperatures and heater powers varied little during the steadystate period. The cartridge and coil heater powers are roughly equal for each side of the HCE, as should be the case because the $\mathrm{HCE}$ is symmetric. The absorber temperatures range between $401{ }^{\circ} \mathrm{C}$ and $404{ }^{\circ} \mathrm{C}$, except for Abs $2\left(409{ }^{\circ} \mathrm{C}\right)$ and Abs $5\left(400{ }^{\circ} \mathrm{C}\right)$. The absorber temperature uncertainty is $0.4 \% \cdot 400{ }^{\circ} \mathrm{C}=1.6{ }^{\circ} \mathrm{C} \approx 2{ }^{\circ} \mathrm{C}$, which means that individual thermocouple temperatures should range between $405^{\circ} \mathrm{C}$ and $401{ }^{\circ} \mathrm{C}$ for an actual absorber temperature of 403 ${ }^{\circ} \mathrm{C}$. Abs 2 and Abs 5 are outside of this range, and Figure I-2 supports the conclusion that these temperature variations are real.

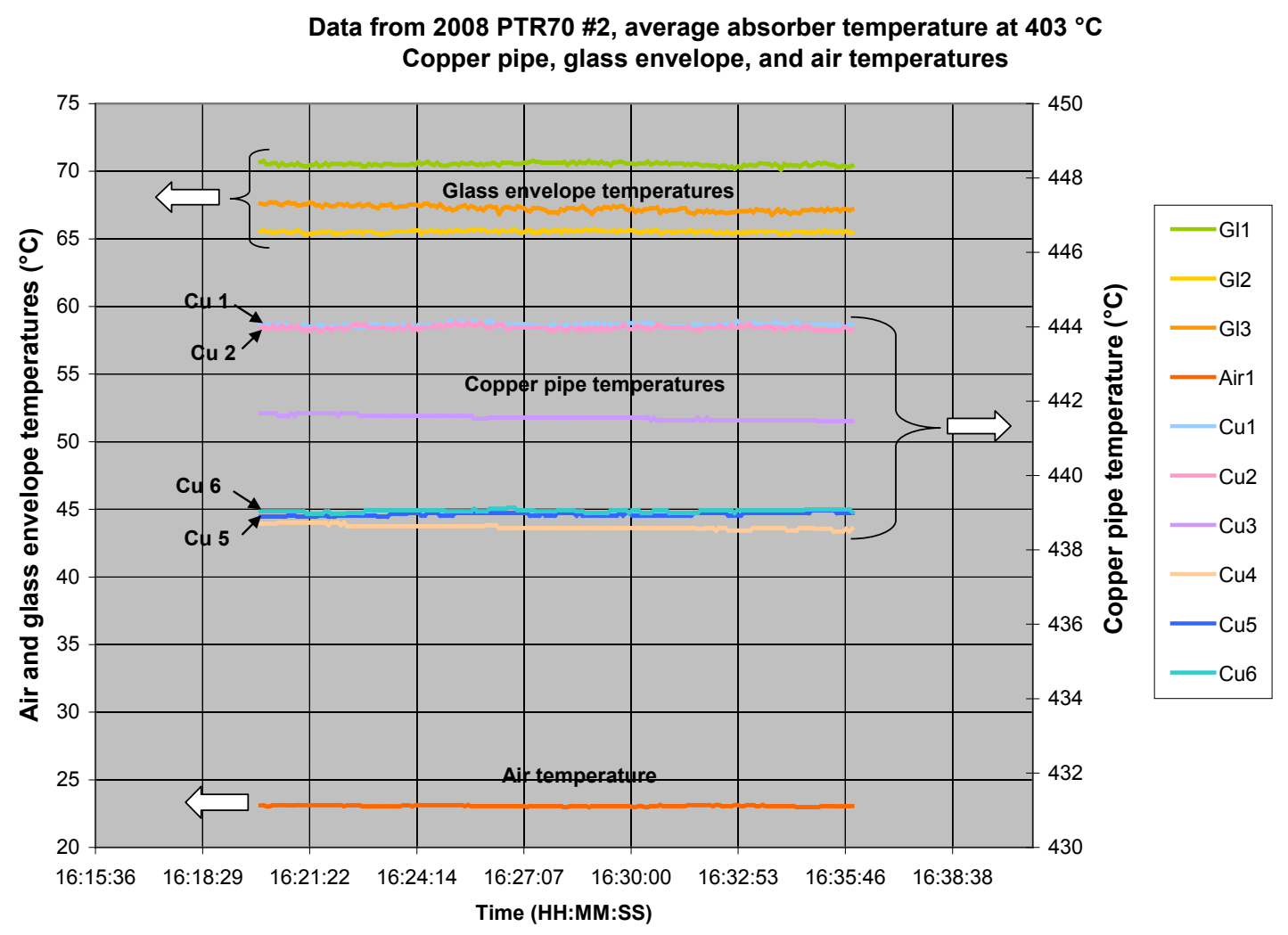

Figure I-2. Absorber temperatures and heater powers during Test 6 of 2008 PTR70 \#2

Note that Gl $1>$ Gl $3>$ Gl 2 in Figure I-2. This indicates that the glass envelope temperatures at the ends are slightly higher than the center-of-glass temperature. As shown in Figure 6, Gl 1 measures the glass envelope temperature at an axial location on the HCE between Abs 2 and Abs 3, while Gl 2 measures the glass envelope temperature between Abs 4 and Abs 5. Abs 2's increased temperature relative to the other absorber temperatures means that the glass envelope in its vicinity ( $\mathrm{Gl} \mathrm{1}$ ) is heated more than the others. Likewise, the absorber temperatures in the middle (Abs 4 and Abs 5) are less than the mean absorber temperature, and Gl 2's temperature is correspondingly less than Gl 1 and Gl 2. The point of this discussion is to make the case that the HCE isn't being heated uniformly.

Other than serving as support structures for the thermocouples, the purpose of the copper pipes is to provide uniform heating to the absorber surface. Figures I-1 and I-2 indicate that they fulfill this task imperfectly. The heating inside them isn't uniform - the inner coil heaters provide additional heating at the ends to counteract increased end conduction, and it's likely that the tips 
of the cartridge heaters aren't putting out as much power as sections nearer the middle. Therefore heating and temperature variations exist. However, these variations are small and investigating their effect through the use of the HCE model presented in Appendix III shows that a variation of $\pm 5^{\circ} \mathrm{C}$ for one section (of six) of the absorber from the mean absorber temperature corresponds to a heat loss variation of less than $\pm 3 \mathrm{~W} / \mathrm{m}$ for the entire absorber for almost all testing temperatures. Appendix II shows that the heat loss measurement uncertainty is significantly greater than this, so the effect of small, local temperature variations on the overall heat loss calculation is minor.

The average absorber temperature is approximated as

$$
A b s_{\text {ave }}=\frac{A b s 2+A b s 3+A b s 4+A b s 5+A b s 6+A b s 7}{6}
$$

and the average glass temperature is

$$
G l_{\text {ave }}=\frac{G l 1+G l 2+G l 3}{3}
$$

The heat loss is calculated from

$$
H L_{w / m}=\frac{\text { Coil } 1+\text { Cart } 1+\text { Cart } 2+\text { Coil } 2+\frac{k \cdot A}{\Delta x}(C u 1-C u 2)+\frac{k \cdot A}{\Delta x}(C u 6-C u 5)}{L_{H C E}}
$$

where:

$H L_{W / m}$ is the total heat lost $(\mathrm{W} / \mathrm{m})$

Coil 1 and Coil 2 are the inner coil heater powers (W)

Cart 1 and Cart 2 are the cartridge heater powers (W)

$k$ is the thermal conductivity of copper $\left(\mathrm{W} / \mathrm{m} \cdot{ }^{\circ} \mathrm{C}\right)$

$A$ is the copper pipe's cross-sectional area $\left(\mathrm{m}^{2}\right)$

$\triangle x$ is the distance between $C u 1$ and $C u 2$, and $C u 5$ and $C u \quad 6(\mathrm{~m})$

$\mathrm{Cu} 1, \mathrm{Cu} 2, \mathrm{Cu} 5$ and $\mathrm{Cu} 6$ are the temperatures of the copper near the ends of the $\mathrm{HCE}\left({ }^{\circ} \mathrm{C}\right)$, as shown in Figure 6.

$\mathrm{L}_{\mathrm{HCE}}$ is the length of the HCE at the time of the test (m) 
Finally, the absorber temperature above ambient is

$$
\Delta T_{A b s-a i r}=A b s_{a v e}-A i r
$$

The conduction terms at the end of I-3 are included to account for heat conduction into and out of the HCE due to a non-adiabatic boundary along the copper. Figure I-2 shows that these terms will be small $(\mathrm{Cu} 1 \approx \mathrm{Cu} 2$ and $\mathrm{Cu} 5 \approx \mathrm{Cu} 6)$. Note that the temperatures and heater powers presented in equations I-1 through I-4 are averages of values taken every 5 seconds for a total of 15 minutes.

Inserting values into equations I-1 through I-4 for this test:

$$
\begin{gathered}
A b s_{\text {ave }}=\frac{408.9+402.6+402.2+400.1+403.3+402.7}{6}=403.3^{\circ} \mathrm{C} \\
G l_{\text {ave }}=\frac{70.5+65.5+67.3}{3}=67.8^{\circ} \mathrm{C} \\
H L_{w / m}=\frac{14.3+456.7+458.8+10.2+\frac{372 \cdot\left(3.69 \cdot 10^{-4}\right)}{0.04}(444.1-444.0)+\frac{372 \cdot\left(3.69 \cdot 10^{-4}\right)}{0.04}(439.0-439.0)}{4.08} \\
H L_{w / m}=231 \mathrm{~W} / \mathrm{m} \\
\Delta T_{A b s-a i r}=403.3-23.1=380.2^{\circ} \mathrm{C}
\end{gathered}
$$

These values are presented in the table at the beginning of this section. 


\section{Appendix II - Uncertainty analysis}

Measurement uncertainty is quantified using the root sum-of-the-squares method described by Dieck [25]. The expression for $\mathrm{n}$ error sources is

where

$$
U_{f}^{2}=\sum_{i=1}^{n}\left(\frac{\partial f}{\partial x_{i}}\right)^{2} \Delta x_{i}^{2}
$$

$U_{f} \quad$ is the uncertainty in some function, $f$, due to either bias or precision errors

$\frac{\partial f}{\partial x_{i}}$ is the partial derivative of function $f$ with respect to variable $\mathrm{x}_{\mathrm{i}}$

$\Delta x_{i} \quad$ is the bias or precision error of variable $\mathrm{x}_{\mathrm{i}}$

The uncertainty associated with the average absorber temperature, equation I-1, is evaluated using II-1 as follows:

$$
\begin{gathered}
\left(U_{A b s_{\text {ave }}}\right)^{2}=\left(\frac{\partial A b s_{\text {ave }}}{\partial A b s 2}\right)^{2}(\Delta A b s 2)^{2}+\left(\frac{\partial A b s_{\text {ave }}}{\partial A b s 3}\right)^{2}(\Delta A b s 3)^{2}+\left(\frac{\partial A b s_{\text {ave }}}{\partial A b s}\right)^{2}(\Delta A b s 4)^{2}+\left(\frac{\partial A b s_{\text {ave }}}{\partial A b s 5}\right)^{2}(\Delta A b s 5)^{2}+\left(\frac{\partial A b s_{\text {ave }}}{\partial A b s 6}\right)^{2}(\Delta A b s 6)^{2}+\left(\frac{\partial A b s_{\text {ave }}}{\partial A b s}\right)^{2}(\Delta A b s 7)^{2} \\
\frac{\partial A b s_{\text {ave }}}{\partial A b s 2}=\frac{\partial A b s_{\text {ave }}}{\partial A b s 3}=\frac{\partial A b s_{\text {ave }}}{\partial A b s 4}=\frac{\partial A b s_{\text {ave }}}{\partial A b s 5}=\frac{\partial A b s_{\text {ave }}}{\partial A b s 6}=\frac{\partial A b s_{\text {ave }}}{\partial A b s 7}=\frac{1}{6} \text { and } \Delta A b s 2 \approx \Delta A b s 3 \approx \Delta A b s 4 \approx \Delta A b s 5 \approx \Delta A b s 6 \approx \Delta A b s 7 \equiv \Delta A b s
\end{gathered}
$$

so

$$
\left(U_{A b s_{a v e}}\right)^{2}=6 \cdot\left(\left(\frac{1}{6}\right)^{2} \Delta A b s^{2}\right)
$$

The uncertainty in the average glass temperature in I-2 is found similarly

$$
\left(U_{G l_{\text {ave }}}\right)^{2}=3 \cdot\left(\left(\frac{1}{3}\right)^{2} \Delta G l^{2}\right)
$$


The uncertainty in the heat loss equation, I-3, is found by

$$
\begin{aligned}
\left(U_{H L}\right)^{2} & =\left(\frac{\partial H L}{\partial C o i l 1}\right)^{2} \Delta \operatorname{Coil}^{2}+\left(\frac{\partial H L}{\partial \operatorname{Cart} 1}\right)^{2} \Delta \operatorname{Cart} 1^{2}+\left(\frac{\partial H L}{\partial \operatorname{Cart} 2}\right)^{2} \Delta \operatorname{Cart} 2^{2}+\left(\frac{\partial H L}{\partial \operatorname{Coil} 2}\right)^{2} \Delta C o i l 2^{2}+\left(\frac{\partial H L}{\partial C u 1}\right)^{2} \Delta C u 1^{2}+\left(\frac{\partial H L}{\partial C u 2}\right)^{2} \Delta C u 2^{2} \ldots \\
\ldots & +\left(\frac{\partial H L}{\partial C u 5}\right)^{2} \Delta C u 5^{2}+\left(\frac{\partial H L}{\partial C u 6}\right)^{2} \Delta C u 6^{2}+\left(\frac{\partial H L}{\partial L_{H C E}}\right)^{2} \Delta L_{H C E}^{2}
\end{aligned}
$$

where no uncertainty has been assumed for the copper thermal conductivity, the copper pipe's cross-sectional area, and the distance between the thermocouples on the ends of the copper pipe. The partial derivatives are

$\frac{\partial H L}{\partial \text { Coil } 1}=\frac{\partial H L}{\partial \operatorname{Cart} 1}=\frac{\partial H L}{\partial \operatorname{Cart} 2}=\frac{\partial H L}{\partial \operatorname{Coil} 2}=\frac{1}{L_{H C E}}, \frac{\partial H L}{\partial C u 1}=\frac{\partial H L}{\partial C u 6}=\frac{k \cdot A}{\Delta x \cdot L_{H C E}}, \frac{\partial H L}{\partial C u 2}=\frac{\partial H L}{\partial C u 5}=-\frac{k \cdot A}{\Delta x \cdot L_{H C E}}$, and $\frac{\partial H L}{\partial L_{H C E}}=-\frac{X X}{L_{H C E}^{2}}$

where $X X=$ Coil $1+$ Cart $1+$ Cart $2+$ Coil $2+\frac{k \cdot A}{\Delta x}(C u 1-C u 2)+\frac{k \cdot A}{\Delta x}(C u 6-C u 5)$

Approximating $\quad \Delta$ Coil $1 \approx \Delta$ Coil $2 \equiv \Delta$ Coil,$\Delta$ Cart $1 \approx \Delta$ Cart $2 \equiv \Delta$ Cart, and $\Delta C u 1 \approx \Delta C u 2 \approx \Delta C u 5 \approx \Delta C u 6 \equiv \Delta C u$ the uncertainty equation simplifies to

$$
\left(U_{H L}\right)^{2}=2 \cdot\left(\left(\frac{1}{L_{H C E}}\right)^{2} \Delta \text { Coil }^{2}\right)+2 \cdot\left(\left(\frac{1}{L_{H C E}}\right)^{2} \Delta \operatorname{Cart}^{2}\right)+4 \cdot\left(\left(\frac{k \cdot A}{\Delta x \cdot L_{H C E}}\right)^{2} \Delta C u^{2}\right)+\left(\frac{X X}{L_{H C E}^{2}}\right)^{2} \Delta L_{H C E}^{2}
$$

Finally, the uncertainty associated with the absorber's temperature above ambient (I-4) is found using

$$
\left(U_{\Delta T}\right)^{2}=\left(\frac{\partial \Delta T}{\partial A b s_{\text {ave }}}\right)^{2}\left(\Delta A b s_{\text {ave }}\right)^{2}+\left(\frac{\partial \Delta T}{\partial A i r}\right)^{2}(\Delta A i r)^{2}=\left(\Delta A b s_{\text {ave }}\right)^{2}+(\Delta A i r)^{2}
$$

while being careful not to confuse $\Delta A b s_{\text {ave }}$ (the result of applying precision and bias errors in II-2) with $\Delta A b s$. 
Equations II-2, II-3, II-4, and II-5 are evaluated for both precision and bias errors so that the total uncertainty associated with the measured and calculated values is

$$
\left.U_{\text {total }}= \pm \sqrt{U_{\text {bias }}^{2}+\left(2 \cdot U_{\text {precision }}\right.}\right)^{2}
$$

Calculations of the uncertainties in the average absorber temperature and heat loss for Tests 1, 5, and 9 of 2008 PTR70 \#2 are detailed in Tables II-1 and II-2, respectively. These tables show that uncertainties associated with temperature and heat loss measurement increase as testing temperatures increase. Calculation of average glass temperature, average absorber temperature above ambient, and air temperature proceed similarly.

Table II-1. Calculation of average absorber temperature uncertainty

\begin{tabular}{|c|c|c|c|c|c|c|c|c|}
\hline & $\begin{array}{c}\text { Average } \\
\text { absorber } \\
\text { temperature } \\
\left({ }^{\circ} \mathrm{C}\right)\end{array}$ & $\begin{array}{c}\text { Number of } \\
\text { data points } \\
\text { during test, } n\end{array}$ & $\begin{array}{c}\text { Thermocouple } \\
\text { bias, } \Delta \mathrm{Abs}_{\text {Bias }} \\
\left({ }^{\circ} \mathrm{C}\right)\end{array}$ & $\begin{array}{c}\text { Std. dev. during } \\
\text { testing, } \sigma\left({ }^{\circ} \mathrm{C}\right)\end{array}$ & $\begin{array}{c}\text { Precision } \\
\text { uncertainty, } \\
\sigma / \sqrt{n} \\
\Delta \mathrm{Abs} \text { Prec. }\left({ }^{\circ} \mathrm{C}\right)\end{array}$ & $\begin{array}{c}\left(\mathrm{U}_{\text {Bias }}\right)^{2} \\
\left({ }^{\circ} \mathrm{C}^{2}\right)\end{array}$ & $\begin{array}{c}\left(\mathrm{U}_{\text {Prec. }}\right)^{2} \\
\left({ }^{\circ} \mathrm{C}^{2}\right)\end{array}$ & $\begin{array}{c}\mathbf{U}_{\text {Total }} \\
\left(\mathbf{\pm}^{\circ} \mathrm{C}\right)\end{array}$ \\
\hline 1 & 120 & 192 & 1.1 & 0.2 & 0.01 & 0.20 & $2.8 \mathrm{E}-05$ & $\mathbf{0 . 4}$ \\
\hline 5 & 343 & 192 & 1.4 & 0.2 & 0.01 & 0.31 & $2.0 \mathrm{E}-05$ & $\mathbf{0 . 6}$ \\
\hline 9 & 501 & 192 & 2.0 & 0.1 & 0.01 & 0.67 & $1.1 \mathrm{E}-05$ & $\mathbf{0 . 8}$ \\
\hline
\end{tabular}

Table II-2. Calculation of heat loss uncertainty

\begin{tabular}{|c|c|c|c|c|c|c|c|c|c|c|c|c|c|c|}
\hline \multirow[b]{2}{*}{ Test } & \multirow{2}{*}{$\begin{array}{c}\text { Ave. absorber } \\
\text { temp. }\left({ }^{\circ} \mathrm{C}\right)\end{array}$} & \multicolumn{2}{|c|}{$\Delta$ Coil } & \multicolumn{2}{|c|}{$\Delta$ Cart } & \multicolumn{2}{|c|}{$\Delta \mathrm{Cu}$} & \multirow{2}{*}{$\begin{array}{c}\Delta \mathrm{L} \\
\operatorname{Bias}(\mathrm{m})\end{array}$} & \multirow{2}{*}{$\mathrm{XX}(\mathrm{W})$} & \multirow{2}{*}{$\begin{array}{c}\text { L HCE } \\
(\mathrm{m})\end{array}$} & \multirow{2}{*}{$\begin{array}{l}(\mathrm{kA}) /(\mathrm{L} \Delta \mathrm{x}) \\
\left(\mathrm{W} / \mathrm{m} \cdot{ }^{\circ} \mathrm{C}\right)\end{array}$} & \multirow{2}{*}{$\begin{array}{c}\left(\mathrm{U}_{\text {Bias }}\right)^{2} \\
\left(\mathrm{~W}^{2} / \mathrm{m}^{2}\right)\end{array}$} & \multirow{2}{*}{$\begin{array}{c}\left(\mathrm{U}_{\text {Prec. }}\right)^{2} \\
\left(\mathrm{~W}^{2} / \mathrm{m}^{2}\right)\end{array}$} & \multirow{2}{*}{$\begin{array}{c}\mathrm{U}_{\text {Total }} \\
( \pm \mathrm{W} / \mathrm{m})\end{array}$} \\
\hline & & Bias (W) & Prec. (W) & Bias (W) & Prec. (W) & Bias $\left({ }^{\circ} \mathrm{C}\right)$ & Prec. $\left({ }^{\circ} \mathrm{C}\right)$ & & & & & & & \\
\hline 1 & 120 & 2.5 & 0.01 & 25 & 0.9 & 1.1 & 0.003 & 0.005 & 61 & 4.07 & 0.90 & 80 & 0.10 & 9.0 \\
\hline 5 & 343 & 2.5 & 0.06 & 25 & 0.5 & 1.5 & 0.008 & 0.005 & 571 & 4.08 & 0.86 & 83 & 0.04 & 9.1 \\
\hline 9 & 501 & 2.5 & 0.06 & 25 & 0.8 & 2.2 & 0.006 & 0.005 & 1964 & 4.09 & 0.83 & 89 & 0.08 & 9.5 \\
\hline
\end{tabular}

The maximum uncertainties associated with average absorber, glass, air, and absorber above ambient temperatures are $0.8^{\circ} \mathrm{C}$, $0.6^{\circ} \mathrm{C}, 1.1^{\circ} \mathrm{C}$, and $1.4^{\circ} \mathrm{C}$, respectively. The maximum heat loss uncertainty is $9.5 \mathrm{~W} / \mathrm{m}$. To be conservative, this report assumes an average absorber temperature uncertainty of $\pm 1{ }^{\circ} \mathrm{C}$ and a heat loss uncertainty of $\pm 10 \mathrm{~W} / \mathrm{m}$.

Engineering Equation Solver (EES) [26] evaluates uncertainty propagation numerically. As a function of interest becomes more complicated, EES is faster than evaluating all the partial derivates by hand. EES duplicated the uncertainty results presented above, and calculated other uncertainties presented in this report. 


\section{Appendix III - 1D HCE heat loss model and sensitivity study}

Dudley et al [5] and more recently Forristall $[13,14]$ present parabolic trough collector and HCE models validated by experimental data. Both are one-dimensional, steady-state, neglect the nonuniform nature of the flux incident on the absorber tube, and rely on user-entered optical characteristics (e.g. optical efficiency, incidence-angle modifier) instead of ray-tracing to determine the radiation incident on the HCE absorber. Both models calculate HCE heat loss as well as the overall thermal efficiency of the collector (which includes the HCE).

This model is presented for two reasons:

1) To explore the sensitivity of the HCE heat loss results to laboratory testing conditions

2) To explore the sensitivity of the HCE heat loss and collector thermal efficiency to variations in solar field conditions.

Figure III-1 presents Forristall's 1D HCE model simplified for heat loss in evacuated HCEs. This model includes a collector with a specified aperture. Both collector and HCE are assumed to be 1 meter long perpendicular to the page.

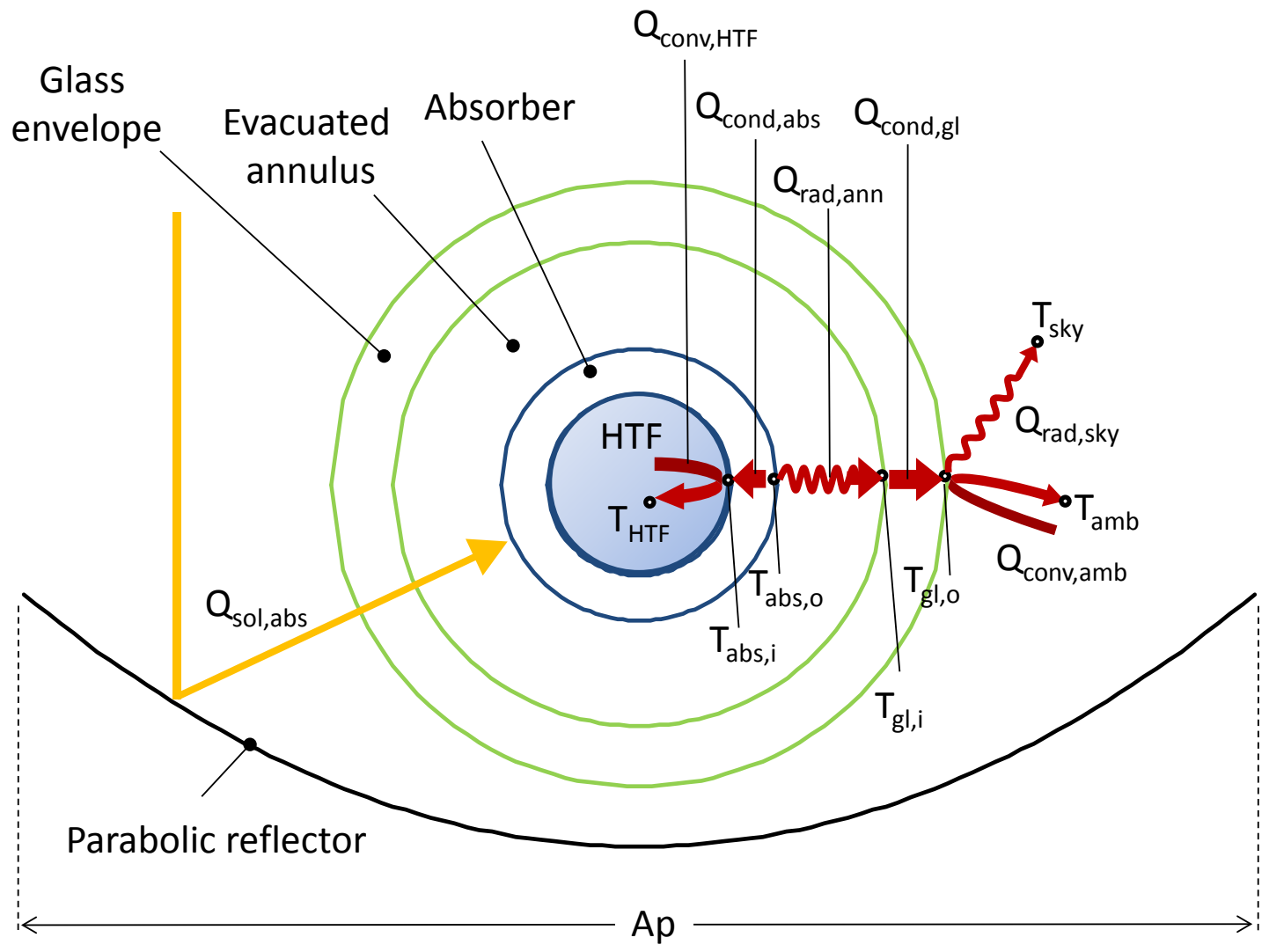

Figure III-1. 1D HCE heat loss model $[13,14]$. Not to scale. 
Quantities in Figure III-1 are described below. The sources for the equations are Forristall [13, 14] and Incropera and Dewitt [11].

$A p$ - The parabolic reflector aperture. An LS3 collector's aperture is $5.75 \mathrm{~m}$.

$T_{a b s, i}, T_{a b s, o}-$ The inner and outer average absorber surface temperatures, ${ }^{\circ} \mathrm{C}$.

$T_{g l, i}, T_{g l, o}-$ The inner and outer average glass surface temperatures, ${ }^{\circ} \mathrm{C}$.

$T_{H T F}-$ The heat transfer fluid (HTF) temperature, ${ }^{\circ} \mathrm{C}$. Therminol VP1 is the HTF assumed in this section. VP1 thermophysical properties are described in [13].

$T_{a m b}-$ Ambient temperature, ${ }^{\circ} \mathrm{C}$.

$T_{s k y}-$ The sky temperature for radiation heat transfer, ${ }^{\circ} \mathrm{C}$.

$r_{a b s, i}, r_{a b s, o}, r_{g l, i}, r_{g l, o}-$ PTR70 radii: the inner absorber surface $(0.033 \mathrm{~m})$, outer absorber surface $(0.035 \mathrm{~m})$, inner glass envelope surface $(0.057 \mathrm{~m})$, and outer glass envelope surface $(0.06 \mathrm{~m})$.

$Q_{\text {sol,abs }}$ - The concentrated solar radiation absorbed by the absorber tube $(\mathrm{W} / \mathrm{m})$.

$$
Q_{\text {sol }, a b s}=I_{b} \cdot \cos \theta \cdot A p \cdot \eta_{o p t} \cdot I A M
$$

where

$I_{b}$ is the direct normal radiation, $\mathrm{W} / \mathrm{m}^{2}$.

$\theta$ is the incidence angle, degrees.

$\eta_{\text {opt }}$ is the optical efficiency at normal incidence. This term includes the reflector reflectance, glass envelope transmittance, absorber absorptance, and effects of dirt, geometry, and shading. Forristall's more detailed model [13, 14] allows independent specification of these parameters.

$I A M$ is the incidence angle modifier. The IAM is a function of incidence angle and the optical quality of the collector. It's assumed that the IAM is that determined by Dudley et al. [5]:

$$
I A M=\min \left(1, \frac{\cos \theta+0.000884 \cdot \theta-0.0000537 \cdot \theta^{2}}{\cos \theta}\right)
$$

Dudley et al. chose to include the foreshortened collector aperture in their incidence angle modifier, as shown by the inclusion of $\cos \theta$ in the numerator of the above expression. This work includes the cosine effect in the $Q_{\text {sol,abs }}$ calculation, so Dudley's IAM is divided by $\cos \theta$ here. 
$Q_{c o n v, H T F}$ - The heat transferred to the HTF from the inner absorber surface through convection $(\mathrm{W} / \mathrm{m})$.

$$
Q_{c o n v, H T F}=h_{a b s, H T F} \cdot 2 \pi \cdot r_{a b s, i} \cdot\left(T_{a b s, i}-T_{H T F}\right)
$$

where

$h_{a b s, H T F}$ is the convective heat transfer coefficient. It depends on the thermophysical properties of the HTF, the diameter of the tube, the flow rate, and the temperatures of the HTF and inner absorber surface. Forristall $[13,14]$ fully describes its calculation. For typical conditions in the loop of an operating plant (Therminol VP1, $6.6 \mathrm{~cm}$ inner diameter absorber, average HTF temperature of $340^{\circ} \mathrm{C}$ ), the convective coefficient can be calculated from the mass flow rate from $4 \mathrm{~kg} / \mathrm{s}$ to $12 \mathrm{~kg} / \mathrm{s}$ as

$$
h_{a b s, H T F}=522+478 \cdot \dot{m}
$$

The units of $h_{a b s, H T F}$ are $\mathrm{W} /\left(\mathrm{m}^{2} \cdot{ }^{\circ} \mathrm{C}\right) . \quad \dot{m}$ is the VP1 mass flow rate (roughly $8 \mathrm{~kg} / \mathrm{s}$ in an LS3 loop).

When sufficient solar radiation exists, $Q_{c o n v, H T F}$ is positive (heat is transferred to the HTF). When the collector is off-sun, $Q_{c o n v, H T F}$ is negative.

$Q_{\text {cond,abs }}$ - The heat transferred through the absorber from the outer absorber surface to the inner absorber surface by conduction $(\mathrm{W} / \mathrm{m})$.

$$
Q_{c o n d, a b s}=\frac{2 \pi \cdot k_{a b s} \cdot\left(T_{a b s, o}-T_{a b s, i}\right)}{\ln \left(\frac{r_{a b s, o}}{r_{a b s, i}}\right)}
$$

where

$k_{a b s}$ is the thermal conductivity of the stainless steel absorber. Forristall [13] uses

$$
k_{a b s}=14.8+0.0153 \cdot T_{a b s}
$$

$T_{a b s}$ is the average of $T_{a b s, i}$ and $T_{a b s, o u t}$, and is in ${ }^{\circ} \mathrm{C}$. The units of $\mathrm{k}_{\mathrm{abs}}$ are $\mathrm{W} /\left(\mathrm{m} \cdot{ }^{\circ} \mathrm{C}\right)$.

Similar to $Q_{c o n v, H T F}, Q_{c o n d, a b s}$ is positive when there is net heat transfer to the HTF.

$Q_{\text {rad,ann }}$ - The heat transferred across the evacuated annulus from the outer absorber surface to the inner glass surface through radiation $(\mathrm{W} / \mathrm{m})$.

$$
Q_{\text {rad }, a n n}=\frac{\sigma \cdot 2 \pi \cdot r_{a b s, o} \cdot\left(T_{a b s, o, \text { Kelvin }}^{4}-T_{g l, i, \text { Kelvin }}^{4}\right)}{\frac{1}{\varepsilon_{a b s}}+\frac{1-\varepsilon_{g l}}{\varepsilon_{g l}}\left(\frac{r_{a b s, o}}{r_{g l, i}}\right)}
$$


where

$T_{a b s, o, \text { Kelvin }}$ is the outer absorber surface temperature in Kelvin

$T_{g l, i, K e l v i n}$ is the inner glass surface temperature in Kelvin.

$\varepsilon_{\text {abs }}$ is the emittance of the outer absorber surface. This value is determined by the heat

loss testing of this report. The emittance of the 2008 PTR70 is

$$
\varepsilon_{a b s}=0.062+(2.00 E-7) \cdot T_{a b s}^{2}
$$

where $T_{a b s}$ is in ${ }^{\circ} \mathrm{C}$.

$\varepsilon_{\mathrm{gl}}$ is the emittance of the borosilicate glass surface, 0.89 [15].

$\sigma$ is the Stefan-Boltzmann constant, $5.670 \mathrm{e}-8 \mathrm{~W} /\left(\mathrm{m}^{2} \cdot \mathrm{K}^{4}\right)$.

$Q_{c o n d, g l}$ - The heat transferred through the glass envelope from the inner glass surface to the outer glass surface by conduction $(\mathrm{W} / \mathrm{m})$.

$$
Q_{\text {cond }, g l}=\frac{2 \pi \cdot k_{g l} \cdot\left(T_{g l, i}-T_{g l, o}\right)}{\ln \left(\frac{r_{g l, o}}{r_{g l, i}}\right)}
$$

where

$k_{g l}$ is the thermal conductivity of the glass, $1.1 \mathrm{~W} /\left(\mathrm{m} \cdot{ }^{\circ} \mathrm{C}\right)[12]$.

$Q_{\text {rad,sky }}$ - The heat transferred from the glass envelope to the sky through radiation $(\mathrm{W} / \mathrm{m})$. Forristall [13] shows that the effects of the view factor to the reflector and temperature of the reflector in the calculation of this value are minor.

$$
Q_{\text {rad }, \text { sky }}=\sigma \cdot \varepsilon_{g l} \cdot 2 \pi \cdot r_{g l, o} \cdot\left(T_{g l, o, \text { Kelvin }}^{4}-T_{\text {sky, Kelvin }}^{4}\right)
$$

where

$T_{g l, o, \text { Kelvin }}$ is the outer glass envelope surface temperature in Kelvin

$T_{\text {sky,Kelvin }}$ is the sky temperature in Kelvin. Forristall [13] finds the sky temperature $\left({ }^{\circ} \mathrm{C}\right)$ from ambient temperature $\left({ }^{\circ} \mathrm{C}\right)$ using

$$
T_{s k y}=T_{a m b}-8
$$

$Q_{\text {conv,amb }}$ - The heat transferred to ambient from the outer glass surface through convection $(\mathrm{W} / \mathrm{m})$.

$$
Q_{\text {conv }, a m b}=h_{a m b} \cdot 2 \pi \cdot r_{g l, o} \cdot\left(T_{g l, o}-T_{a m b}\right)
$$

where

$h_{a m b}$ is the convective heat transfer coefficient to ambient. It is strongly a function of wind speed. Forristall $[13,14]$ presents the detailed calculation, but for the PTR70 geometry and expected ambient temperatures the convection coefficient can be estimated from 


$$
h_{a m b}=4.9+4.9 \cdot v_{w}-0.18 \cdot v_{w}^{2}
$$

$v_{w}$ is the wind speed in $\mathrm{m} / \mathrm{s}$. The units of $h_{a m b}$ are $\mathrm{W} /\left(\mathrm{m}^{2} \cdot{ }^{\circ} \mathrm{C}\right)$.

An additional thermal input not shown in Figure III-1 is the absorption of a small amount of insolation by the glass envelope. This increases the glass envelope temperature. Forristall [13] describes this calculation in detail, but his method is simplified here:

where

$$
Q_{\text {SolarAbsbyGlass }}=I_{b} \cdot \cos \theta \cdot A p \cdot \frac{\eta_{o p t}}{\tau_{g l} \cdot \alpha_{a b s}} \cdot I A M \cdot \alpha_{\text {glass }}
$$

$\tau_{g l}$ is the glass envelope transmittance, 0.96 [24]

$\alpha_{a b s}$ is the absorber absorptance, 0.96 [16]

$\alpha_{\text {glass }}$ is the glass's absorptance (Forristall [13] uses 0.02).

At steady-state the following quantities are equal:

$$
\begin{aligned}
& Q_{\text {conv, } H T F}=Q_{\text {cond, } a b s} \\
& Q_{\text {sol, }, a b s}=Q_{\text {cond }, a b s}+Q_{\text {rad, }, a n n} \\
& Q_{\text {rad,ann }}=Q_{\text {cond,gl }} \\
& Q_{\text {cond, }, \mathrm{l}}+Q_{\text {SolarAbsbyGlass }}=Q_{\text {rad,sky }}+Q_{\text {conv, amb }}
\end{aligned}
$$

The heat loss from the HCE absorber is $Q_{\text {rad,ann }}$. Testing this value is the subject of this report. If the HCE wasn't evacuated and there were a gas in the annulus, then the heat loss would include the heat radiated across the annulus $\left(Q_{\text {rad,ann }}\right)$ as well as that conducted/convected across the annulus by the gas.

The net heat gain of the fluid over the 1 meter section is $Q_{c o n v, H T F}$, and the temperature rise of the fluid is calculated using

$$
\begin{gathered}
T_{H T F}=\frac{T_{H T F, \text { in }}+T_{H T F, \text { out }}}{2} \\
T_{H T F, \text { out }}=T_{H T F, \text { in }}+\frac{Q_{\text {conv }, H T F} \cdot L}{\dot{m} \cdot c_{H T F}}
\end{gathered}
$$

where

$\mathrm{L}=$ length of HCE simulated: 1 meter

$T_{H T F}$ is the average HTF temperature in the 1 meter section

$T_{H T F, \text { in }}$ is the HTF temperature entering the 1 meter section

$T_{H T F, \text { out }}$ is the HTF temperature leaving the 1 meter section

$\dot{m}$ is the HTF mass flow rate

$c_{\text {HTF }}$ is the heat capacity of the HTF. The heat capacity is a function of the HTF

temperature and for VP1 can be calculated from [13] 


$$
c_{H T F}=1494+2.76 \cdot T_{H T F}
$$

The units of $c_{H T F}$ are $\mathrm{J} /\left(\mathrm{kg} \cdot{ }^{\circ} \mathrm{C}\right)$.

Finally, the thermal efficiency of the collector and HCE is calculated with

$$
\eta_{\text {th }}=\frac{Q_{\text {conv }, H T F}}{q_{i, 0 \text { inc }}}
$$

where

$\eta_{\text {th }}$ is the thermal efficiency of the collector and HCE

$q_{i, \text { inc }}$ is the insolation on the trough aperture at zero incidence angle, $(\mathrm{W} / \mathrm{m})$.

$$
q_{i, \text { inc }}=I_{b} \cdot A p
$$

Note that the denominator of the efficiency equation does not contain $\cos \theta$, which would correct for the decreased insolation on the aperture at non-zero incidence.

The equations above comprise the 1D HCE heat loss model. This model is used to investigate the sensitivity of heat loss results to laboratory test conditions and operating conditions in a solar field for the duration of this section.

Table III-1 shows the sensitivity of HCE heat loss results to laboratory conditions. There are fewer model inputs for laboratory testing than solar field operation. The solar radiation, collector aperture, and mass flow rates are unused. $\mathrm{T}_{\mathrm{HTF}}$ is the temperature of the inner absorber surface, and the radiant sky temperature is identical to ambient air temperature. The sensitivity study focuses on an absorber temperature of $340^{\circ} \mathrm{C}$. Case 1 models the laboratory environment that the heat loss tests occur in: $23^{\circ} \mathrm{C}$ with no wind. Cases 2 through 4 show that reasonable variations in temperature and wind speed affect the heat loss from the HCE, $Q_{\text {rad,ann }}$, by $\pm 3 \mathrm{~W} / \mathrm{m}$ or less. The glass temperature changes signficantly, however. A $1 \mathrm{~m} / \mathrm{s}$ wind speed decreases the glass temperature by about $10^{\circ} \mathrm{C}$, although heat loss changes by only $2 \mathrm{~W} / \mathrm{m}$. Wind speed is not measured in the laboratory, and the convective coefficient from the glass surface is not determined during testing. Therefore even though the glass temperature is measured, there is uncertainty associated with its temperature. This increases the uncertainty associated with the calculated absorber emittance, as described in the Calculating Absorber Emittance section. The baseline absorber emittance in Tables III-1 and III-2 are from the 2008 PTR70 curve fit determined in the Calculating Absorber Emittance section.

Case 5 shows that the heat loss from the HCE depends strongly on the absorber emittance, while Case 6 shows that the glass emittance is less important and some uncertainty with its value can be tolerated. Case 1 and Case 7 have the same absorber and glass temperatures, but different absorber emittances. Even though these cases have the same temperatures, the larger heat loss associated with Case 7 indicates the larger emittance of its absorber surface. 
Table III-1. Modeled sensitivity of HCE heat loss results to laboratory conditions

\begin{tabular}{|c|c|c|c|c|c|c|c|c|}
\hline & Sensitivity case: & $\begin{array}{l}\text { Case } 1 \text { - } \\
\text { Baseline } \\
\text { simulation }\end{array}$ & $\begin{array}{c}\text { Case } 2 \text { - } \\
\text { Decreased } \\
\mathrm{T}_{\mathrm{amb}} \text { and } \\
\mathrm{T}_{\text {sky }}\end{array}$ & $\begin{array}{l}\text { Case } 3 \text { - } \\
\text { Wind } \\
\text { speed } 1 \\
\text { m/s }\end{array}$ & $\begin{array}{c}\text { Case } 4 \text { - } \\
\text { Wind } \\
\text { speed } 2.5 \\
\text { m/s }\end{array}$ & $\begin{array}{c}\text { Case } 5 \text { - } \\
20 \% \\
\text { increased } \\
\varepsilon_{\text {abs }}\end{array}$ & $\begin{array}{c}\text { Case } 6-5 \% \\
\text { increased } \\
\varepsilon_{\mathrm{gl}}\end{array}$ & $\begin{array}{c}\text { Case } 7 \text { - Same } \\
\text { temperatures, } \\
\text { different } \varepsilon_{\text {abs }}\end{array}$ \\
\hline \multirow{11}{*}{ 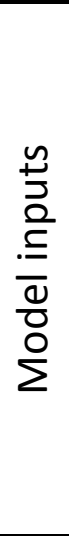 } & $\mathrm{I}_{\mathrm{b}}\left(\mathrm{W} / \mathrm{m}^{2}\right)$ & 0 & 0 & 0 & 0 & 0 & 0 & 0 \\
\hline & $\theta$ (deg) & 0 & 0 & 0 & 0 & 0 & 0 & 0 \\
\hline & $\mathrm{Ap}(\mathrm{m})$ & 0 & 0 & 0 & 0 & 0 & 0 & 0 \\
\hline & $\eta_{\text {opt }}$ & 0 & 0 & 0 & 0 & 0 & 0 & 0 \\
\hline & $\dot{\mathrm{m}}(\mathrm{kg} / \mathrm{s})$ & 0 & 0 & 0 & 0 & 0 & 0 & 0 \\
\hline & $\mathrm{T}_{\mathrm{HTF}}\left({ }^{\circ} \mathrm{C}\right)$ & $340^{*}$ & $340 *$ & $340 *$ & $340^{*}$ & $340 *$ & $340 *$ & $340 *$ \\
\hline & $\mathrm{T}_{\mathrm{amb}}\left({ }^{\circ} \mathrm{C}\right)$ & 23 & 10 & 23 & 23 & 23 & 23 & 23 \\
\hline & $\mathrm{T}_{\text {sky }}\left({ }^{\circ} \mathrm{C}\right)$ & 23 & 10 & 23 & 23 & 23 & 23 & 23 \\
\hline & $\mathrm{v}_{\mathrm{w}}(\mathrm{m} / \mathrm{s})$ & 0 & 0 & 1 & 2.5 & 0 & 0 & 0.4 \\
\hline & $\varepsilon_{\mathrm{abs}}$ & 0.085 & 0.085 & 0.085 & 0.085 & 0.102 & 0.085 & 0.102 \\
\hline & $\varepsilon_{\mathrm{gl}}$ & 0.89 & 0.89 & 0.89 & 0.89 & 0.89 & 0.94 & 0.89 \\
\hline \multirow{15}{*}{ 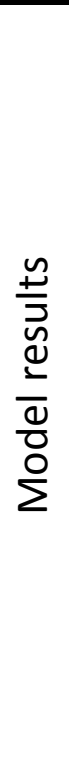 } & $\mathrm{q}_{\mathrm{i}, \text { Oinc }}(\mathrm{W} / \mathrm{m})$ & 0 & 0 & 0 & 0 & 0 & 0 & 0 \\
\hline & $\mathrm{Q}_{\text {sol,abs }}(\mathrm{W} / \mathrm{m})$ & 0 & 0 & 0 & 0 & 0 & 0 & 0 \\
\hline & $\mathrm{Q}_{\text {conv,HTF }}(\mathrm{W} / \mathrm{m})$ & 0 & 0 & 0 & 0 & 0 & 0 & 0 \\
\hline & $\mathrm{Q}_{\text {cond,abs }}(\mathrm{W} / \mathrm{m})$ & -136 & -138 & -138 & -139 & -164 & -137 & -163 \\
\hline & $\mathrm{Q}_{\mathrm{rad}, \mathrm{ann}}(\mathrm{W} / \mathrm{m})$ & 136 & 138 & 138 & 139 & 164 & 137 & 163 \\
\hline & $\mathrm{Q}_{\text {cond,gl }}(\mathrm{W} / \mathrm{m})$ & 136 & 138 & 138 & 139 & 164 & 137 & 163 \\
\hline & $\mathrm{Q}_{\text {SolAbsbyGI }}(\mathrm{W} / \mathrm{m})$ & 0 & 0 & 0 & 0 & 0 & 0 & 0 \\
\hline & $\mathrm{Q}_{\text {rad,sky }}(\mathrm{W} / \mathrm{m})$ & 76 & 73 & 52 & 37 & 63 & 78 & 77 \\
\hline & $\mathrm{Q}_{\text {conv,amb }}(\mathrm{W} / \mathrm{m})$ & 60 & 65 & 86 & 102 & 101 & 59 & 86 \\
\hline & $\mathrm{T}_{\mathrm{abs}, \mathrm{i}}\left({ }^{\circ} \mathrm{C}\right)$ & 340 & 340 & 340 & 340 & 340 & 340 & 340 \\
\hline & $\mathrm{T}_{\mathrm{abs}, \mathrm{o}}\left({ }^{\circ} \mathrm{C}\right)$ & 340 & 340 & 340 & 340 & 340 & 340 & 340 \\
\hline & $\mathrm{T}_{\mathrm{gl}, \mathrm{i}}\left({ }^{\circ} \mathrm{C}\right)$ & 57 & 46 & 48 & 41 & 63 & 56 & 57 \\
\hline & $\mathrm{T}_{\mathrm{gl}, \mathrm{o}}\left({ }^{\circ} \mathrm{C}\right)$ & 56 & 45 & 47 & 40 & 61 & 55 & 56 \\
\hline & $\mathrm{T}_{\mathrm{HTF}, \text { out }}-\mathrm{T}_{\mathrm{HTF}, \text { in }}\left({ }^{\circ} \mathrm{C}\right)$ & $\mathrm{N} / \mathrm{A}$ & N/A & N/A & N/A & $\mathrm{N} / \mathrm{A}$ & N/A & N/A \\
\hline & $\eta_{\text {th }}$ & N/A & $\mathrm{N} / \mathrm{A}$ & N/A & N/A & $\mathrm{N} / \mathrm{A}$ & N/A & N/A \\
\hline
\end{tabular}

*HTF isn't used in the laboratory heat loss testing - electric heaters bring the inner absorber surface up to desired test temperatures. Therefore $T_{H T F}$ is the inner absorber surface temperature in the laboratory heat loss tests.

Table III-2 shows the sensitivity of HCE heat loss results to solar field conditions. 17 cases are studied. Case 1 is the baseline simulation - it uses inputs typical of solar field geometry, performance, and environmental conditions for a north-south tracking axis trough located about $35^{\circ}$ from the equator operating between $293^{\circ} \mathrm{C}$ and $391^{\circ} \mathrm{C}$ using VP1. The incidence angle will be $20^{\circ}$ or less for about half the daylight hours of the year, with larger values associated with early spring, late fall, and winter. Except for cases 9, 10, and 11, the mass flow is controlled to maintain a $0.2^{\circ} \mathrm{C}$ temperature rise over the 1 meter length simulated. 
Table III-2. Modeled sensitivity of evacuated annulus (vacuum) HCE heat loss and collector/HCE thermal efficiency to solar field conditions

\begin{tabular}{|c|c|c|c|c|c|c|c|c|c|c|c|c|c|c|c|c|c|c|}
\hline & Sensitivity case: & $\begin{array}{l}\text { Case } 1 \text { - } \\
\text { Baseline } \\
\text { simulation }\end{array}$ & $\begin{array}{c}\text { Case } 2 \text { - } \\
\mathrm{I}_{\mathrm{b}}=800 \\
\mathrm{~W} / \mathrm{m}^{2}\end{array}$ & $\begin{array}{c}\text { Case } 3 \text { - } \\
\mathrm{I}_{\mathrm{b}}=0 \\
\mathrm{~W} / \mathrm{m}^{2}\end{array}$ & $\begin{array}{r}\text { Case } 4 \text { - } \\
\theta=0^{\circ}\end{array}$ & $\begin{array}{l}\text { Case } 5 \text { - } \\
\theta=45^{\circ}\end{array}$ & $\begin{array}{c}\text { Case } 6 \text { - } \\
5 \mathrm{~m} \\
\text { aperture }\end{array}$ & $\begin{array}{c}\text { Case } 7 \text { - } \\
8 \mathrm{~m} \\
\text { aperture }\end{array}$ & $\begin{array}{c}\text { Case } 8 \text { - } \\
80 \% \text { optical } \\
\text { efficiency }\end{array}$ & $\begin{array}{l}\text { Case } 9 \text { - } \\
\text { decreased } \\
\text { mass flow } \\
\text { rate }\end{array}$ & $\begin{array}{c}\text { Case } 10- \\
\text { HTF loop } \\
\text { inlet } \\
\text { temp. }\end{array}$ & $\begin{array}{c}\text { Case } 11- \\
\text { HTF loop } \\
\text { outlet } \\
\text { temp. }\end{array}$ & $\begin{array}{c}\text { Case } 12 \text { - } \\
\text { Decreased } \\
\text { ambient } \\
\text { temps. }\end{array}$ & $\begin{array}{c}\text { Case } 13 \text { - } \\
\text { Increased } \\
\text { wind speed }\end{array}$ & $\begin{array}{l}\text { Case } 14 \text { - } \\
\text { Maximizing } \\
\text { heat } \\
\text { transfer to } \\
\text { ambient }\end{array}$ & $\begin{array}{c}\text { Case } 15 \text { - } \\
20 \% \\
\text { increased } \\
\varepsilon_{\text {abs }}\end{array}$ & $\begin{array}{c}\text { Case } 16- \\
\text { Heat loss } \\
\text { in } \\
{[2,3,4]}\end{array}$ & $\begin{array}{c}\text { Case } 17 \text { - } \\
5 \% \\
\text { increased } \\
\varepsilon_{\mathrm{gl}}\end{array}$ \\
\hline \multirow{11}{*}{ 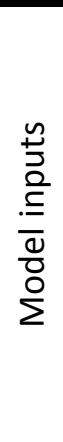 } & $\mathrm{I}_{\mathrm{b}}\left(\mathrm{W} / \mathrm{m}^{2}\right)$ & 950 & 800 & 0 & 950 & 950 & 950 & 950 & 950 & 950 & 950 & 950 & 950 & 950 & 950 & 950 & 950 & 950 \\
\hline & $\theta$ (deg) & 20 & 20 & 20 & 0 & 45 & 20 & 20 & 20 & 20 & 20 & 20 & 20 & 20 & 20 & 20 & 20 & 20 \\
\hline & $A p(m)$ & 5.75 & 5.75 & 5.75 & 5.75 & 5.75 & 5.0 & 8.0 & 5.75 & 5.75 & 5.75 & 5.75 & 5.75 & 5.75 & 5.75 & 5.75 & 5.75 & 5.75 \\
\hline & $\eta_{\text {opt }}$ & 0.75 & 0.75 & 0.75 & 0.75 & 0.75 & 0.75 & 0.75 & 0.80 & 0.75 & 0.75 & 0.75 & 0.75 & 0.75 & 0.75 & 0.75 & 0.75 & 0.75 \\
\hline & $\mathrm{m}(\mathrm{kg} / \mathrm{s})$ & 7.6 & 6.3 & 7.6 & 8.1 & 5.1 & 6.6 & 10.7 & 8.1 & 5.0 & 7.6 & 7.6 & 7.6 & 7.6 & 7.6 & 7.5 & 7.5 & 7.6 \\
\hline & $\mathrm{T}_{\mathrm{HTF}}\left({ }^{\circ} \mathrm{C}\right)$ & 340 & 340 & 340 & 340 & 340 & 340 & 340 & 340 & 340 & 293 & 391 & 340 & 340 & 340 & 340 & 340 & 340 \\
\hline & $\mathrm{T}_{\mathrm{amb}}\left({ }^{\circ} \mathrm{C}\right)$ & 30 & 30 & 30 & 30 & 30 & 30 & 30 & 30 & 30 & 30 & 30 & 10 & 30 & 10 & 30 & 30 & 30 \\
\hline & $\mathrm{T}_{\text {sky }}\left({ }^{\circ} \mathrm{C}\right)$ & 22 & 22 & 22 & 22 & 22 & 22 & 22 & 22 & 22 & 22 & 22 & 2 & 22 & 2 & 22 & 22 & 22 \\
\hline & $\mathrm{v}_{\mathrm{w}}(\mathrm{m} / \mathrm{s})$ & 2.5 & 2.5 & 2.5 & 2.5 & 2.5 & 2.5 & 2.5 & 2.5 & 2.5 & 2.5 & 2.5 & 2.5 & 8 & 8 & 2.5 & 2.5 & 2.5 \\
\hline & $\varepsilon_{\text {abs }}$ & 0.086 & 0.086 & 0.085 & 0.086 & 0.086 & 0.086 & 0.086 & 0.086 & 0.086 & 0.080 & 0.093 & 0.086 & 0.086 & 0.086 & 0.103 & 0.150 & 0.086 \\
\hline & $\varepsilon_{\mathrm{gl}}$ & 0.89 & 0.89 & 0.89 & 0.89 & 0.89 & 0.89 & 0.89 & 0.89 & 0.89 & 0.89 & 0.89 & 0.89 & 0.89 & 0.89 & 0.89 & 0.89 & 0.94 \\
\hline \multirow{15}{*}{ 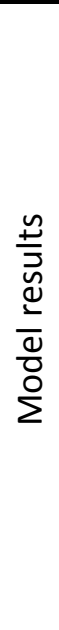 } & $\mathrm{q}_{\mathrm{i}, \text { oinc }}(\mathrm{W} / \mathrm{m})$ & 5463 & 4600 & 0 & 5463 & 5463 & 4750 & 7600 & 5463 & 5463 & 5463 & 5463 & 5463 & 5463 & 5463 & 5463 & 5463 & 5463 \\
\hline & $\mathrm{Q}_{\text {sol,abs }}(\mathrm{W} / \mathrm{m})$ & 3834 & 3229 & 0 & 4097 & 2614 & 3334 & 5335 & 4090 & 3834 & 3834 & 3834 & 3834 & 3834 & 3834 & 3834 & 3834 & 3834 \\
\hline & $\mathrm{Q}_{\text {conv, HTF }}(\mathrm{W} / \mathrm{m})$ & 3690 & 3085 & -138 & 3953 & 2471 & 3190 & 5190 & 3946 & 3688 & 3739 & 3616 & 3688 & 3689 & 3686 & 3657 & 3587 & 3690 \\
\hline & $\mathrm{Q}_{\text {cond,abs }}(\mathrm{W} / \mathrm{m})$ & 3690 & 3085 & -138 & 3953 & 2471 & 3190 & 5190 & 3946 & 3688 & 3739 & 3616 & 3688 & 3689 & 3686 & 3657 & 3587 & 3690 \\
\hline & $Q_{\text {rad,ann }}(W / m)$ & 144 & 144 & 138 & 144 & 143 & 144 & 145 & 144 & 146 & 95 & 218 & 147 & 145 & 148 & 177 & 247 & 144 \\
\hline & $\mathrm{Q}_{\text {cond,gl }}(\mathrm{W} / \mathrm{m})$ & 144 & 144 & 138 & 144 & 143 & 144 & 145 & 144 & 146 & 95 & 218 & 147 & 145 & 148 & 177 & 247 & 144 \\
\hline & $\mathrm{Q}_{\text {SolAbsbyGI }}(\mathrm{W} / \mathrm{m})$ & 82 & 69 & 0 & 88 & 57 & 72 & 114 & 88 & 82 & 82 & 82 & 82 & 82 & 82 & 82 & 82 & 82 \\
\hline & $\mathrm{Q}_{\mathrm{rad}, \mathrm{sky}}(\mathrm{W} / \mathrm{m})$ & 76 & 72 & 50 & 78 & 68 & 73 & 86 & 78 & 76 & 61 & 99 & 67 & 49 & 42 & 46 & 109 & 79 \\
\hline & $\mathrm{Q}_{\text {conv,amb }}(\mathrm{W} / \mathrm{m})$ & 150 & 141 & 88 & 154 & 132 & 143 & 173 & 154 & 152 & 116 & 201 & 162 & 178 & 188 & 213 & 220 & 148 \\
\hline & $\mathrm{T}_{\mathrm{abs}, \mathrm{i}}\left({ }^{\circ} \mathrm{C}\right)$ & 344 & 344 & 340 & 344 & 344 & 344 & 345 & 344 & 346 & 297 & 395 & 344 & 344 & 344 & 344 & 344 & 344 \\
\hline & $\mathrm{T}_{\mathrm{abs}, \mathrm{o}}\left({ }^{\circ} \mathrm{C}\right)$ & 346 & 346 & 340 & 346 & 345 & 346 & 347 & 346 & 348 & 299 & 397 & 346 & 346 & 346 & 346 & 346 & 346 \\
\hline & $\mathrm{T}_{\mathrm{gl,i}, \mathrm{i}}\left({ }^{\circ} \mathrm{C}\right)$ & 56 & 54 & 46 & 57 & 53 & 55 & 60 & 57 & 56 & 50 & 65 & 38 & 46 & 26 & 59 & 68 & 56 \\
\hline & $\mathrm{T}_{\mathrm{gl}, \mathrm{o}}\left({ }^{\circ} \mathrm{C}\right)$ & 55 & 53 & 45 & 56 & 52 & 54 & 59 & 56 & 55 & 49 & 63 & 37 & 45 & 25 & 58 & 66 & 55 \\
\hline & $\mathrm{T}_{\mathrm{HTF}, \text { out }}-\mathrm{T}_{\mathrm{HTF}, \text { in }}\left({ }^{\circ} \mathrm{C}\right)$ & 0.2 & 0.2 & -0.007 & 0.2 & 0.2 & 0.2 & 0.2 & 0.2 & 0.3 & 0.21 & 0.18 & 0.2 & 0.2 & 0.2 & 0.2 & 0.2 & 0.2 \\
\hline & $\eta_{\text {th }}$ & 0.675 & 0.671 & 0 & 0.724 & 0.452 & 0.672 & 0.683 & 0.722 & 0.675 & 0.684 & 0.662 & 0.675 & 0.675 & 0.675 & 0.669 & 0.657 & 0.675 \\
\hline
\end{tabular}


Inspection of the HCE heat loss, $Q_{\text {rad,ann }}$, in Table III-2 shows that it changes little with changes in insolation, incidence angle, aperture, optical efficiency, mass flow rate, ambient temperature, wind speed, and glass emittance. The largest differences from the baseline case occur for no insolation (case 3), changes in HTF temperature (cases 10 and 11), and increases in absorber emittance (cases 15 and 16). A change in the outer absorber temperature is associated with most of these cases. Note that the average outer absorber temperature is only $5-10^{\circ} \mathrm{C}$ above the HTF temperature. This is due to large mass flow rates and consequent large pipe wall convection coefficients.

The heat gained by the HTF is $Q_{c o n v, H T F}$, and the thermal efficiency, $\eta_{t h}$, is defined as $Q_{\text {conv }, H T F} / q_{i, O i n c}$. The thermal efficiencies in Table III-1 are affected by changes in $I_{b}$ (especially $I_{b}$ $=0 \mathrm{~W} / \mathrm{m}^{2}$ ), incidence angle $(\theta)$, aperture, optical efficiency $\left(\eta_{\text {opt }}\right)$, HTF temperature, and absorber emittance. Note that the decreased heat loss of the 2008 PTR70 (case 1) relative to previous PTR70s (case 16) causes an increase in thermal efficiency increase of nearly $2 \%$ at $T_{H T F}=$ $340^{\circ} \mathrm{C}$. This performance increase will be larger at higher HTF temperatures as well as larger incidence angles.

In summary, Tables III-1 and III-2 show that ambient temperature and wind conditions don't significantly affect evacuated HCE heat loss, although they do affect glass surface temperature. Table III-2 quantifies how much HCE heat loss affects thermal efficiency, and shows that the relatively low heat loss of the 2008 PTR70 will increase thermal performance significantly relative to previous models. This is explored in the Estimated Field Performance section.

The insensitivity of HCE heat loss to ambient conditions depends on small heat transfer values between the absorber and glass envelope. If air leaks into the annulus, or a high thermal conductivity gas such as hydrogen infiltrates it, the sensitivity of heat loss to ambient conditions increases. This is demonstrated in Table III-3. This table uses the heat loss correlation coefficients derived in Table 8 to determine radiation and conduction/convection heat loss for four HCE annular conditions:

1) vacuum (modeled previously in Table III-2),

2) hydrogen

3) lost vacuum

4) broken glass (no glass envelope).

These annular conditions are described in the "Determining the heat loss correlation coefficients" section. 
Table III-3. Effect of annulus condition on heat loss and thermal efficiency.

Uses heat loss coefficients derived in Table 8 for the 2008 PTR70.

\begin{tabular}{|c|c|c|c|c|c|c|c|c|c|}
\hline & Sensitivity case: & $\begin{array}{c}\text { Case } 1 \text { - } \\
\text { Vacuum HCE }\end{array}$ & $\begin{array}{c}\text { Case } 2 \text { - } \\
\text { Vacuum HCE, } \\
8 \mathrm{~m} / \mathrm{s} \\
\text { windspeed }\end{array}$ & $\begin{array}{c}\text { Case } 3 \text { - } \\
\text { Hydrogen HCE }\end{array}$ & $\begin{array}{c}\text { Case } 4 \text { - } \\
\text { Hydrogen HCE, } \\
8 \mathrm{~m} / \mathrm{s} \\
\text { windspeed }\end{array}$ & $\begin{array}{l}\text { Case } 5 \text { - } \\
\text { Lost Vacuum } \\
\text { HCE }\end{array}$ & $\begin{array}{l}\text { Case } 6 \text { - } \\
\text { Lost Vacuum } \\
\text { HCE, } 8 \mathrm{~m} / \mathrm{s} \\
\text { windspeed }\end{array}$ & $\begin{array}{c}\text { Case } 7 \text { - } \\
\text { Broken glass } \\
\text { HCE }\end{array}$ & $\begin{array}{c}\text { Case } 8 \text { - } \\
\text { Broken glass } \\
\mathrm{HCE}, 8 \mathrm{~m} / \mathrm{s} \\
\text { windspeed }\end{array}$ \\
\hline \multirow{17}{*}{ 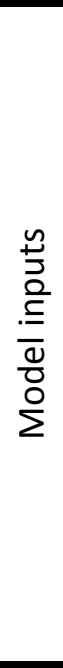 } & $\mathrm{I}_{\mathrm{b}}\left(\mathrm{W} / \mathrm{m}^{2}\right)$ & 950 & 950 & 950 & 950 & 950 & 950 & 950 & 950 \\
\hline & $\theta$ (deg) & 20 & 20 & 20 & 20 & 20 & 20 & 20 & 20 \\
\hline & $\mathrm{Ap}(\mathrm{m})$ & 5.75 & 5.75 & 5.75 & 5.75 & 5.75 & 5.75 & 5.75 & 5.75 \\
\hline & $\eta_{\text {opt }}$ & 0.75 & 0.75 & 0.75 & 0.75 & 0.75 & 0.75 & 0.75 & 0.75 \\
\hline & $\mathrm{m}(\mathrm{kg} / \mathrm{s})$ & 7.6 & 7.6 & 7.6 & 7.6 & 7.6 & 7.6 & 7.6 & 7.6 \\
\hline & $\mathrm{T}_{\mathrm{HTF}}\left({ }^{\circ} \mathrm{C}\right)$ & 340 & 340 & 340 & 340 & 340 & 340 & 340 & 340 \\
\hline & $\mathrm{T}_{\mathrm{amb}}\left({ }^{\circ} \mathrm{C}\right)$ & 30 & 30 & 30 & 30 & 30 & 30 & 30 & 30 \\
\hline & $\mathrm{T}_{\text {sky }}\left({ }^{\circ} \mathrm{C}\right)$ & 22 & 22 & 22 & 22 & 22 & 22 & 22 & 22 \\
\hline & $v_{w}(m / s)$ & 2.5 & 8 & 2.5 & 8 & 2.5 & 8 & 2.5 & 8 \\
\hline & $\varepsilon_{\mathrm{gl}}$ & 0.89 & 0.89 & 0.89 & 0.89 & 0.89 & 0.89 & N/A & N/A \\
\hline & $\mathrm{A} 0$ & 4.05 & 4.05 & 11.8 & 11.8 & 50.8 & 50.8 & -9.95 & -9.95 \\
\hline & $\mathrm{A} 1$ & 0.247 & 0.247 & 1.35 & 1.35 & 0.904 & 0.904 & 0.465 & 0.465 \\
\hline & $\mathrm{A} 2$ & -0.00146 & -0.00146 & $7.50 \mathrm{E}-04$ & $7.50 \mathrm{E}-04$ & $5.79 \mathrm{E}-04$ & $5.79 \mathrm{E}-04$ & $-8.54 \mathrm{E}-04$ & $-8.54 \mathrm{E}-04$ \\
\hline & $\mathrm{A} 3$ & $5.65 \mathrm{E}-06$ & $5.65 \mathrm{E}-06$ & 4.07E-06 & 4.07E-06 & $1.13 \mathrm{E}-05$ & $1.13 \mathrm{E}-05$ & $1.85 \mathrm{E}-05$ & $1.85 \mathrm{E}-05$ \\
\hline & $\mathrm{A} 4$ & $7.62 \mathrm{E}-08$ & $7.62 \mathrm{E}-08$ & $5.85 \mathrm{E}-08$ & $5.85 \mathrm{E}-08$ & $1.73 \mathrm{E}-07$ & $1.73 \mathrm{E}-07$ & $6.89 \mathrm{E}-07$ & $6.89 \mathrm{E}-07$ \\
\hline & A5 & -1.7 & -1.7 & -4.48 & -4.48 & -43.2 & -43.2 & 24.7 & 24.7 \\
\hline & A6 & 0.0125 & 0.0125 & 0.285 & 0.285 & 0.524 & 0.524 & 3.37 & 3.37 \\
\hline \multirow{15}{*}{ 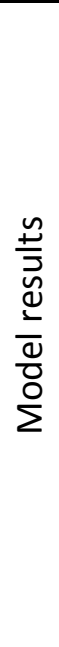 } & $\mathrm{q}_{\mathrm{i}, \text { oinc }}(\mathrm{W} / \mathrm{m})$ & 5463 & 5463 & 5463 & 5463 & 5463 & 5463 & 5463 & 5463 \\
\hline & $\mathrm{Q}_{\text {sol,abs }}(\mathrm{W} / \mathrm{m})$ & 3834 & 3834 & 3834 & 3834 & 3834 & 3834 & 3834 & 3834 \\
\hline & $\mathrm{Q}_{\text {conv }, \mathrm{HTF}}(\mathrm{W} / \mathrm{m})$ & 3689 & 3686 & 3019 & 2914 & 2786 & 2637 & 1310 & -24 \\
\hline & $\mathrm{Q}_{\text {cond,abs }}(\mathrm{W} / \mathrm{m})$ & 3689 & 3686 & 3019 & 2914 & 2786 & 2637 & 1310 & -24 \\
\hline & $\mathrm{Q}_{\text {heatloss }}(\mathrm{W} / \mathrm{m})$ & 145 & 148 & 816 & 920 & 1048 & 1197 & 2524 & 3858 \\
\hline & $\mathrm{Q}_{\text {cond,gl }}(\mathrm{W} / \mathrm{m})$ & 145 & 148 & 816 & 920 & 1048 & 1197 & $\mathrm{~N} / \mathrm{A}$ & $\mathrm{N} / \mathrm{A}$ \\
\hline & $\mathrm{Q}_{\text {SolAbsbyGI }}(\mathrm{W} / \mathrm{m})$ & 83 & 83 & 83 & 83 & 83 & 83 & $\mathrm{~N} / \mathrm{A}$ & $\mathrm{N} / \mathrm{A}$ \\
\hline & $\mathrm{Q}_{\mathrm{rad}, \text { sky }}(\mathrm{W} / \mathrm{m})$ & 76 & 50 & 330 & 205 & 437 & 274 & \multirow{2}{*}{2524} & \multirow{2}{*}{3858} \\
\hline & $\mathrm{Q}_{\text {conv,amb }}(\mathrm{W} / \mathrm{m})$ & 152 & 181 & 569 & 798 & 694 & 1006 & & \\
\hline & $\mathrm{T}_{\mathrm{abs}, \mathrm{i}}\left({ }^{\circ} \mathrm{C}\right)$ & 344 & 344 & 344 & 343 & 343 & 343 & 342 & 340 \\
\hline & $\mathrm{T}_{\mathrm{abs}, \mathrm{o}}\left({ }^{\circ} \mathrm{C}\right)$ & 346 & 346 & 345 & 345 & 345 & 344 & 342 & 340 \\
\hline & $\mathrm{T}_{\mathrm{gl}, \mathrm{i}}\left({ }^{\circ} \mathrm{C}\right)$ & 56 & 46 & 130 & 102 & 153 & 121 & N/A & N/A \\
\hline & $\mathrm{T}_{\mathrm{gl}, \mathrm{o}}\left({ }^{\circ} \mathrm{C}\right)$ & 55 & 45 & 124 & 95 & 145 & 112 & $\mathrm{~N} / \mathrm{A}$ & N/A \\
\hline & $T_{H T F, \text { out }}-T_{H T F, \text { in }}\left({ }^{\circ} \mathrm{C}\right)$ & 0.2 & 0.2 & 0.16 & 0.16 & 0.15 & 0.14 & 0.07 & -0.001 \\
\hline & $\eta_{\text {th }}$ & 0.675 & 0.675 & 0.552 & 0.533 & 0.510 & 0.483 & 0.240 & 0 \\
\hline
\end{tabular}




\section{Appendix IV - Bellows shading calculation}

The bellows shading parameter in SAM quantifies the fraction of collector aperture that sees the HCE absorber at normal incidence. It is the ratio of the HCE absorber length, $L_{a b s}$, to the length of the mirror underneath it, $L_{\text {mirror }}$, as shown in Figure IV-1. A bellows shading parameter of 1 indicates that $L_{\text {mirror }}$ is less than or equal to $L_{a b s}$. Though Figure IV-1 illustrates this concept for a single HCE and the collector mirrors underneath it, the bellows shading calculation is typically done for an entire Solar Collector Assembly (SCA).

At off-normal incidence some of the insolation reflected from the collector will strike the bellows instead of the absorber tube. The incidence angle modifier (IAM) takes this effect into account. Thus it is important that a SAM simulation use an IAM derived from ray-tracing or experimental data that is consistent with the HCE and collector simulated.

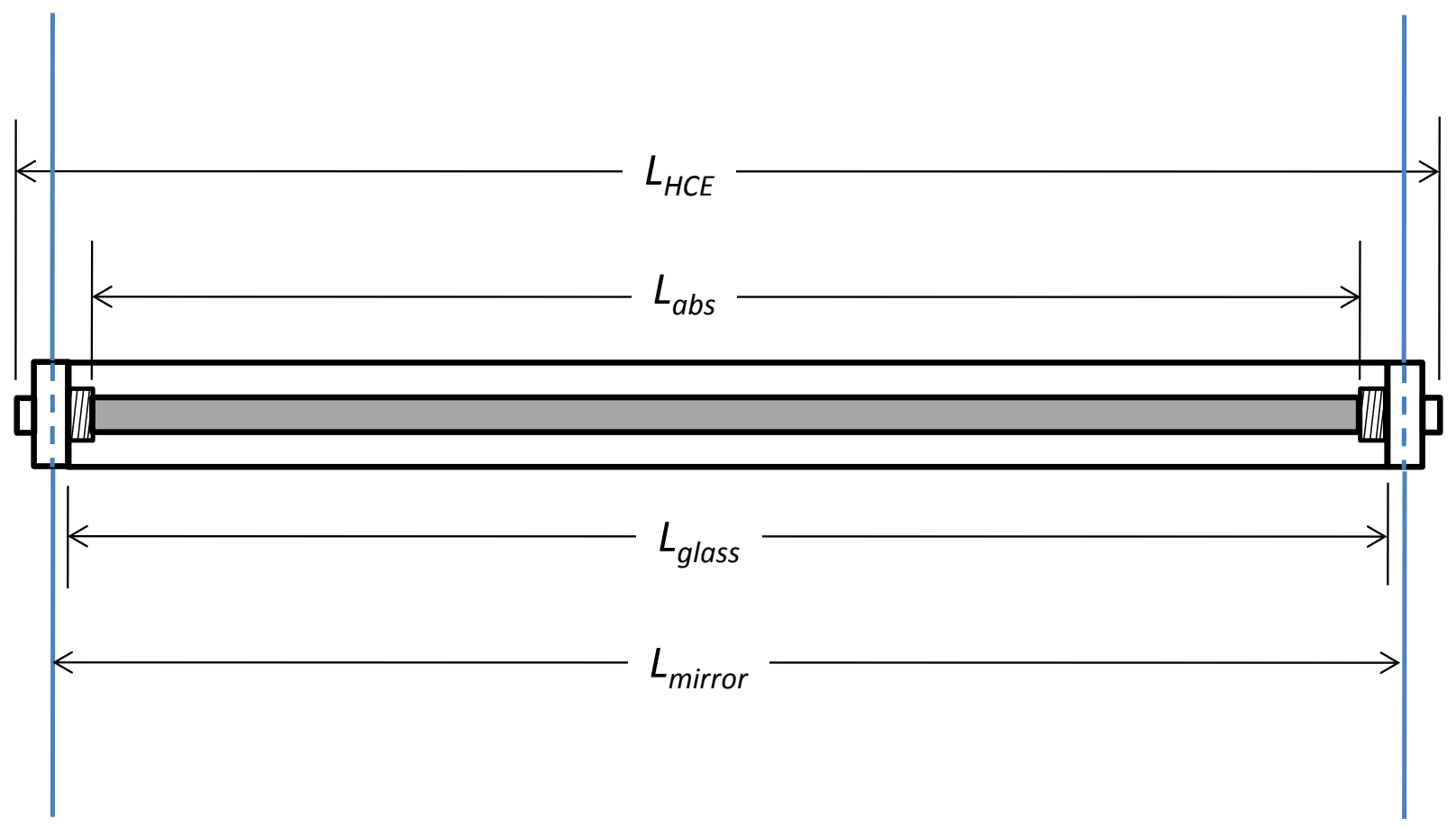

Figure IV-1. Lengths in the bellows shading parameter calculation. Not to scale.

The length of the mirror $\left(L_{\text {mirror }}\right)$ under the HCE is not an explicit SAM input; it is lumped in with the total SCA aperture area. Therefore a SAM user must have dimensions of the SCA and exact HCE mounting locations to correctly calculate the bellows shading parameter.

This study uses a different, simpler approach to approximate the bellows shading parameter. It is not collector dependent, and therefore does not require collector and mirror dimensions. It assumes that $L_{\text {mirror }}=L_{H C E}$ (as shown in Figure IV-1), so that the bellows shading parameter is: 


$$
B S=\frac{\min \left(L_{\text {glass }}, L_{a b s}\right)}{L_{H C E}}
$$

where

$B S$ is the bellows shading parameter

$L_{\text {glass }}$ is the length $(\mathrm{m})$ of the borosilicate glass envelope. This length puts an upper limit on the collecting length of the HCE.

$L_{a b s}$ is the length of the absorber within the glass envelope. This length is coated with a solar selective coating. Schott employs internal bellows that allow for relative expansion between the stainless steel absorber and borosilicate glass envelope. The internal bellows collapse towards the ends in response to the thermal expansion of $L_{a b s}$.

$L_{H C E}$ is the total length of the HCE. The stubs on the end are an extension of the absorber pipe, but are not coated with the solar selective coating.

The lengths in the bellows shading calculation are based on measured lengths at room temperature, the linear expansion coefficients of the materials, and representative operating temperatures. The estimated operating temperatures are based on a loop with HTF increasing from $293^{\circ} \mathrm{C}$ to $391^{\circ} \mathrm{C}$ and the glass temperature measured in the heat loss tests (Table 3 ).

Table IV-1 presents the calculated bellows shading parameter for the Schott 2008 PTR70.

Table IV-1. Calculation of bellows shading parameter

\begin{tabular}{|c|c|c|c|c|c|c|c|}
\hline Component & Variable & Material & $\begin{array}{l}\text { Coefficient } \\
\text { of linear } \\
\text { thermal } \\
\text { expansion } \\
\left(\mu \mathrm{m} / \mathrm{m} \cdot{ }^{\circ} \mathrm{C}\right)^{3}\end{array}$ & $\begin{array}{c}\text { Measured } \\
\text { length at } \\
23^{\circ} \mathrm{C} \\
(\mathrm{m})\end{array}$ & $\begin{array}{c}\text { Estimated } \\
\text { operating } \\
\text { temperature } \\
\left({ }^{\circ} \mathrm{C}\right)\end{array}$ & $\begin{array}{l}\text { Calculated } \\
\text { length at } \\
\text { operating } \\
\text { temperature } \\
\text { (m) }\end{array}$ & $\begin{array}{c}\text { Bellows } \\
\text { Shading } \\
\text { Parameter }\end{array}$ \\
\hline Coated absorber & $L_{a b s}$ & stainless steel & 17.3 & 3.91 & 350 & 3.93 & \multirow{3}{*}{0.963} \\
\hline Glass envelope & $L_{\text {glass }}$ & borosilicate glass & 3.3 & 3.95 & 55 & 3.95 & \\
\hline Absorber and ends & $L_{H C E}$ & stainless steel & 17.3 & 4.06 & 350 & 4.08 & \\
\hline
\end{tabular}

The calculated 0.963 bellows shading parameter agrees with the " $>96 \%$ active length" statement by Schott [24].

\footnotetext{
${ }^{3}$ Wikipedia, 8 May 2009. < http://en.wikipedia.org/wiki/Coefficient_of_thermal_expansion>
} 


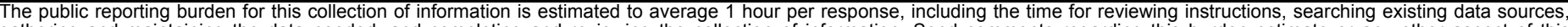

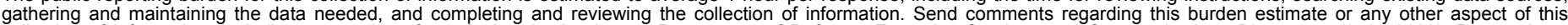

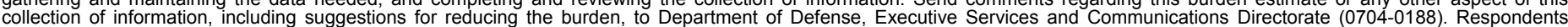

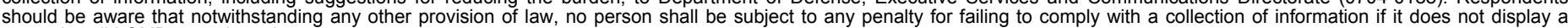

should be aware that notwithstanding

PLEASE DO NOT RETURN YOUR FORM TO THE ABOVE ORGANIZATION.

\begin{tabular}{l|l|l|}
\hline 1. REPORT DATE (DD-MM-YYYY) & 2. REPORT TYPE & 3. DATES COVERED (FrOm - TO)
\end{tabular} May 2009

Technical Report

4. TITLE AND SUBTITLE

Heat Loss Testing of Schott's 2008 PTR70 Parabolic Trough

Receiver 5a. CONTRACT NUMBER

DE-AC36-08-GO28308

5b. GRANT NUMBER

5c. PROGRAM ELEMENT NUMBER

5d. PROJECT NUMBER

NREL/TP-550-45633

5e. TASK NUMBER

CP091001

5f. WORK UNIT NUMBER
7. PERFORMING ORGANIZATION NAME(S) AND ADDRESS(ES)

National Renewable Energy Laboratory

1617 Cole Blvd.

Golden, CO 80401-3393
8. PERFORMING ORGANIZATION REPORT NUMBER

NREL/TP-550-45633

9. SPONSORING/MONITORING AGENCY NAME(S) AND ADDRESS(ES)

10. SPONSOR/MONITOR'S ACRONYM(S) NREL

11. SPONSORING/MONITORING AGENCY REPORT NUMBER

12. DISTRIBUTION AVAILABILITY STATEMENT

National Technical Information Service

U.S. Department of Commerce

5285 Port Royal Road

Springfield, VA 22161

13. SUPPLEMENTARY NOTES

14. ABSTRACT (Maximum 200 Words)

Two Schott 2008 model year PTR70 HCEs were tested on NREL's heat loss test stand from $100-500^{\circ} \mathrm{C}$ in $50^{\circ} \mathrm{C}$ increments. Absorber emittance was determined from the laboratory testing so that the performance of the HCEs could be modeled in a parabolic trough collector. Collector/HCE simulation results for many different field operation conditions were used to create heat loss correlation coefficients for Excelergy and SAM. SAM estimates that the decreased emittance of the 2008 PTR70 will decrease the LCOE for parabolic trough power plants by $0.5 \phi / k W h$ and increase the electricity generated by $5 \%$ relative to previous PTR70s. These conclusions assume that the 2008 PTR70 is supplied at the same cost and with the same optical performance as earlier PTR70 models.

15. SUBJECT TERMS

Parabolic trough receiver; HCE; parabolic trough; solar power plant; heat loss

\begin{tabular}{|c|c|c|c|c|}
\hline \multicolumn{3}{|c|}{ 16. SECURITY CLASSIFICATION OF: } & \multirow{2}{*}{$\begin{array}{l}\text { 17. LIMITATION } \\
\text { OF ABSTRACT } \\
\text { UL }\end{array}$} & \multirow{2}{*}{$\begin{array}{l}\text { 18. NUMBER } \\
\text { OF PAGES }\end{array}$} \\
\hline $\begin{array}{l}\text { a. REPORT } \\
\text { Unclassified }\end{array}$ & $\begin{array}{l}\text { b. ABSTRACT } \\
\text { Unclassified }\end{array}$ & $\begin{array}{l}\text { c. THIS PAGE } \\
\text { Unclassified }\end{array}$ & & \\
\hline
\end{tabular}

19a. NAME OF RESPONSIBLE PERSON

19b. TELEPHONE NUMBER (Include area code) 